\title{
CÁlCULO E ARMAÇÃO DE LAJES DE CONCRETO ARMADO COM A CONSIDERAÇÃO DO MOMENTO VOLVENTE
}

ENG. GUILHERME ARIS PARSEKIAN

Dissertação apresentada à Escola de Engenharia de São Carlos, da Universidade de São Paulo, como parte dos requisitos para obtenção do Título de Mestre em Engenharia de Estruturas.

ORIENTADOR: Prof. Dr. Márcio Roberto Silva Corrêa

São Carlos 


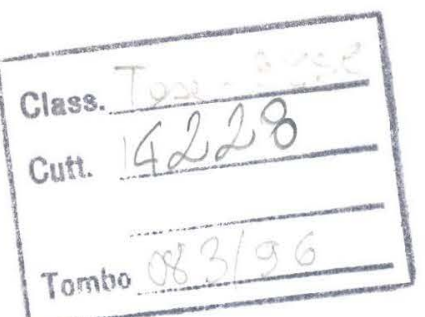

$$
778
$$

Parsekian, Guilherme Aris

P276c Cálculo e armação de lajes de concreto armado com a consideração do momento volvente / Guilherme Aris Parsekian.-São Carlos, 1996

$116 p$.

Dissertação (Mestrado) -- Escola de Engenharia de São CarlosUniversidade de São Paulo, 1996.

Orientador: Prof.Dr. Marcio Roberto Silva Corrêa

1. Concreto armado - Lajes. 2. Momento volvente. I. Título. 
Para meus pais,

Rapiel e Beatriz 


\section{AGRADECIMENTOS}

Ao Prof. Dr. Márcio Roberto Silva Corrêa, pela dedicação dispensada à competente orientação deste trabalho, pelas lições de conhecimento e, principalmente, pela sua amizade.

Ao Departamento de Estruturas da Escola de Engenharia de São Carlos, por permitir e dar todas as condições para realização deste trabalho.

Ao Prof. Dr. Wilson Sérgio Venturini pelas sugestões.

Ao Prof. Dr. Marcio Antonio Ramalho pela contribuição e amizade.

À D. C. Matos Engenharia de Projetos e Consultoria Ltda e à TECSOF Engenharia de Estruturas S/C Ltda por permitirem que projetos de sua propriedade fossem usados como exemplos.

À Sra. Maria Nadir Minatel pela ajuda com a bibliografia.

A todos aqueles que de alguma forma contribuíram para a realização deste trabalho.

Ao CNPQ pela bolsa de estudos.

Ao Luiz André M. C. Bicudo e ao Juarez Felipe Jr. pela ajuda e pela amizade.

Ao Sérgio e à Lilian pelo apoio e à Marilu pelo amor e carinho. 


\section{SUMÁRIO}

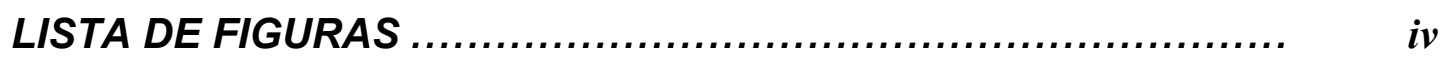

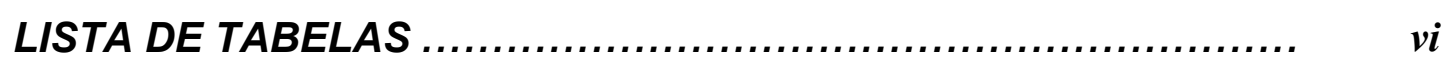

LISTA DE SÍMBOLOS ............................................. vii

LISTA DE ABREVIATURAS E SIGLAS .......................... $x$

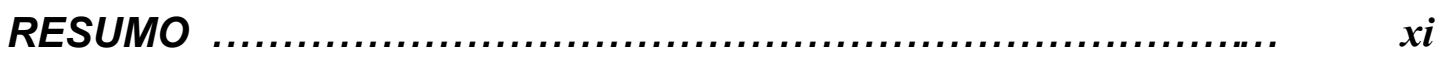

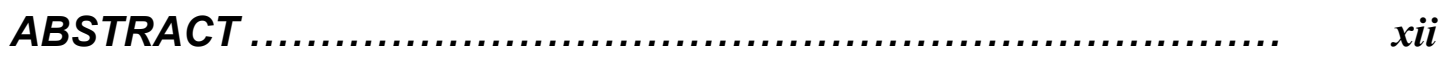

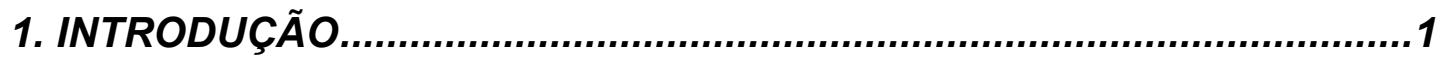

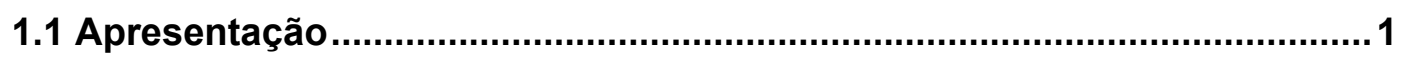

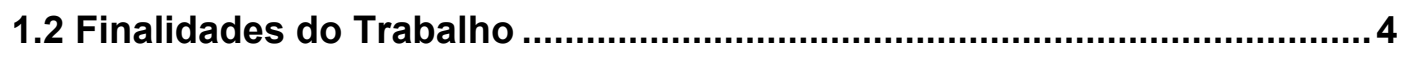

1.3 Discussão Sucinta dos Capítulos ........................................................... 5

2. MOMENTOS EQUIVALENTES AO TERNO DE ESFORÇOS MX, MY E

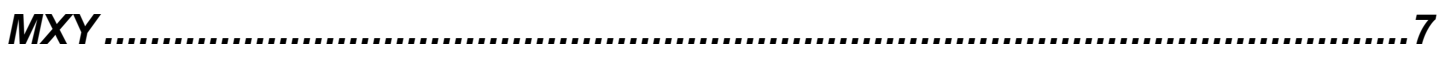

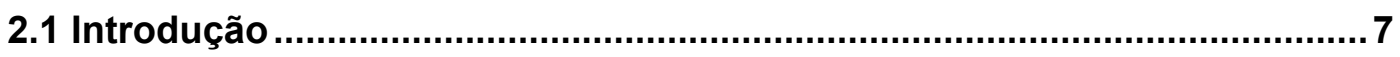

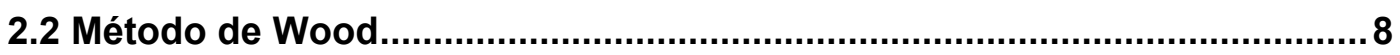

2.2.1 Momentos Positivos em Todas as Direções ...................................................... 11

2.2.2 Momentos Negativos em Todas as Direções .................................................... 15

2.2.3 Campos de Momentos Positivos e Negativos ................................................. 16

2.3 Método de Leonhardt \& Mönnig............................................................... 18

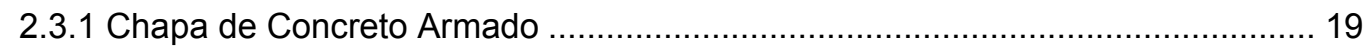

2.3.2 Lajes com Armaduras Ortogonais.............................................................. 23

2.4 Momentos Equivalentes em Duas Direções Oblíquas Entre Si ................25

3. RESISTÊNCIA DO CONCRETO AO MOMENTO VOLVENTE.................31

3.1 Introdução 31 
3.2 Tensões Cisalhantes Devidas à Força Cortante em Vigas........................32

3.3 Tensões Cisalhantes Devidas à Torção em Vigas ...................................34

3.4 Interação Entre Força Cortante e Momento Torçor ..................................36

3.5 Tensões Cisalhantes Devidas à Força Cortante em Lajes .......................38

3.6 Tensões Cisalhantes Devidas à Torção em Lajes.....................................40

3.7 Recomendação Para o Cálculo do Máximo Momento Volvente ..............41

4. SOFTWARE BÁSICO E DE ANÁLISE.............................................44

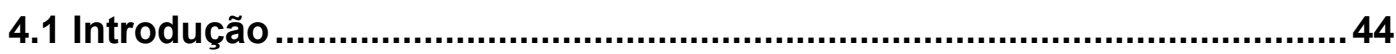

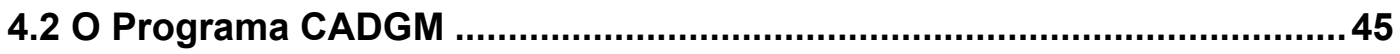

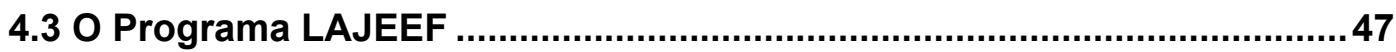

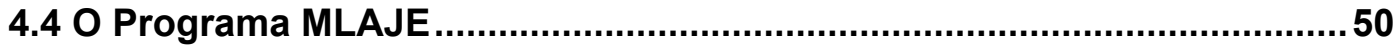

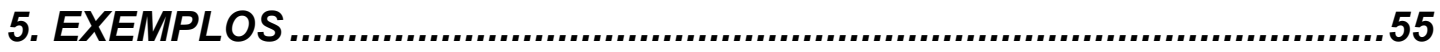

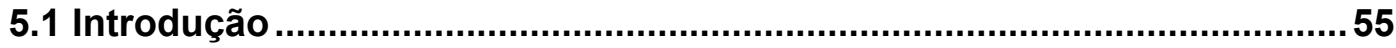

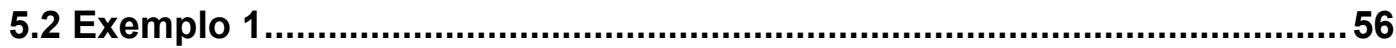

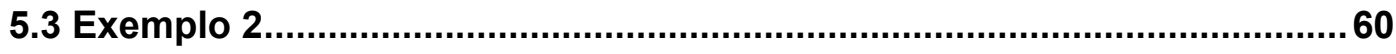

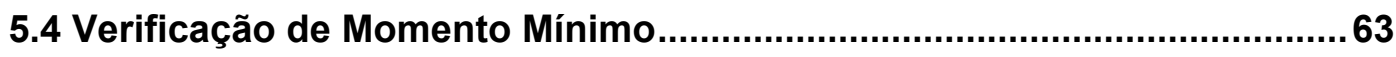

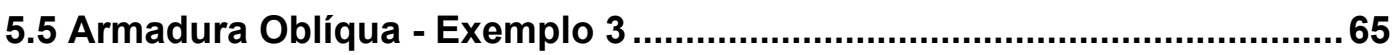

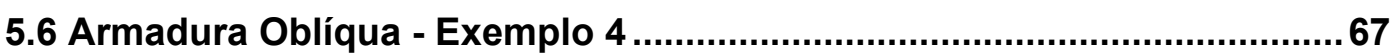

5.7 Laje retangular apoiada nos quatro lados ...........................................68

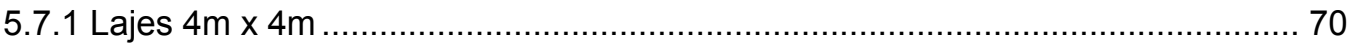

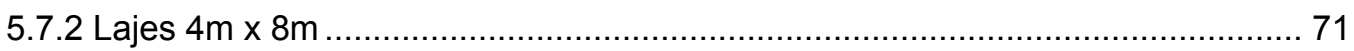

5.7.3 Laje 4m x 4m Apoiada em Vigas Deformáveis ............................................... 72

5.7.4 Análise dos Resultados dos Processamentos............................................... 73

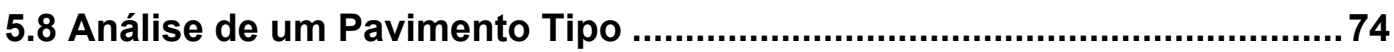

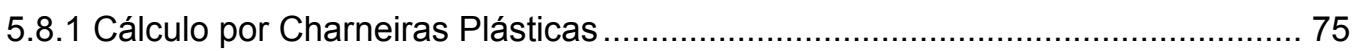

5.8.2 Cálculo por Elementos Finitos (sem Mxy) ……............................................. 79

5.8.3 Cálculo por Elementos Finitos (considerando Mxy)........................................ 80

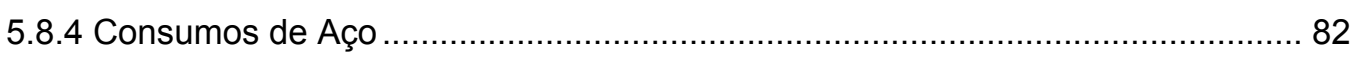

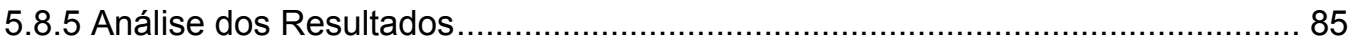




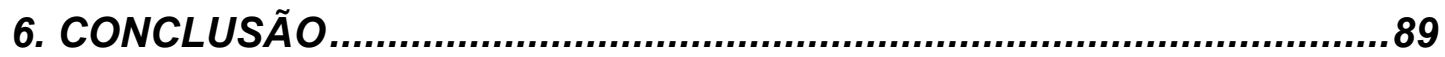

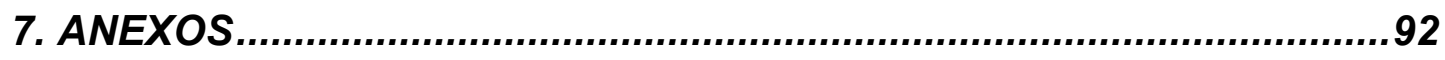

7.1 Anexo A - Subrotina Para Cálculo dos Momentos Equivalentes.............92

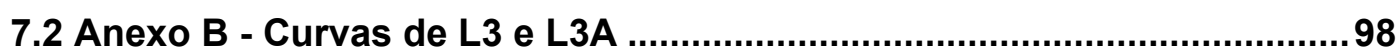

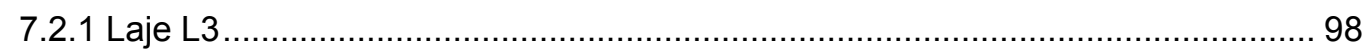

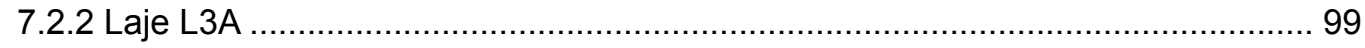

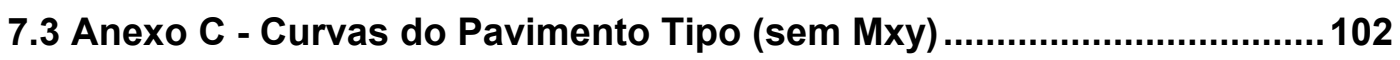

7.4 Anexo D - Curvas do Pavimento Tipo (com Mxy) ................................... 106

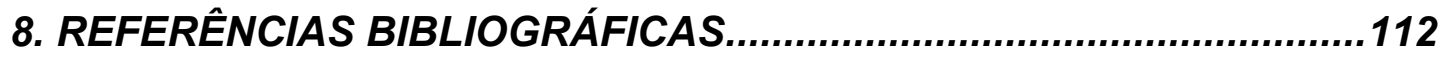




\section{LISTA DE FIGURAS}

FIGURA 2.1 - Terno de esforços Mx, My e Mxy e armaduras segundo as direções X e Y 7

FIGURA 2.2 - Momentos normais desenvolvidos a partir de Mx, My e Mxy e de $M^{*} \times$ e $M^{*}$ y.....8

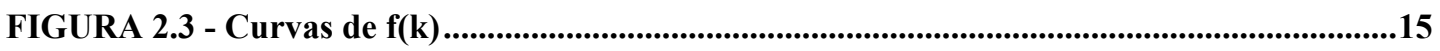

FIGURA 2.4 - Esforços solicitantes na chapa..................................................................................20

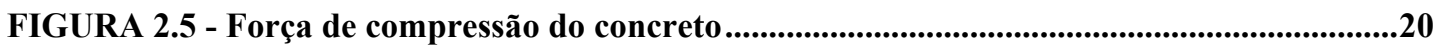

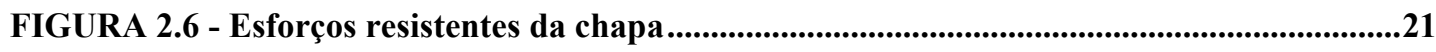

FIGURA 2.7 - Esforços em uma chapa de concreto: direção paralela a $\varphi$.......................................21

FIGURA 2.8 - Esforços em uma chapa de concreto: direção perpendicular a $\varphi$............................23

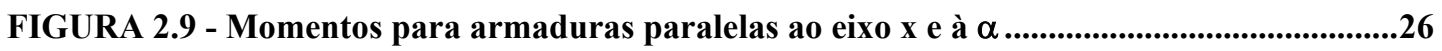

FIGURA 3.1 - Tensões cisalhantes devidas à força cortante..................................................32

FIGURA 3.2 - Tensões cisalhantes de torção...................................................................................35

FIGURA 3.3 - Superfície de interação entre torção, flexão e força cortante [ HSU (1968) ] .......37

FIGURA 3.4 - Tensões cisalhantes de torção em lajes.........................................................................40

FIGURA 3.5 - Combinação de tensões cisalhantes em lajes ...............................................................42

FIGURA 4.1 - Arquivo de saída do programa CADGM........................................................46

FIGURA 4.2 - Forma do pavimento tipo a ser modelado...........................................................47

FIGURA 4.3 - Malha gerada pelo programa GM........................................................................48

FIGURA 4.4 - Tela do programa LAJEEF mostrando as espessuras dos elementos placa ..........50

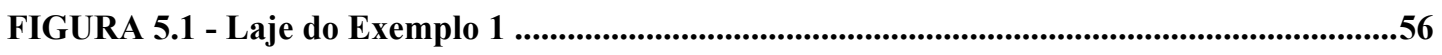

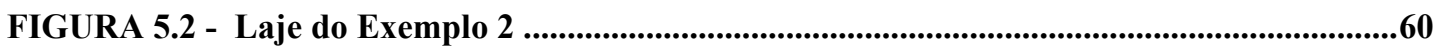

FIGURA 5.3 - Disposição das armaduras do Exemplo 3..............................................................65

FIGURA 5.4 - Recomendações encontradas sobre a armadura de canto ........................................69

FIGURA 5.5 - Laje quadrada apoiada em vigas ............................................................................72

FIGURA 5.6 - Forma do pavimento tipo do Ed. Andaluzia............................................................75

FIGURA 5.7 - Detalhamento das armaduras positivas - método das charneiras pláticas ..........78

FIGURA 5.8 - Detalhamento das armaduras negativas - método das charneiras plásticas..........78

FIGURA 5.9 - Detalhamento das armaduras positivas - MEF sem Mxy.........................................79

FIGURA 5.10 - Detalhamento das armaduras negativas - MEF sem Mxy .................................80

FIGURA 5.11 - Detalhamento das armaduras positivas - MEF com Mxy …................................81

FIGURA 5.12 - Detalhamento das armaduras negativas - MEF com Mxy .................................82

FIGURA 5.13 - Comparação dos consumos de aço ...............................................................85

FIGURA 7.1 - Curvas de momentos calculados para L3 ............................................................98

FIGURA 7.2 - Curvas de momentos equivalentes para L3 _.....................................................98

FIGURA 7.3 - Curvas de armaduras calculadas para L3 ….........................................................99 
FIGURA 7.4 - Curvas de momentos calculados para L3A .........................................................99

FIGURA 7.5 - Curvas de momentos equivalentes para L3A considerando $\mathrm{Mxy}_{\mathrm{c}}$.......................100

FIGURA 7.6 - Curvas de armaduras calculadas para L3A considerando $\mathrm{Mxy}_{\mathbf{c}}$..........................100

FIGURA 7.7 - Curvas de momentos equivalentes para L3A sem considerar Mxy $\mathrm{y}_{\mathrm{c}}$....................101

FIGURA 7.8 - Curvas de armaduras calculadas para L3A sem considerar Mxy $\mathrm{C}_{\mathrm{c}}$......................101

FIGURA 7.9 - Curvas de Mx [MEF sem Mxy (KN.m/m)] .....................................................102

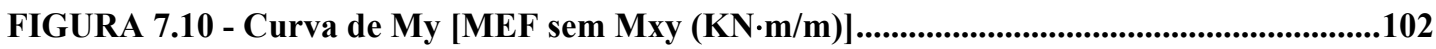

FIGURA 7.11 - Curvas de deslocamento transversal [MEF sem Mxy (cm)] .............................103

FIGURA 7.12 - Curvas de Asx positivas [MEF sem Mxy (cm²/m)] .............................................103

FIGURA 7.13 - Curvas de Asy positivas [MEF sem Mxy $\left.\left(\mathrm{cm}^{2} / \mathrm{m}\right)\right]$............................................104

FIGURA 7.14 - Curvas de Asx negativas [MEF sem Mxy (cm $\left.\left.{ }^{2} / \mathrm{m}\right)\right]$...........................................104

FIGURA 7.15 - Curvas de Asy negativas [MEF sem Mxy $\left.\left(\mathrm{cm}^{2} / \mathrm{m}\right)\right]$.......................................105

FIGURA 7.16 - Curvas de Mx [MEF com Mxy (KN·m/m)].................................................106

FIGURA 7.17 - Curva de My [MEF com Mxy $(\mathrm{KN} \cdot \mathrm{m} / \mathrm{m})]$........................................................106

FIGURA 7.19 - Curva de Mxy [MEF com Mxy $(\mathrm{KN} \cdot \mathrm{m} / \mathrm{m})]$.......................................................107

FIGURA 7.20 - Curvas de deslocamento transversal [MEF com Mxy (cm)] .............................107

FIGURA 7.21 - Curva de $M^{*} x$ positvos [MEF $\operatorname{com}$ Mxy $\left.(\mathrm{KN} \cdot \mathrm{m} / \mathrm{m})\right]$...........................................108

FIGURA 7.22 - Curva de $M^{*}$ y positvos [MEF com Mxy (KN·m/m)] ...........................................108

FIGURA 7.23 - Curva de $M * x$ negatvos [MEF com Mxy (KN·m/m)] ...........................................109

FIGURA 7.24 - Curva de $M^{*}$ y negativos [MEF com Mxy (KN·m/m)] .......................................109

FIGURA 7.25 - Curvas de Asx positivas [MEF com Mxy $\left.\left(\mathrm{cm}^{2} / \mathrm{m}\right)\right]$........................................110

FIGURA 7.26 - Curvas de Asy positivas [MEF com Mxy (cm $\left.\left.{ }^{2} / \mathrm{m}\right)\right]$.........................................110

FIGURA 7.27 - Curvas de Asx negativas [MEF com Mxy $\left.\left(\mathrm{cm}^{2} / \mathrm{m}\right)\right]$........................................111

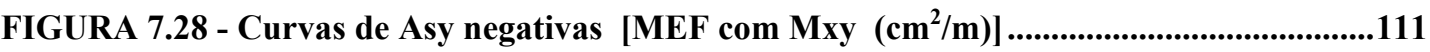




\section{LISTA DE TABELAS}

TABELA 2.1 - Valores dos momentos normais e de $\mathbf{f}(\mathbf{k})$.............................................................14

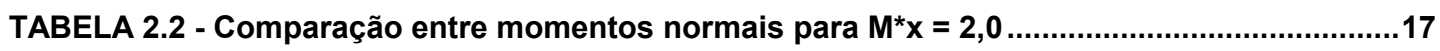

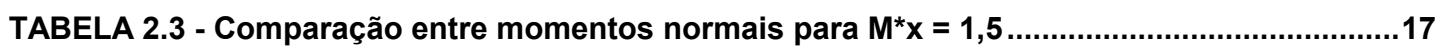

TABELA 5.1 - Posição dos pontos analisados no Exemplo 1 ......................................................56

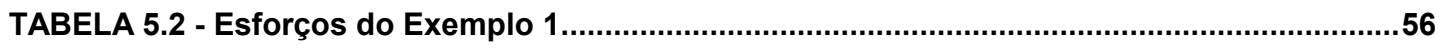

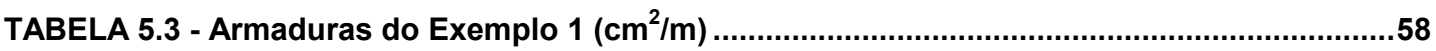

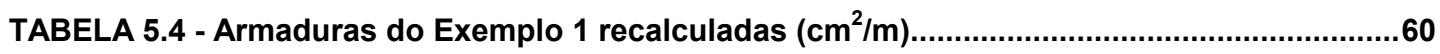

TABELA 5.5 - Esforços do Exemplo 2 ......................................................................................61

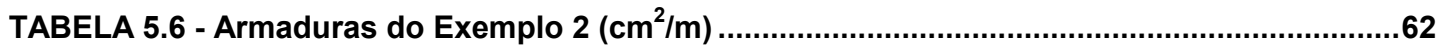

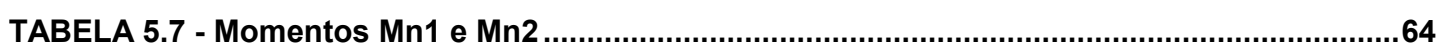

TABELA 5.8 - Momentos Mn1 e Mn2 para o Exemplo 3 ...............................................................66

TABELA 5.9 - Momentos Mn1 e Mn2 para o Exemplo 4 .........................................................67

TABELA 5.10 - Armaduras encontradas para lajes 4mx4m ........................................................71

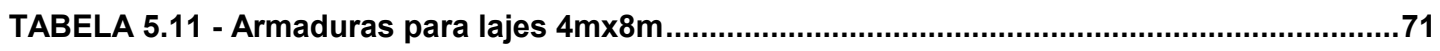

TABELA 5.12 - Lista de armaduras - método das charneiras plásticas ........................................83

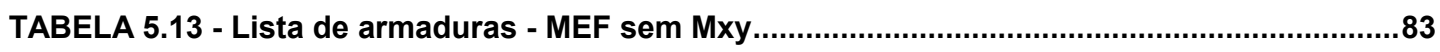

TABELA 5.14 - Lista de armaduras - MEF com Mxy ..................................................................84

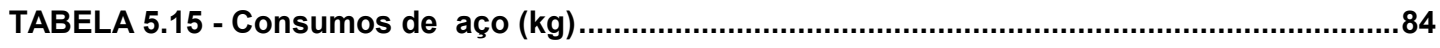




\section{LISTA DE SÍMBOLOS}

Letras romanas maiúsculas:

\begin{tabular}{|c|c|}
\hline$A s_{x}, A s_{y}$ & - áreas de armaduras dispostas segundo as direções $\mathrm{X}$ e $\mathrm{Y}$ \\
\hline$F_{c}$ & - força de compressão no concreto \\
\hline$F_{x}, F_{y}$ & - forças segundo as direções $X$ e $Y$ \\
\hline I & - momento de inércia de flexão \\
\hline K & - valor absoluto da tangente do ângulo crítico \\
\hline$M^{*} x, M^{*} y$ & - momentos fletores equivalentes normais às direções $\mathrm{X}$ e $\mathrm{Y}$ \\
\hline Mn1 & - momento normal correspondente a $\mathrm{M}^{*} \mathrm{x}$ e $\mathrm{M}^{*} \mathrm{y}$ \\
\hline Mn2 & - momento normal correspondente Mx, My e Mxy \\
\hline $\mathrm{Mn} \theta$ & - momento normal ao plano $\theta$ \\
\hline $\mathrm{Mn}_{\theta, \mathrm{x}}, \mathrm{Mn}_{\theta, \alpha}$ & - parcelas do momento normal ao plano $\theta$, nas direções X e $\alpha$ \\
\hline Ms & - momento estático \\
\hline Mx, My & - momentos fletores normais às direções $X$ e $Y$ \\
\hline Mxy & - momento volvente \\
\hline $\mathrm{Mxy}_{\mathrm{c}}$ & - momento volvente resistido pelo concreto \\
\hline $\mathrm{N}_{1}, \mathrm{~N}_{2}$ & - forças normais segundo as direções principais 1 e 2 \\
\hline $\mathrm{T}$ & - momento torçor \\
\hline $\mathrm{T}_{\mathrm{c}}$ & - momento torçor resistido pelo concreto \\
\hline $\mathrm{Tu}$ & - momento torçor último \\
\hline V & - força cortante \\
\hline Vu & - força cortante última \\
\hline
\end{tabular}

Letras romanas minúsculas:

al - distância do deslocamento de diagrama de momentos

b - base de uma seção

$b_{\mathrm{w}} \quad$ - largura das vigas de seção retangular 


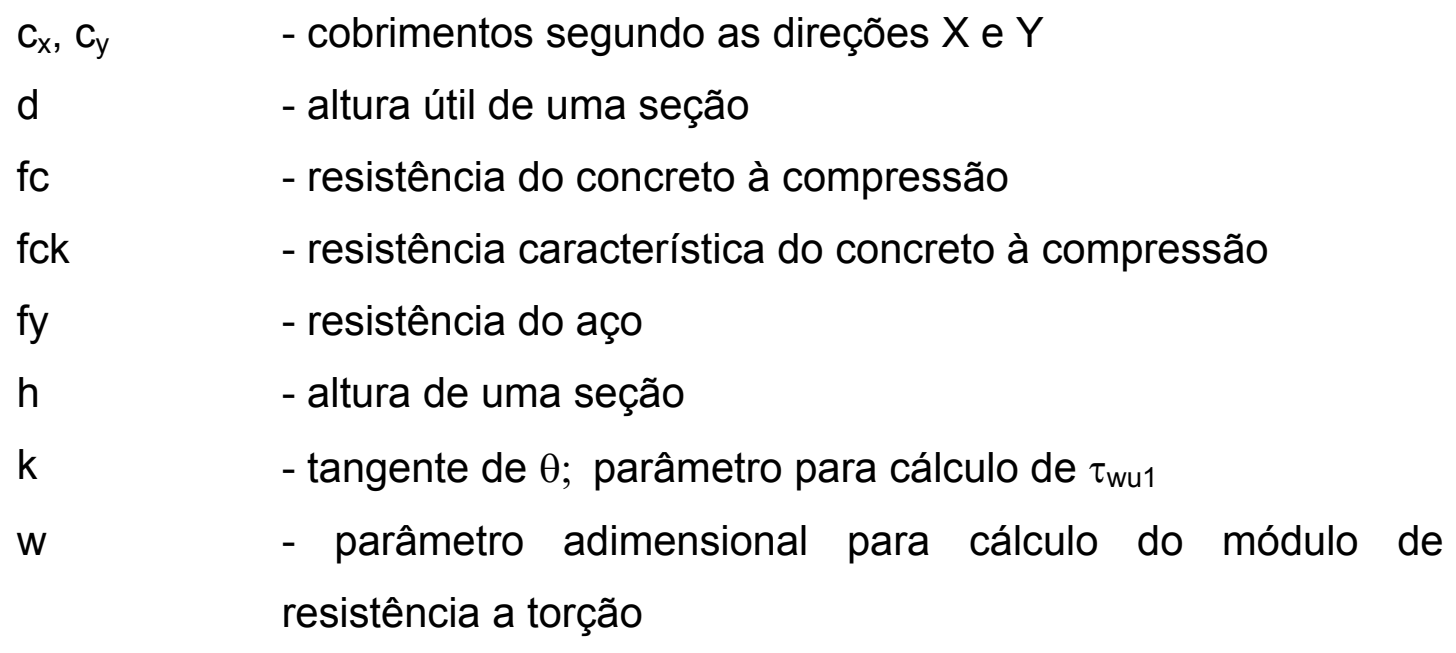

Letra grega maiúscula:

$\Phi \quad$ - coeficiente de segurança do $\mathrm{ACl}$

Letras gregas minúsculas:

\begin{tabular}{|c|c|}
\hline$\alpha$ & - ângulo de referência; parâmetro para cálculo de $\tau_{\text {wu1 }}$ \\
\hline$\varphi$ & - direção crítica \\
\hline$\lambda$ & - razão entre o maior e o menor lado de uma laje \\
\hline$\theta$ & - direção de um plano qualquer \\
\hline$\rho, \rho_{x}, \rho_{y}$ & - taxas geométricas de armadura \\
\hline$\tau$ & - tensão cisalhante \\
\hline$\tau_{\mathrm{c}}$ & $\begin{array}{l}\text { - tensão cisalhante devida à força cortante resistida pelo } \\
\text { concreto }\end{array}$ \\
\hline$\tau$ & - tensão cisalhante devida ao momento torçor \\
\hline$\tau_{\mathrm{tc}}$ & $\begin{array}{l}\text { - tensão cisalhante devida ao momento torçor resistida pelo } \\
\text { concreto }\end{array}$ \\
\hline & - tensão cisalhante de projeto devida ao momento torçor \\
\hline$\tau$ & - tensão cisalhante devida à força cortante de referência \\
\hline & $\begin{array}{l}\text { - tensão cisalhante de projeto devida à força cortante de } \\
\text { referência }\end{array}$ \\
\hline
\end{tabular}


$\tau_{\mathrm{wu} 1}$ tensão cisalhante permitida em lajes sem armadura transversal

$\psi_{4} \quad$ parâmetro para cálculo de $\tau_{\text {wu1 }}$ 


\title{
LISTA DE ABREVIATURAS E SIGLAS
}

\author{
$\mathrm{ACl}$ - American Concrete Institute \\ ASCE - American Society of Civil Engineers \\ CEB - Comité Euro-International du Béton \\ EESC - Escola de Engenharia de São Carlos \\ MEF - Método dos Elementos Finitos \\ NB - Norma Brasileira \\ NBR - Norma Brasileira Registrada \\ USP - Universidade de São Paulo
}




\section{RESUMO}

PARSEKIAN, G. A. (1996). Cálculo e armação de lajes de concreto armado com a consideração do momento volvente. 116p. Dissertação (Mestrado) - Escola de Engenharia de São Carlos, Universidade de São Paulo.

Para calcularem-se lajes de concreto armado considerando todos os esforços resistentes, incluindo o momento volvente, é necessário o conhecimento de procedimentos para determinar momentos normais a duas direções escolhidas, segundo as quais serão dispostas as armaduras, que cubram o terno de esforços Mx, My e Mxy. No presente trabalho são estudados e comparados dois métodos para armaduras ortogonais e um método para o caso de armaduras oblíquas entre si.

Com a finalidade de se considerar a resistência do concreto ao momento volvente no detalhamento das armaduras, são estudadas as resistências do concreto às tensões cisalhantes devidas à força cortante e ao momento torçor e as maneiras de se combinarem essas tensões.

Outra finalidade do trabalho foi a de desenvolver pré-processadores para facilitar a modelagem de pavimentos por elementos finitos e um pós-processador que permitisse a análise dos resultados utilizando os conceitos estudados.

Utilizando estes "softwares" fez-se um pequeno estudo de lajes retangulares apoiadas nos quatro lados, procurando avaliar as recomendações existentes na bibliografia especializada, sobre as armaduras de canto necessárias a esse tipo de laje. Fez-se, também uma comparação de detalhamentos das lajes de um pavimento tipo calculadas pelo método das charneiras plásticas, pelo método dos elementos finitos sem a consideração da rigidez à torção e pelo método dos elementos finitos considerando a rigidez à torção.

Palavras-chave: Concreto armado; Lajes; Momento volvente; Elementos Finitos. 


\section{ABSTRACT}

PARSEKIAN, G. A. (1996). Design of reinforced concrete slabs considering torsion. 116p. Dissertação (Mestrado) - Escola de Engenharia de São Carlos, Universidade de São Paulo.

In order to design reinforced concrete slabs considering all the resisting moments, including the torsional moment, it is necessary to know procedures to determine normal moments, in two chosen reinforcement directions, that are equivalent to the field of moments Mx, My and Mxy. In this work, two methods for orthogonal reinforcement are studied and compared and one for skew reinforcement is studied.

In an attempt to consider the resistance of concrete to the torsional moment, the shear stress due to shear carried by concrete and the shear stress due to torsion carried by concrete and the ways of combining them are studied.

Another aim of this work was to develop pre-processors to facilitate the process of modeling building floors in finite elements and one post-processor that permits the analysis of the results, using the concepts of this work.

Using these softwares, a short study of simply supported rectangular slabs was made, in an attempt to evaluate the recommendations, found in the specialized bibliography, about the corner reinforcement necessary in these kinds of slabs. A comparison of the slabs design of one building floor, calculated using the yield line theory, using the finite element method without the torsional strength and using the finite element method with the torsional strength was also made.

Keywords: Reinforced concrete; Slabs; Torsion; Finite Element 


\section{INTRODUÇÃO}

\subsection{Apresentação}

Existe várias maneiras de se calcular a armadura necessária para uma laje. A partir de valores de momentos fletores e volvente (Mx, My e Mxy), pode-se pensar em calcular os valores dos momentos principais e dispor as armaduras segundo as direções principais. Este procedimento tem pouco sentido prático, uma vez que para cada ponto da laje existem duas direções principais perpendiculares diferentes.

Um procedimento bastante utilizado é o de desconsiderar a rigidez à torção na laje, tratando-a como faixas ortogonais fletidas. Desta maneira tem-se como esforços solicitantes apenas por Mx e My, o que implica no aumento dos valores destes momentos e da flecha, porém define as direções $\mathrm{x}$ e y como principais. Neste caso o projetista deve estar sempre atento às regiões de canto de laje onde há necessidade de uma armadura de combate aos momentos volventes, apesar do método de cálculo empregado não as indicar.

Uma maneira mais eficiente de calcular lajes de concreto armado é considerar todos os esforços resistentes, incluindo o momento volvente. Para tanto se faz necessário o estudo de algoritmos que permitam determinar momentos normais a duas direções escolhidas, que cubram o terno de esforços Mx, My e Mxy calculados, para que, a partir destes, sejam 
determinadas as armaduras necessárias à laje, dispostas segundo estas direções.

Alguns projetistas utilizam, para o cálculo de lajes, procedimentos que consideram a contribuição do momento volvente, porém detalham as lajes utilizando os valores de $\mathrm{Mx}$ e My encontrados e simplesmente desconsideram o valor de Mxy. Este procedimento é incorreto pois vão existir na laje direções onde o momento normal dado pelo par de esforços Mx e My é insuficiente para cobrir o momento normal resultante do terno de esforços calculado. Na prática, porém, os efeitos da desconsideração do momento volvente no detalhamento é sentida apenas em regiões onde os valores deste momento são relativamente altos.

Esta disparidade entre a teoria e a prática pode ser explicada, entre outros fatores, pelo coeficiente de majoração dos esforços e por existir uma resistência do concreto ao cisalhamento provocado pelo momento volvente, que, em geral, é desprezada na armação.

Hoje em dia já é rotina a utilização de microcomputadores no projeto de edifícios, existindo vários "softwares" desenvolvidos para esta finalidade. Historicamente, pode-se dividir o desenvolvimento desses "softwares" em duas etapas:

i) inicialmente, foram criados "softwares" que apenas agilizavam o cálculo prático, utilizando as mesmas simplificações que seriam feitas em projetos sem a ajuda de computadores, sendo o procedimento de cálculo igual ao feito sem a ajuda de computares;

ii) com o desenvolvimento dos programas foi possível aprimorar o procedimento de cálculo, criando modelos matemáticos mais próximos do modelo real e estudando o edifício de maneira mais exata.

Dentro da primeira classe, para o cálculo de pavimentos de edifícios formados por lajes e vigas, pode-se citar programas que calculam lajes e vigas independentemente, sendo que a única interação laje-viga é a reação vertical. 
Esses tipos de programas não representam rigorosamente o pavimento, sendo feitas algumas simplificações no procedimento de cálculo da laje, tais como considerar indeformáveis os seus apoios, tratar a continuidade dos painéis como se não houvesse nenhuma interação entre eles ou simplificando o comportamento conjunto, considerar o carregamento e as reações nos apoios uniformes, simplificar lajes recortadas ou com aberturas para formas mais conhecidas e outras. Informações mais detalhadas sobre modelagem de pavimentos de edifícios podem ser encontrados em CORRÊA (1991).

As aproximações, em geral, alteram o consumo de materiais. Este aumento depende da teoria utilizada no cálculo da laje: o cálculo utilizando a teoria de charneiras plásticas implica, em geral, num consumo menor do que o obtido utilizando a teoria da elasticidade clássica.

No cálculo de vigas também tente a ser maior, uma vez que as reações das lajes são passadas totalmente para as vigas e de maneira uniforme, o que não é verdade, pois parte desta reação migra diretamente para o pilar e estas são maiores perto dos apoios e menores no centro do vão.

$\mathrm{Na}$ outra classe pode-se destacar os programas de grelha e elementos finitos, atualmente de uso mais difundido. Com um programa de grelha é possível aproximar as lajes e vigas do pavimento, fazendo-se uma analogia destas com barras de propriedades equivalentes ao trecho que representa. Os programas de elementos finitos podem representar 0 pavimento de maneira mais rigorosa: vigas como elementos do tipo barra e lajes como elementos do tipo placa. Comparações entre modelagens de lajes com a analogia de grelha e através de elementos finitos podem ser encontradas em FIGUEREDO FILHO (1989).

Para o processamento de pavimento utilizando elementos finitos é necessário criar uma malha apropriada, determinando para cada elemento placa sua espessura e carregamento distribuído, atribuir restrições aos nós e determinar as cargas em nós e elementos viga; se a malha for densa o 
suficiente pode-se adotar as cargas nos elementos como concentradas nos nós. Para que o procedimento possua agilidade e confiabilidade, se faz necessário o desenvolvimento de "softwares" que sirvam para gerar, alterar e conferir os modelos.

\subsection{Finalidades do Trabalho}

Apesar de serem relativamente simples as expressões que permitem levar em conta a contribuição do momento volvente no cálculo lajes de concreto armado, tanto no caso de armaduras dispostas ortogonalmente, quanto no caso de armaduras oblíquas entre si, são poucos os engenheiros que as conhecem. Este trabalho teve como proposta inicial, tornar mais conhecidos os procedimentos que permitem, de maneira prática e segura, a consideração do momento volvente em lajes de concreto armado.

Durante o desenvolvimento do trabalho, percebeu-se que, apesar de ser comum entre os projetistas de estruturas de concreto armado desprezar o valor do momento volvente no detalhamento da armadura, admitindo que este seja resistido pelo próprio concreto, não existiam, dentre os métodos pesquisados, critérios para determinar o valor do máximo momento volvente resistido pelo concreto, passando a ser este um outro objetivo do trabalho.

Outra finalidade do trabalho foi a de desenvolver pré-processadores para facilitar a modelagem de pavimentos por elementos finitos e um pósprocessador que permitisse a análise dos resultados utilizando os conceitos estudados.

Utilizando estes "softwares" fez-se um pequeno estudo de lajes retangulares apoiadas nos quatro lados, procurando avaliar as recomendações existentes na bibliografia especializada, sobre as armaduras de canto necessárias a esse tipo de laje. Fez-se, também uma comparação de detalhamentos das lajes de um pavimento tipo calculadas pelo método 
das charneiras plásticas, pelo método dos elementos finitos sem a consideração da rigidez à torção e pelo método dos elementos finitos considerando a rigidez à torção.

\subsection{Discussão Sucinta dos Capítulos}

No segundo capítulo são discutidas e comparadas as teorias descritas em WOOD (1968) e em LEONHARDT \& MÖNNING (1978 ${ }^{a}$ ) que possibilitam o cálculo das armaduras segundo duas direções ortogonais escolhidas. É discutido também o procedimento de Wood para o cálculo de armaduras segundo duas direções oblíquas entre si.

No capítulo 3 são detalhados critérios para determinar o máximo valor do momento volvente resistido pelo concreto, a fim de considerar esta contribuição no detalhamento das armaduras. São discutidos dois critérios: um critério obtido a partir de estudos do AMERICAN CONCRETE INSTITUTE (ACI) e outro adaptado da norma brasileira que indica o valor máximo de tensão cisalhante resistida pelo concreto para o caso de lajes.

No capítulo 4, estão descritos os programas de entrada, conferência e correção de dados de malhas de elementos finitos, e do programa de análise dos resultados do processamento segundo os critérios de tratamento do momento volvente.

No quinto capítulo são apresentados exemplos da utilização dos conceitos descritos nos capítulos anteriores. É feito um pequeno estudo de lajes retangulares apoiadas nos quatro lados, procurando avaliar as recomendações existentes na bibliografia especializada sobre a armadura de canto necessária neste tipo de laje. É feita, também, uma comparação de detalhamentos de lajes de um pavimento tipo calculadas pelo método das charneiras plásticas, pelo método dos elementos finitos (MEF) sem a 
consideração da rigidez à torção e pelo MEF considerando a rigidez a torção. 


\section{MOMENTOS EQUIVALENTES AO TERNO DE ESFORÇOS MX, MY E MXY}

\subsection{Introdução}

O presente capítulo mostra a dedução de algoritmos de cálculo de momentos equivalentes normais a duas direções escolhidas, que cubram o terno de esforços Mx, My e Mxy. A partir destes momentos, pode-se calcular as armaduras e dispô-las segundo as direções escolhidas.

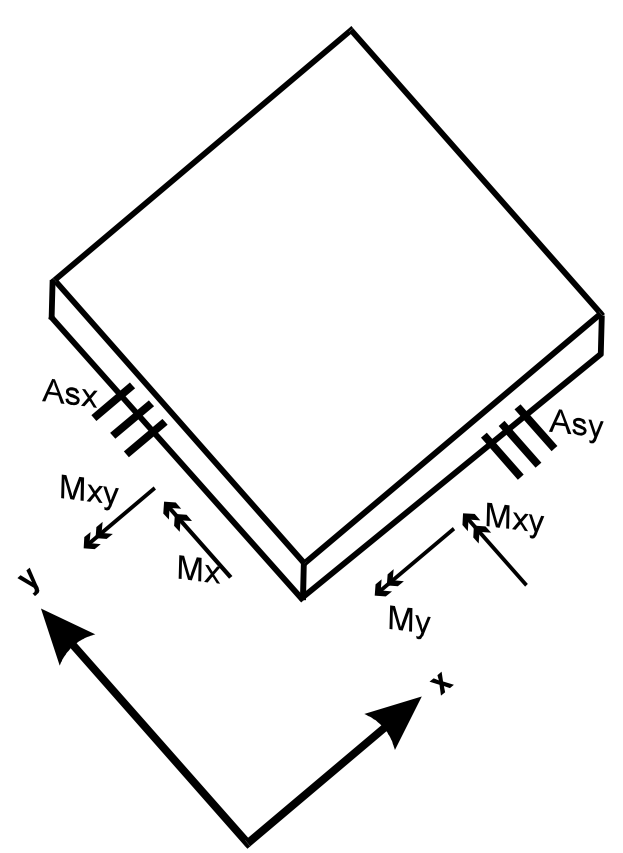
Convenção de Sinais:
sentidos positivos

- momentos fletores

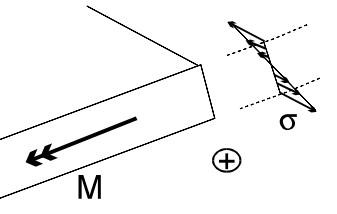

- momento volvente

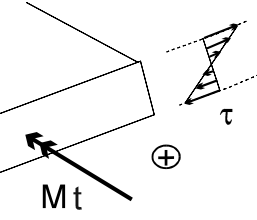

FIGURA 2.1 - Terno de esforços Mx, My e Mxy e armaduras segundo as direções X e Y 
São descritos dois métodos: o primeiro baseado na verificação dos momentos normais, de acordo com WOOD (1968), e o segundo baseado no equilíbrio de forças, de acordo com LEONHARDT \& MÖNNIG (1978a).

\subsection{Método de Wood}

As rotinas de detalhamento de armaduras segundo duas direções preferencias, descritas em WOOD (1968), têm como base o critério de resistência do momento normal, conhecido como critério de Johansen, ou critério das linhas de plastificação. O momento normal a um plano qualquer calculado com os momentos $M^{*} x$ e $M^{*} y$, correspondentes às armaduras dispostas na laje, deve ser maior ou igual ao momento normal ao mesmo plano dado pelos esforços Mx, My e Mxy. A armadura começará a plastificar segundo o plano de menor resistência.
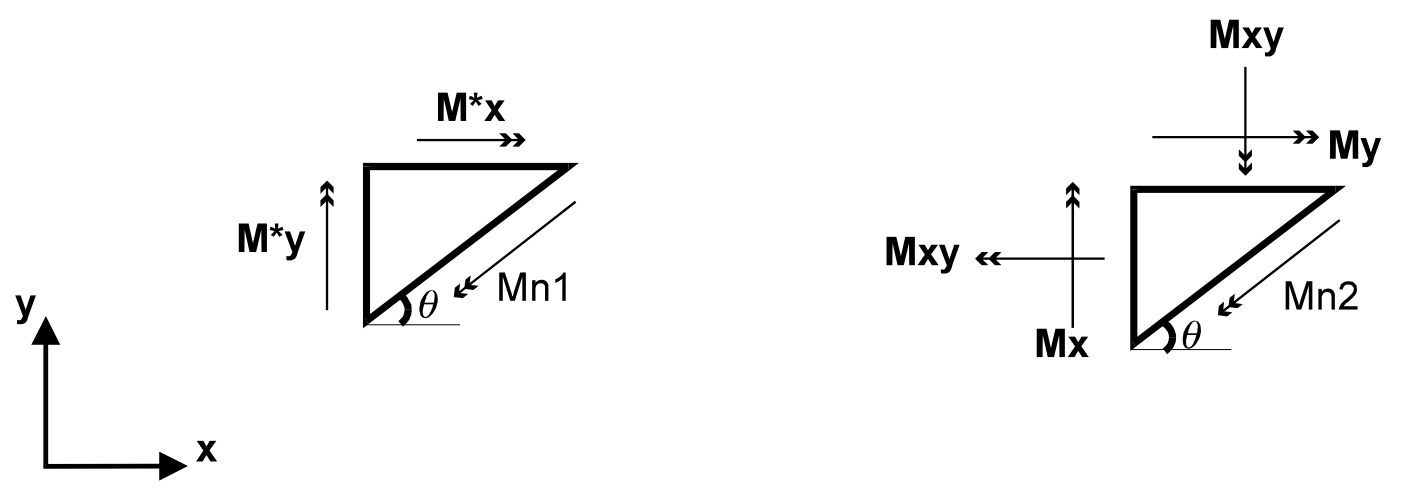

FIGURA 2.2 - Momentos normais desenvolvidos a partir de $M x$, My e Mxy e de $M^{*} x$ e $M^{*} y$

Existem vários aspectos a serem discutidos sobre a utilização desse critério.

Alguns aspectos trazem vantagens, no sentido de conduzir a uma maior segurança. Dentre estes pode-se citar:

- aumento da resistência do concreto devida à compressão biaxial, não considerado no método;

- efeito de "kinking" ou retorção da armadura, ou seja, as barras das armaduras tendem a se rearranjarem de maneira a cortarem 
perpendicularmente as fissuras, sendo admitido que elas permaneçam na sua posição original;

- efeito de membrana, também não considerado no método;

- laje calculada pelo método elástico, existindo ainda uma "reserva" de resistência.

Outros aspectos trazem desvantagens, no sentido de serem aproximações contra a segurança, e devem ser analisados com cuidado.

Dentre esses aspectos, pode-se citar o fato de o braço de alavanca dos momentos ser considerado constante em cada ponto verificado. Esta simplificação não implica em grandes erros, uma vez que, em geral, o braço de alavanca varia pouco. Equações para o cálculo do momento resistente, considerando braços de alavancas diferentes nas direções $\mathrm{X}$ e $\mathrm{Y}$, podem ser encontradas em PARK \& GAMBLE (1980). Em JAIN \& KENNEDY (1974) é verificado que a diferença entre considerar ou não a variação do braço alavanca é de no máximo $2 \%$, para os casos usuais de laje.

Outra desvantagem da utilização do critério de verificação do momento normal, é o fato de apenas o momento normal ser verificado, não levando em conta o momento volvente na direção crítica. Para o caso de lajes isótropas (com áreas de armaduras iguais nas duas direções) é possível provar analiticamente que, no plano de menor resistência, os momentos volventes, aplicado e resistente, também serão iguais se os momentos normais aplicado e resistente o forem. Esta verificação pode ser encontrada em LENSCHOW \& SOZEN (1967).

Para o caso de lajes ortótropas, os momentos volventes na direção crítica não são iguais. A presença de momentos volventes na direção do plano de plastificação pode fazer com que haja um pequeno desvio entre a direção crítica teórica e a real (verificada em ensaios). Em LENSCHOW \& SOZEN (1967) e em JAIN \& KENNEDY (1974) são relatados ensaios experimentais em lajes isótropas e ortótropas, sujeitas a diferentes tipos de carregamento (momentos fletores e torçores). 
Lenschow e Sozen ensaiaram 5 lajes armadas isotropicamente sujeitas a momentos fletores em duas direções, 8 lajes sujeitas a momentos torçores (6 com armadura isótropa e 2 com armadura ortótropa) e 8 lajes com momento aplicado em uma direção. Nestes ensaios, os autores verificaram que a direção medida do plano de plastificação era bem próxima da direção calculada segundo o princípio do plano de menor resistência, e que, em alguns casos, podem existir momentos volventes na direção crítica.

Jain e Kennedy ensaiaram 12 lajes com momento aplicado em uma direção, 8 lajes sujeitas a torção pura e 9 lajes sujeitas a momentos fletores e volvente. Em todos os casos de carregamentos foram ensaiadas lajes isótropas e ortótropas. A partir dos resultados dos ensaios, os autores afirmam que a direção do plano de plastificação é orientado conforme o princípio do plano de menor resistência e que os efeitos da mudança do braço de alavanca devido à rotação dos planos de plastificação, de compressão biaxial e de "kinking" são insignificantes.

Apesar do artigo WOOD (1968) ter sido publicado há quase trinta anos, foram poucas as críticas contrárias à utilização do método descrito, sendo encontradas várias bibliografias que adotam este método para tratamento do momento volvente. A única restrição encontrada se refere à lajes onde os valores de momento volvente calculados nas direções das armaduras são relativamente altos, ainda assim para casos de taxas de armaduras médias e altas.

Em MARTI \& KONG (1987) é estudado o caso extremo de lajes sujeitas a torção pura, sendo relatado que o critério é a favor da segurança até o limite da taxa geométrica de armadura ( $\rho$ ) das eqs. (2.1).

$$
\rho_{x}=\frac{A s_{x}}{h}<\frac{C_{x} \cdot f c}{2 \cdot f y \cdot h} \quad \text { e } \quad \rho_{y}=\frac{A s_{x}}{h}<\frac{C_{y} \cdot f c}{2 \cdot f y \cdot h}
$$

onde $\rho_{x}$ e $\rho_{y}$ são as taxas de armadura segundo $X$ e $Y$, $A s_{x}$ e $A s_{y}$ são as áreas de armadura segundo $X$ e $Y$, $c_{x}$ e c cão os cobrimentos segundo $X$ e $Y$, 
fc é a resistência do concreto,

fy é a resistência do aço, e

h é a altura da laje.

Para lajes com $c / h=0,10$, para o caso de torção pura, verificam-se taxas de armaduras $100 \%$ seguras até os limites iguais a 0,20\% para C20 e $0,25 \%$ para C25. Para valores maiores, pode-se obter resultados contra a segurança, aumentando-se o erro proporcionalmente à taxa de armadura.

Ainda segundo MARTI \& KONG (1987), este aspecto é relevante apenas em lajes com armadura ortogonal com cargas concentradas nos cantos, como em lajes em balanço com cargas concentradas em um dos cantos do balanço ou em lajes isoladas com os quatro cantos apoiados em pilares, não sendo encontradas maiores considerações quanto à utilização deste método no cálculo de pavimentos de concreto armado.

Modelos mais avançados podem ser utilizados para cálculo de lajes com maior precisão. FANTI \& MANCINI (1995) sugere a utilização de um modelo de elemento tipo "sanduíche" para determinar o estado limite último de placas de concreto armado.

\subsubsection{Momentos Positivos em Todas as Direções}

Pode-se calcular Mn1 e Mn2 de acordo com as seguintes expressões de transformação tensorial [vide TIMONSHENKO \& KRIEGER (1959)]:

$$
\begin{aligned}
& M n 1=M_{x}^{*} \cdot \cos ^{2} \theta+M_{y}^{*} \cdot \operatorname{sen}^{2} \theta \\
& M n 2=M_{x} \cdot \cos ^{2} \theta+M_{y} \cdot \operatorname{sen}^{2} \theta+2 \cdot M_{x y} \cdot \operatorname{sen} \theta \cdot \cos \theta
\end{aligned}
$$

Deve-se ter, portanto, Mn1 > Mn2 ou Mn1 - Mn2 > 0. A parte esquerda da inequação, aqui chamada de $f(\theta)$, é a função do excesso de momento normal. 


$$
f(\theta)=M_{x}^{*} \cdot \cos ^{2} \theta+M_{y}^{*} \cdot \operatorname{sen}^{2} \theta-M_{x} \cdot \cos ^{2} \theta+M_{y} \cdot \operatorname{sen}^{2} \theta+M_{x y} \cdot \operatorname{sen} \theta \cdot \cos \theta \geq 0
$$

Dividindo por $\cos ^{2} \theta$ e chamando $\tan \theta$ de $k$, tem-se:

$$
f(k)=M_{x}^{*}+M_{y}^{*} \cdot k^{2}-M_{x}-M_{y} \cdot k^{2}-M_{x y} \cdot 2 \cdot k \geq 0
$$

Para cada par de $M^{*} x$ e $M^{*} y$ tem-se um valor crítico de $k$, onde a função $f(k)$ é mínima. Para calcular este valor pode-se utilizar a primeira derivada da função:

$$
\frac{d f(\theta)}{d \theta}=\frac{d f(k)}{d \theta}=\frac{d f(\tan \theta)}{d \theta}=\frac{d f(\tan \theta)}{d(\tan \theta)} \cdot \frac{d f(\tan \theta)}{d \theta}=\frac{d f(k)}{d k} \cdot \sec ^{2} \theta
$$

Como $\sec ^{2} \theta$ não pode ser zero; $d f(k) / d k=0$ :

$$
\begin{aligned}
& \frac{d f(k)}{d k}=2 \cdot M_{y}^{*} \cdot k-2 \cdot M_{y} \cdot k-2 \cdot M_{x y}=0 \\
& M_{y}^{*}=M_{y}+\frac{1}{k} \cdot M_{x y} \quad \ldots(2.3) \\
& \therefore k_{\text {critico }}=\frac{M_{x y}}{M_{y}^{*}-M_{y}} \quad \ldots(2.4)
\end{aligned}
$$

Neste ponto $f(k)$ deve ser igual a zero para que os momentos normais sejam iguais, portanto substituindo-se a eq. (2.3) na eq. (2.2) e igualando a zero, obtém-se:

$$
M_{x}^{*}=M_{x}+k \cdot M_{x y}
$$

Nas outras direções $f(k)$ deve ser sempre positivo, ou seja $f\left(k_{\text {critico }}\right)$ deve ser um ponto de mínimo. Para tanto a segunda derivada da função deve ser maior que zero: 
$\frac{d^{2} f(k)}{d k^{2}}>0$

2. $M_{y}^{*}-2 \cdot M_{y}>0 \Rightarrow M_{y}^{*}>M_{y}$

$\mathrm{O}$ valor de $\mathrm{k}_{\text {critico }}$ define a tangente do ângulo onde os momentos normais são iguais, sendo esta a direção onde está havendo equilíbrio dos esforços aplicados e resistentes. Em um caso limite apareceriam fissuras segundo esta direção.

Se $M_{y}^{*}=M_{y}+\frac{1}{k} \cdot M_{x y}$ e $M_{y}^{*}>M_{y}$, chega-se à conclusão que $M_{x y} / k$ é positivo. Portanto, pode-se adotar $k$ sempre positivo e Mxy em valor absoluto.

Então é possível simplificar as expressões para cálculo de momentos equivalentes, fazendo:

$$
\begin{aligned}
& M_{x}^{*}=M_{x}+K \cdot\left|M_{x y}\right| \\
& M_{y}^{*}=M_{y}+\frac{1}{K} \cdot\left|M_{x y}\right| \quad \ldots(2.6), \quad \text { onde } K \text { deve ser sempre positivo }
\end{aligned}
$$

O parâmetro de K, valor absoluto da tangente do ângulo crítico, determina quanto do momento Mxy será resistido por Mx e quanto por My. Admitindo-se que o braço de alavanca do momento resistente seja igual para as armaduras em $\mathrm{x}$ e $\mathrm{y}$, a quantidade de armadura será proporcional à soma $(M x+M y)$. Para um valor mínimo da área de armadura, tem-se:

$$
\begin{aligned}
& \frac{\mathrm{d}\left(\mathrm{M}_{\mathrm{x}}^{*}+\mathrm{M}_{\mathrm{y}}^{*}\right)}{\mathrm{dK}}=0 \Rightarrow \frac{\mathrm{d}\left(\mathrm{M}_{\mathrm{y}}+\mathrm{K} \cdot\left|\mathrm{M}_{\mathrm{xy}}\right|+\mathrm{M}_{\mathrm{y}}+\frac{1}{\mathrm{~K}} \cdot\left|\mathrm{M}_{\mathrm{xy}}\right|\right)}{\mathrm{dK}}=\mathrm{M}_{\mathrm{xy}} \cdot\left(1-\frac{1}{\mathrm{~K}^{2}}\right)=0 \\
& \therefore \mathrm{K}=1
\end{aligned}
$$

Então a forma mais econômica é fazer:

$$
\begin{aligned}
& M_{x}^{*}=M_{x}+\left|M_{x y}\right| \\
& M_{y}^{*}=M_{y}+\left|M_{x y}\right|
\end{aligned}
$$


Em alguns casos, como aqueles em que a armadura em uma direção é igual à armadura mínima, é possível que esta simplificação seja menos eficiente, podendo o projetista determinar qual o momento resistido pela armadura mínima e calcular o correspondente valor de $k_{\text {critico, }}$ com as eqs. (2.6).

Para ilustrar o equacionamento anterior será usado o terno de esforços $M x=3, M y=1$ e $M x y=1$. A ג indica valores de momentos normais calculados em diversas direções a partir do terno de esforços dado, e a partir de $M^{*} x$ e $M^{*} y$ calculados com $K=0,5, K=1$ e $K=2$, utilizando as eqs. (2.6). Indica, ainda, os valores de $\mathrm{f}(\mathrm{k})$, eq. (2.2), para cada um dos valores de $K$.

Com os valores da $\lambda$, criaram-se curvas ilustrando $f(k)$, ה. Pode-se perceber que os valores de $\mathrm{f}(\mathrm{k})$ são sempre positivos, ou seja, sempre há um excesso de momento normal. Além disto é possível observar que $f(k)$ é nulo nas direções críticas.

TABELA 2.1 - Valores dos momentos normais e de $f(k)$

\begin{tabular}{|c|c|c|c|c|c|c|c|c|}
\hline$\theta\left(^{\circ}\right)$ & $\begin{array}{c}\mathrm{k} \\
\tan \theta\end{array}$ & $\mathrm{Mn} 2$ & $\begin{array}{c}\mathrm{Mn} 1 \\
\mathrm{k}_{\mathrm{crt}}=1\end{array}$ & $\begin{array}{c}\mathrm{Mn} 1 \\
\mathrm{k}_{\mathrm{crt}}=0,5\end{array}$ & $\begin{array}{c}\mathrm{Mn} 1 \\
\mathrm{k}_{\text {crt }}=2\end{array}$ & $\mathrm{f}(\mathrm{k}) \mathrm{k}_{\text {crt }}=1$ & $\begin{array}{c}\mathrm{f}(\mathrm{k}) \\
\mathrm{k}_{\text {crt }}=0,5\end{array}$ & $\begin{array}{c}\mathrm{f}(\mathrm{k}) \\
\mathrm{k}_{\text {crt }}=2\end{array}$ \\
\hline & & $\begin{array}{c}\mathrm{Mx}=3 \\
\mathrm{My}=2 \\
\mathrm{Mxy}=1\end{array}$ & $\begin{array}{c}\mathrm{M}^{*} \mathrm{x}=4 \\
\mathrm{M}^{*} \mathrm{y}=3\end{array}$ & $\begin{array}{c}\mathrm{M}^{*} \mathrm{x}=3,5 \\
\mathrm{M}^{*} \mathrm{y}=4\end{array}$ & $\begin{array}{c}\mathrm{M}^{*} \mathrm{x}=5 \\
\mathrm{M}^{*} \mathrm{y}=2,5\end{array}$ & $\begin{array}{c}\theta_{\text {crt }}= \\
45^{\circ}\end{array}$ & $\begin{array}{c}\theta_{\text {crt }}= \\
26,6^{\circ}\end{array}$ & $\begin{array}{c}\theta_{\text {crt }}= \\
63,4^{\circ}\end{array}$ \\
\hline 0 & 0,000 & 3,000 & 4,000 & 3,500 & 5,000 & 1,000 & 0,500 & 2,000 \\
\hline 20 & 0,364 & 3,526 & 3,883 & 3,558 & 4,708 & 0,357 & 0,033 & 1,182 \\
\hline 40 & 0,839 & 3,572 & 3,587 & 3,707 & 3,967 & 0,015 & 0,135 & 0,395 \\
\hline 60 & 1,732 & 3,116 & 3,250 & 3,875 & 3,125 & 0,134 & 0,759 & 0,009 \\
\hline 80 & 5,671 & 2,372 & 3,030 & 3,985 & 2,575 & 0,658 & 1,613 & 0,203 \\
\hline 100 & $-5,671$ & 1,688 & 3,030 & 3,985 & 2,575 & 1,342 & 2,297 & 0,887 \\
\hline 120 & $-1,732$ & 1,384 & 3,250 & 3,875 & 3,125 & 1,866 & 2,491 & 1,741 \\
\hline 140 & $-0,839$ & 1,602 & 3,587 & 3,707 & 3,967 & 1,985 & 2,105 & 2,365 \\
\hline 160 & $-0,364$ & 2,240 & 3,883 & 3,558 & 4,708 & 1,643 & 1,318 & 2,467 \\
\hline 180 & 0,000 & 3,000 & 4,000 & 3,500 & 5,000 & 1,000 & 0,500 & 2,000 \\
\hline
\end{tabular}


Examinando-se as curvas da $\mathrm{n}$, observa-se que para $\mathrm{K}=0,5$ e $\mathrm{K}=2$, a amplitude da curva é maior do que a amplitude da curva traçada para $\mathrm{K}=1$. Examinando-se a soma de $\left(M^{*} x+M^{*} y\right)$ percebe-se que ela é menor quando $K=1$. Portanto a simplificação de $K=1$ para cálculo de $M^{*} x$ e $M^{*} y$ é perfeitamente justificável.

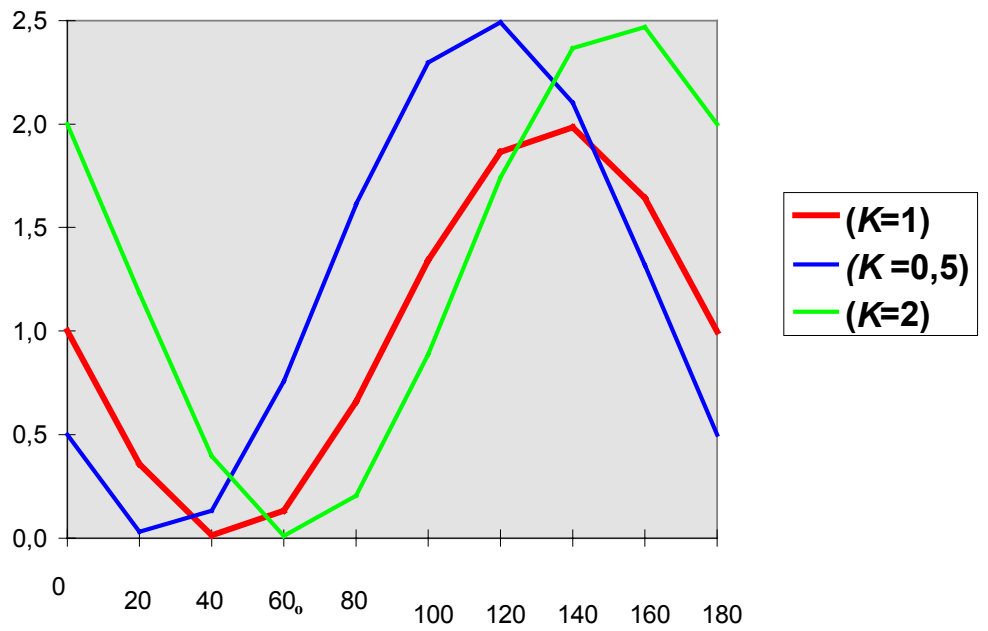

FIGURA 2.3 - Curvas de $\mathrm{f}(\mathrm{k})$

\subsubsection{Momentos Negativos em Todas as Direções}

Para o caso de campos de momentos estritamente negativos, a situação é análoga à anterior, mudando apenas o posicionamento das armaduras e conseqüentemente o sinal dos momentos. Desta forma, temse:

$$
\begin{aligned}
& M_{x}^{*}=M_{x}-\left|M_{x y}\right| \\
& M_{y}^{*}=M_{y}-\left|M_{x y}\right|
\end{aligned}
$$




\subsubsection{Campos de Momentos Positivos e Negativos}

Em casos em que um momento principal é positivo e o outro é negativo, devem ser verificadas tanto as equações positivas, eqs. (2.7), quanto as negativas, eqs. (2.8), podendo haver, em um mesmo ponto da laje, a necessidade de serem dispostas tanto armaduras positivas, quanto e negativas. Neste caso existirão duas direções críticas: uma positiva (com fissuras ocorrendo na parte inferior da laje) e outra negativa (fissuras na parte superior).

Pode acontecer que, ao se tentar calcular momentos positivos, resulte um momento negativo. $O$ terno de esforços $M x=1, M y=-2$ e $M x y=1$ será usado para ilustrar esta situação. Utilizando-se as eq. (2.7), tem-se $M^{*} x=2$ e $M^{*} y=-1$.

O valor negativo não tem significado físico, pois está se tentando combater um momento positivo (com tensões de tração na parte inferior da laje) com uma armadura negativa (disposta na parte superior da laje). Neste caso não há necessidade de armadura positiva segundo esta direção, devendo ser considerado zero o momento calculado negativo. No exemplo $\mathrm{M}^{*} \mathrm{y}$ é feito igual a zero.

Utilizando-se o valor do momento equivalente positivo e tomando igual a zero o outro momento, pode-se verificar que, no campo dos momentos positivos, o valor do momento normal resistente é maior que o momento normal solicitante.

$\mathrm{Na} \lambda$ estão calculados os valores dos momentos normais para o exemplo. Pode-se verificar que, no campo de momentos positivos Mn1 (momento normal calculado com $\mathrm{M}^{*} \mathrm{x}=2$ e $\mathrm{M}^{*} \mathrm{y}=0$ ) é sempre maior que $\mathrm{Mn} 2$ (calculado com $M x=1, M y=-2$ e $M x y=1$ ).

Ao serem comparados os valores de Mn1 e Mn2 no campo de momentos negativos, percebe-se que Mn1 continua sendo maior que Mn2, ou seja matematicamente os resultados parecem certos. Fisicamente, 
porém, os resultados estão errados, uma vez que está se tentando combater momentos negativos com armaduras positivas. A comparação dos valores absolutos de $\mathrm{Mn} 1$ e $\mathrm{Mn} 2$, apesar de também não ser fisicamente correta pelo mesmo motivo anterior, serve para chamar a atenção de que a comparação de momentos positivos com momentos negativos não é consistente.

TABELA 2.2 - Comparação entre momentos normais para $M^{*} x=2,0$

\begin{tabular}{|c|c|c|c|c|}
\hline$\theta\left(^{\circ}\right)$ & $\begin{array}{c}\text { Momento Normal Mn2 } \\
(M x=1, M y=-2, M x y=1)\end{array}$ & $\begin{array}{c}\text { Momento Normal Mn1 } \\
\left(M^{*} \times=2, M^{*} y=0\right)\end{array}$ & Mn1 - Mn2 & $\mid$ IMn1| - IMn2| \\
\hline 0 & $\mathbf{1 , 0 0 0}$ & $\mathbf{2 , 0 0 0}$ & $\mathbf{1 , 0 0 0}$ & $\mathbf{1 , 0 0 0}$ \\
\hline 20 & $\mathbf{1 , 2 9 2}$ & $\mathbf{1 , 7 6 6}$ & $\mathbf{0 , 4 7 4}$ & $\mathbf{0 , 4 7 4}$ \\
\hline 40 & $\mathbf{0 , 7 4 5}$ & $\mathbf{1 , 1 7 4}$ & $\mathbf{0 , 4 2 8}$ & $\mathbf{0 , 4 2 8}$ \\
\hline 60 & $-0,384$ & 0,500 & 0,884 & 0,116 \\
\hline 80 & $-1,568$ & 0,060 & 1,628 & $-1,507$ \\
\hline 100 & $-2,252$ & 0,060 & 2,312 & $-2,191$ \\
\hline 120 & $-2,116$ & 0,500 & 2,616 & $-1,616$ \\
\hline 140 & $-1,224$ & 1,174 & 2,398 & $-0,051$ \\
\hline 160 & $\mathbf{0 , 0 0 6}$ & $\mathbf{1 , 7 6 6}$ & $\mathbf{1 , 7 6 0}$ & $\mathbf{1 , 7 6 0}$ \\
\hline 180 & $\mathbf{1 , 0 0 0}$ & $\mathbf{2 , 0 0 0}$ & $\mathbf{1 , 0 0 0}$ & $\mathbf{1 , 0 0 0}$ \\
\hline
\end{tabular}

Também pode-se verificar que, neste caso, $\mathrm{K}=1$ deixa de ser a solução mais econômica. Melhora-se o resultado calculando-se o valor do ângulo crítico correspondente ao momento feito nulo (neste caso diferente de $45^{\circ}$ ) e determinando-se o valor do outro momento as eq. (2.7).

No exemplo, para $M^{*} y=0$, tem-se $K=0,5$ e $M^{*} x=1,5$; solução $25 \%$ mais econômica que a anterior. $\mathrm{A}$ in indica que, no campo de momentos normais positivos, estes momentos equivalentes são suficientes para equilibrar o momento normal solicitante.

Procedimento análogo deve feito ao obter-se um valor de momento equivalente positivo no cálculo de armaduras negativas.

TABELA 2.3 - Comparação entre momentos normais para $M^{*} x=1,5$

\begin{tabular}{|c|c|c|c|c|}
\hline$\theta\left(^{\circ}\right)$ & $\begin{array}{c}\text { Momento Normal Mn2 } \\
(M x=1, M y=-2, M x y=1)\end{array}$ & $\begin{array}{c}\text { Momento Normal Mn1 } \\
\left(M^{*} x=1,5, M^{*} y=0\right)\end{array}$ & Mn1 - Mn2 & $\mid$ Mn1| - |Mn2| \\
\hline
\end{tabular}




\begin{tabular}{|c|c|c|c|c|}
0 & $\mathbf{1 , 0 0 0}$ & $\mathbf{1 , 5 0 0}$ & $\mathbf{0 , 5 0 0}$ & $\mathbf{0 , 5 0 0}$ \\
\hline 20 & $\mathbf{1 , 2 9 2}$ & $\mathbf{1 , 3 2 5}$ & $\mathbf{0 , 0 3 3}$ & $\mathbf{0 , 0 3 3}$ \\
\hline 40 & $\mathbf{0 , 7 4 5}$ & $\mathbf{0 , 8 8 0}$ & $\mathbf{0 , 1 3 5}$ & $\mathbf{0 , 1 3 5}$ \\
\hline 60 & $-0,384$ & 0,375 & 0,759 & $-0,009$ \\
\hline 80 & $-1,568$ & 0,045 & 1,613 & $-1,522$ \\
\hline 100 & $-2,252$ & 0,045 & 2,297 & $-2,206$ \\
\hline 120 & $-2,116$ & 0,375 & 2,491 & $-1,741$ \\
\hline 140 & $-1,224$ & 0,880 & 2,105 & $-0,344$ \\
\hline 160 & $\mathbf{0 , 0 0 6}$ & $\mathbf{1 , 3 2 5}$ & $\mathbf{1 , 3 1 8}$ & $\mathbf{1 , 3 1 8}$ \\
\hline 180 & $\mathbf{1 , 0 0 0}$ & $\mathbf{1 , 5 0 0}$ & $\mathbf{0 , 5 0 0}$ & $\mathbf{0 , 5 0 0}$ \\
\hline
\end{tabular}

Resumidamente tem-se:

se $\mathrm{M}_{\mathrm{x}}^{*}<0$ impõe-se $\mathrm{M}_{\mathrm{x}}^{*}=0$ sendo $\mathrm{M}_{\mathrm{y}}^{*}=\mathrm{M}_{\mathrm{y}}+\left|\frac{M_{x y}^{2}}{M_{x}}\right|$

se $\mathrm{M}_{\mathrm{y}}^{*}<0$ impõe-se $\mathrm{M}_{\mathrm{y}}^{*}=0$ sendo $\mathrm{M}_{\mathrm{x}}^{*}=\mathrm{M}_{\mathrm{x}}+\left|\frac{M_{x y}^{2}}{M_{y}}\right|$.

Também pode-se obter um resultado positivo ao se tentar calcular momentos negativos. Analogamente:

se $\mathrm{M}_{\mathrm{x}}^{*}>0$ impõe-se $\mathrm{M}_{\mathrm{x}}^{*}=0$ sendo $\mathrm{M}_{\mathrm{y}}^{*}=\mathrm{M}_{\mathrm{y}}-\left|\frac{M_{x y}^{2}}{M_{x}}\right|$;

se $\mathrm{M}_{\mathrm{y}}^{*}>0$ impõe-se $\mathrm{M}_{\mathrm{y}}^{*}=0$ sendo $\mathrm{M}_{\mathrm{x}}^{*}=\mathrm{M}_{\mathrm{x}}-\left|\frac{M_{x y}^{2}}{M_{y}}\right|$.

Este procedimento é adotado no EUROCODE 2 (1992), em PARK \& GAMBLE (1980), em MAC GREGOR (1992) e nos "softwares" STRAP e LUSAS.

\subsection{Método de Leonhardt \& Mönnig}


Uma outra maneira de determinarem-se armaduras oblíquas à direção dos esforços principais é fazer-se o equilíbrio de forças aplicadas e resistentes de uma seção.

Pode-se tratar a região tracionada de uma laje como uma chapa, admitindo que as tensões normais e cisalhantes sejam iguais aos momentos aplicados à laje, divididos por um braço de alavanca médio.

Por ser um problema de mais fácil visualização, será estudada inicialmente uma chapa de concreto armado sujeita a um estado plano de tensões genérico, onde objetiva-se a determinação de tensões normais a dois planos perpendiculares, que cubram este estado de tensão.

\subsubsection{Chapa de Concreto Armado}

Em uma chapa de concreto armado, com armadura de tração em direções diferentes das principais, aparecerão, em um estado limite, fissuras segundo um plano de menor resistência, dependendo das armaduras dispostas.

Imaginando-se uma chapa fissurada apresenta-se o seguinte problema:

- chapa de concreto armado com armaduras por unidade de comprimento $A s_{x}$ e $A s_{y}$ dispostas segundo os eixos $\mathrm{X}$ e $\mathrm{Y}$ de um plano cartesiano,

- tensões principais aplicadas à chapa, $\sigma_{1}$ e $\sigma_{2}$ ( $\sigma_{1}$ é a maior), sendo $\alpha$ o ângulo entre $\sigma_{1}$ e o eixo $X$,

- fissuras ocorrendo segundo um ângulo $\varphi$ medido a partir do eixo Y.

Em LEONHARDT \& MÖNNING $\left(1978^{a}\right)$, para o desenvolvimento das deduções, é imposto que o ângulo $\alpha$ dever ser sempre menor ou igual a $45^{\circ}$. 
Analisando-se um elemento de comprimento unitário nas direções principais determina-se os esforços solicitantes por unidade de comprimento $\mathrm{N}_{1}$ e $\mathrm{N}_{2}$, conforme a I.

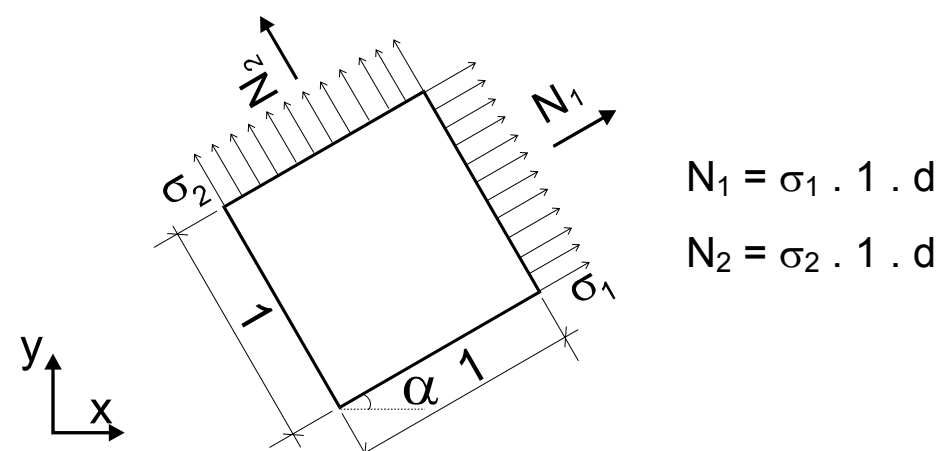

FIGURA 2.4 - Esforços solicitantes na chapa

Imaginando-se a direção das fissuras conhecidas, aparecem entre estas tensões de compressão no concreto $\left(\sigma_{c}\right)$ que resultam em uma força por unidade de comprimento $\mathrm{F}_{\mathrm{c}}{ }^{1}, \mathrm{r}$

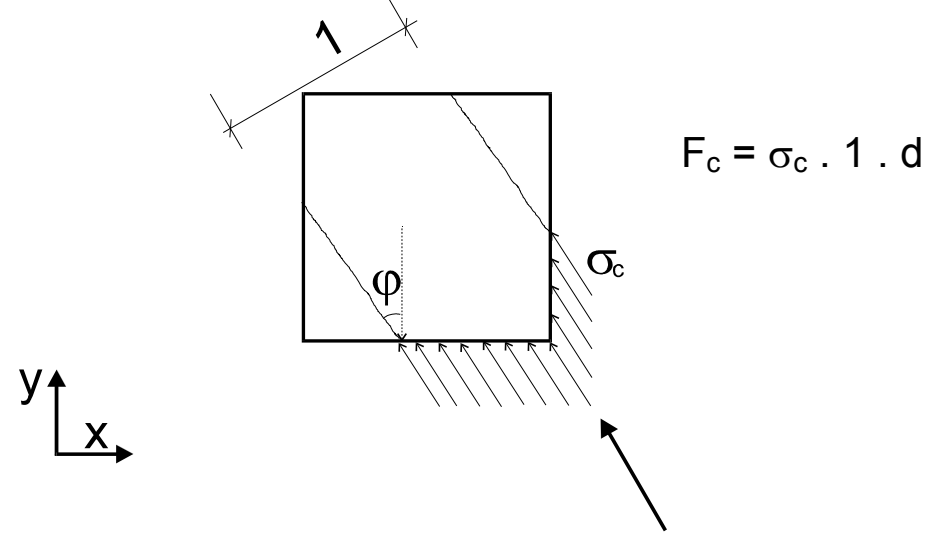

FIGURA 2.5 - Força de compressão do concreto

Das armaduras resultam, nas direções $X$ e $Y$, forças $F_{X}$ e $F_{y}$ por unidade de comprimento proporcionais às suas áreas, sendo estas forças, juntamente com $F_{c}$, os esforços resistentes da chapa, conforme $n$. 


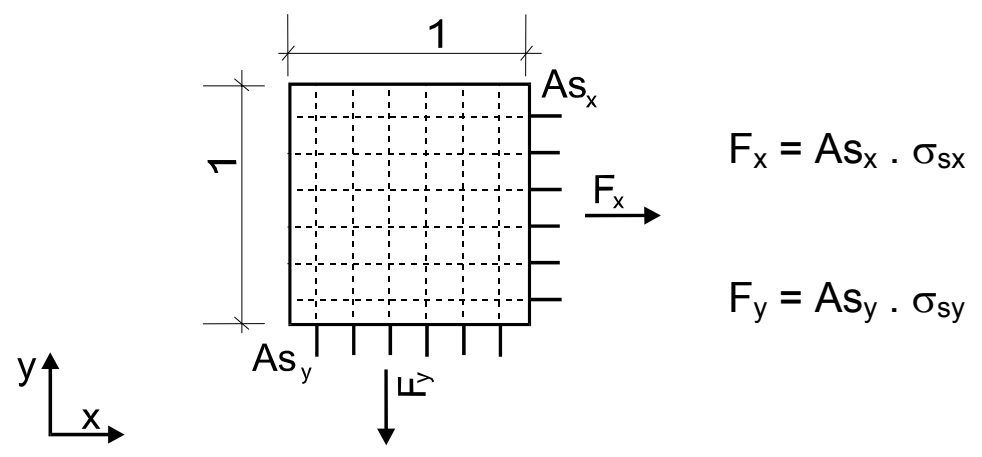

FIGURA 2.6 - Esforços resistentes da chapa

Fazendo o equilíbrio de uma seção paralela a $\varphi$ tem-se:

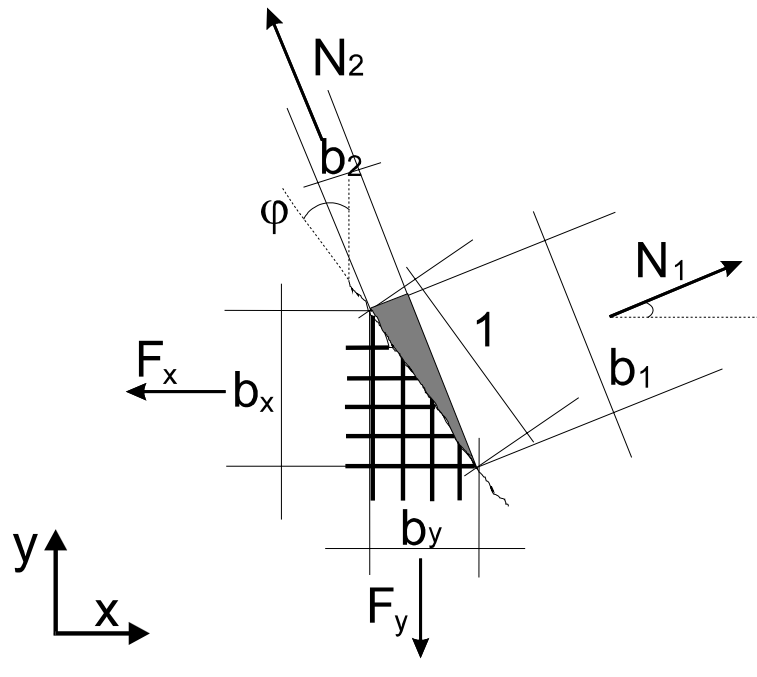

$$
\begin{array}{ll}
1_{\varphi} b_{x} & b_{x}=1 \cdot \cos (\varphi) \\
b_{y}=1 \cdot \operatorname{sen}(\varphi) \\
b_{2} & b_{1}=1 \cdot \cos (\varphi-\alpha) \\
b_{1} & b_{2}=1 \cdot \operatorname{sen}(\varphi-\alpha)
\end{array}
$$

FIGURA 2.7 - Esforços em uma chapa de concreto: direção paralela a $\varphi$

\section{Esforços Externos}

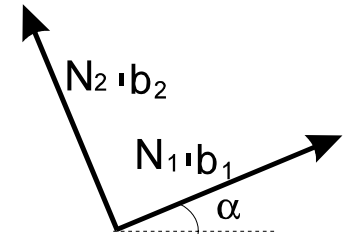

\section{Esforços Internos}

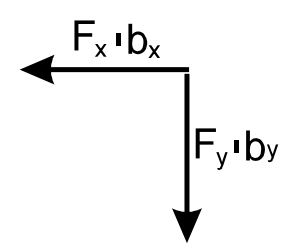

\footnotetext{
1 segundo Leonhardt \& Mönnig (1978a), as tensões de compressão do concreto são ligeiramente inclinadas em relação às fissuras devido aos efeitos de força cortante e engrenamento, sendo a não consideração destes efeitos favorável à segurança.
} 


$$
\begin{aligned}
\sum X=0 & \Rightarrow-N_{1} \cdot b_{1} \cdot \cos \alpha+N_{2} \cdot b_{2} \cdot \operatorname{sen} \alpha+F_{x} \cdot b_{x}=0 \\
& F_{x}=\frac{N_{1} \cdot b_{1} \cdot \cos \alpha-N_{2} \cdot b_{2} \cdot \operatorname{sen} \alpha}{b_{x}} \\
& F_{x}=\frac{N_{1} \cdot \cos (\varphi-\alpha) \cdot \cos \alpha-N_{2} \cdot \operatorname{sen}(\varphi-\alpha) \cdot \operatorname{sen} \alpha}{\cos \varphi} \\
\sum Y=0 \Rightarrow & N_{1} \cdot b_{1} \cdot \operatorname{sen} \alpha+N_{2} \cdot b_{2} \cdot \cos \alpha-F_{x} \cdot b_{x}=0 \\
& F_{y}=\frac{N_{1} \cdot b_{1} \cdot \operatorname{sen} \alpha+N_{2} \cdot b_{2} \cdot \cos \alpha}{b_{y}} \\
F_{y} & =\frac{N_{1} \cdot \cos (\varphi-\alpha) \cdot \operatorname{sen} \alpha+N_{2} \cdot \operatorname{sen}(\varphi-\alpha) \cdot \cos \alpha}{\operatorname{sen} \varphi}
\end{aligned}
$$

Utilizando as transformações trigonométricas:

$$
\begin{aligned}
& \cos (\varphi-\alpha)=\cos \varphi \cdot \cos \alpha+\operatorname{sen} \varphi \cdot \operatorname{sen} \alpha \\
& \operatorname{sen}(\varphi-\alpha)=\operatorname{sen} \varphi \cdot \cos \alpha-\cos \varphi \cdot \operatorname{sen} \alpha
\end{aligned}
$$

pode-se rescrever as equações de equilíbrio como:

$$
\begin{aligned}
& F_{x}=N_{1} \cdot\left(\cos ^{2} \alpha+\tan \varphi \cdot \operatorname{sen} \alpha \cdot \cos \alpha\right)-N_{2} \cdot\left(\tan \varphi \cdot \operatorname{sen} \alpha \cdot \cos \alpha-\operatorname{sen}^{2} \alpha\right) \\
& F_{y}=N_{1} \cdot\left(\cot a n \varphi \cdot \operatorname{sen} \alpha \cdot \cos \alpha+\operatorname{sen}^{2} \alpha\right)+N_{2} \cdot\left(\cos ^{2} \alpha-\cot \tan \varphi \cdot \operatorname{sen} \alpha \cdot \cos \alpha\right)
\end{aligned}
$$

Chamando tan $\varphi=\mathrm{K}$ e rearranjando-se as equações, obtêm-se:

$$
\begin{aligned}
& F_{x}=N_{1} \cdot \cos ^{2} \alpha+N_{2} \cdot \operatorname{sen}^{2} \alpha+\left(N_{1}-N_{2}\right) \cdot K \cdot \operatorname{sen} \alpha \cdot \cos \alpha \\
& F_{y}=N_{1} \cdot \operatorname{sen}^{2} \alpha+N_{2} \cdot \cos ^{2} \alpha+\left(N_{1}-N_{2}\right) \cdot \frac{1}{K} \cdot \operatorname{sen} \alpha \cdot \cos \alpha
\end{aligned}
$$

Para determinar-se a força de compressão no concreto pode-se fazer o equilíbrio do forças em uma seção de comprimento unitário perpendicular a $\varphi$ : 


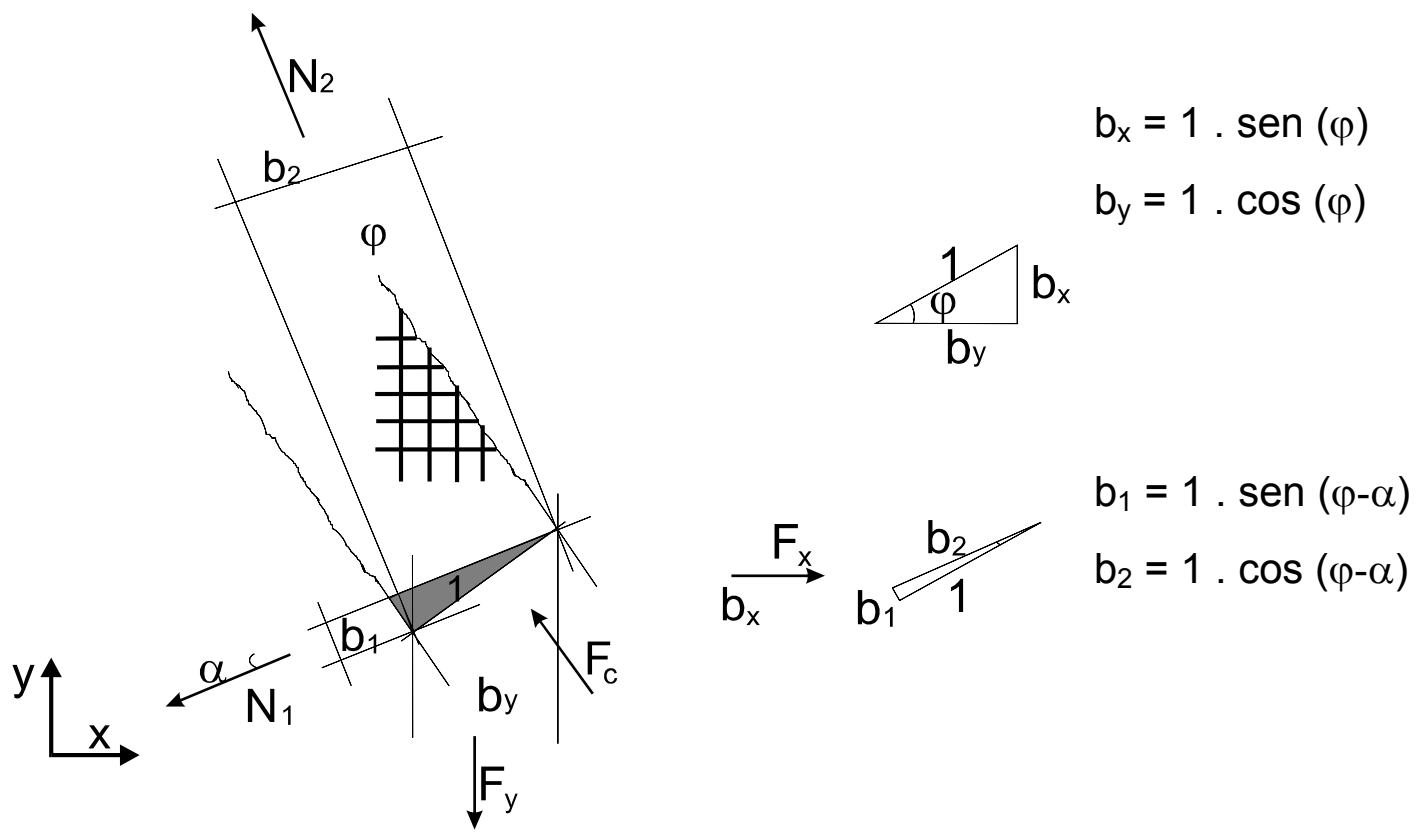

FIGURA 2.8 - Esforços em uma chapa de concreto: direção perpendicular a $\varphi$
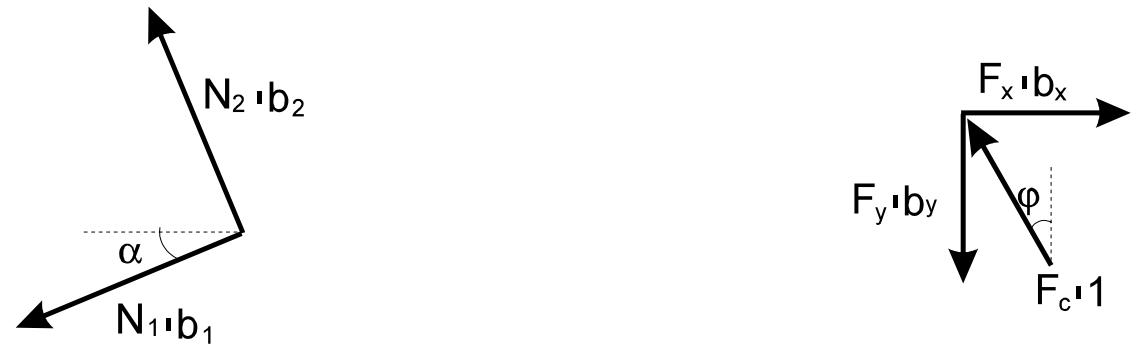

$\sum \varphi=0 \Rightarrow$

$N_{1} \cdot b_{1} \cdot \operatorname{sen}(\varphi-\alpha)+N_{2} \cdot b_{2} \cdot \cos (\varphi-\alpha)-F_{x} \cdot b_{x} \cdot \operatorname{sen} \varphi-F_{y} \cdot b_{y} \cdot \cos \varphi+F_{c}=0$

Substituindo os valores de $b_{x}, b_{y}, b_{1}, b_{2}$ e $\varphi$ tem-se:

$$
F_{c}=\left(N_{1}-N_{2}\right) \cdot \operatorname{sen} 2 \alpha \quad \ldots(2.10)
$$

\subsubsection{Lajes com Armaduras Ortogonais}


Em uma laje sujeita a momentos principais $M_{1}$ e $M_{2}$ onde se quer calcular momentos equivalentes $\mathrm{M}^{*} \mathrm{x}$ e $\mathrm{M}^{*} \mathrm{y}$, pode-se, admitindo um braço de alavanca médio $\left(\mathrm{z}_{\mathrm{m}}\right)$, fazer:

$M^{*} x=F_{x} \cdot z_{m} ; M^{*} y=F_{y} \cdot z_{m} ; M_{1}=N_{1} \cdot z_{m} ; M_{2}=N_{2} \cdot Z_{m}$

Portanto:

$$
\begin{aligned}
& M^{*} x=M_{1} \cdot \cos ^{2} \alpha+M_{2} \cdot \operatorname{sen}^{2} \alpha+\left(M_{1}-M_{2}\right) \cdot K \cdot \operatorname{sen} \alpha \cdot \cos \alpha \\
& M^{*} x=M_{1} \cdot \operatorname{sen}^{2} \alpha+M_{2} \cdot \cos ^{2} \alpha+\left(M_{1}-M_{2}\right) \cdot \frac{1}{K} \cdot \operatorname{sen} \alpha \cdot \cos \alpha
\end{aligned}
$$

O campo de momentos $M_{x}, M_{y}$ e $M_{x y}$ pode ser expresso por seus valores principais $M_{1}$ e $M_{2}$ e pelo ângulo $\alpha$. As equações de transformação tensorial, que relacionam momentos em várias direções, são:

$$
\begin{aligned}
& M \bar{x}=M x \cdot \cos ^{2} \alpha+M y \cdot \operatorname{sen}^{2} \alpha+2 \cdot M x y \cdot \operatorname{sen} \alpha \cdot \cos \alpha \\
& M \bar{y}=M x \cdot \operatorname{sen}^{2} \alpha+M y \cdot \cos ^{2} \alpha+2 \cdot M x y \cdot \operatorname{sen} \alpha \cdot \cos \alpha \\
& M \overline{x y}=M x y \cdot\left(\cos ^{2} \alpha-\operatorname{sen}^{2} \alpha\right)-(M x-M y) \cdot \operatorname{sen} \alpha \cdot \cos \alpha
\end{aligned}
$$

Escrevendo-se Mx, My e Mxy a partir de $M_{1}, M_{2}$ e $\alpha$, chega-se:

$$
\begin{aligned}
& M x=M_{1} \cdot \cos ^{2} \alpha+M_{2} \cdot \operatorname{sen}^{2} \alpha \\
& M y=M_{1} \cdot \operatorname{sen}^{2} \alpha+M_{2} \cdot \cos ^{2} \alpha \\
& M x y=-\left(M_{1}-M_{2}\right) \cdot \operatorname{sen} \alpha \cdot \cos \alpha
\end{aligned}
$$

Substituindo-se as equações (2.12) em (2.11) e ajustando-se o sinal de k, chega-se a:

$$
\begin{aligned}
& M^{*} x=M x+K \cdot M x y \\
& M^{*} y=M y+\frac{1}{K} \cdot M x y
\end{aligned}
$$


Conclui-se, portanto, que os resultados do método de Leonhardt \& Mönnig são equivalentes aos resultados do método de Wood, pois as eqs. (2.13) são iguais às eqs. (2.6).

O método de Leonhardt-Mönnig é uma aproximação física para o problema, enquanto o método de Wood é uma aproximação numérica. A verificação de momentos normais a várias direções, sendo uma direção crítica onde haverá equilíbrio entre os momentos externos e internos, equivale a determinar o equilíbrio de esforços internos e externos admitindo fissuras segundo uma direção crítica.

Em Leonhardt-Mönnig $\left(1978^{\mathrm{a}}\right)$ o ângulo crítico econômico também é verificado como sendo igual a $45^{\circ}$ (o que equivale a $\mathrm{K}=1$ ), sendo comentado que este ângulo deixa de ser econômico para casos em que a área de armadura secundária é menor que $20 \%$ da área de armadura principal, o que equivale ao que foi dito anteriormente sobre a necessidade de armadura mínima, uma vez que, tanto na norma alemã (segundo a qual os autores da referida bibliografia se baseiam), quanto na norma brasileira de concreto armado, esta é um dos valores mínimos da área armadura a ser disposta na laje.

Para caso de momentos principais positivo e negativo, é recomendado que seja verificado o par de momento $M_{1}$ e $M_{2}$ considerando a força $N_{2}=M_{2} / z_{m}$ como de tração ao invés de $N_{1}$, ou seja, invertendo-se os sinais dos momentos. Isto equivale à necessidade de verificação das equações para armaduras positivas e negativas, discutida no item 2.2.3.

\subsection{Momentos Equivalentes em Duas Direções Oblíquas Entre Si}

Em alguns tipos de laje com lados inclinados pode ser interessante disporem-se as armaduras formando um ângulo entre elas diferente de $90^{\circ}$. Desta forma pode-se conseguir uma disposição mais racional das barras de armaduras nas lajes e evitar o corte desnecessário de barras com vários comprimentos diferentes. 
Neste caso se faz necessário encontrar um par de momentos equivalentes $M^{*} x$ (com armadura paralela ao eixo $X$ ) e $M^{*} \alpha$ (armadura paralela a um angulo $\alpha$ formado entre ela e o eixo $X)$ que cubram o terno de esforços Mx, My e Mxy dado, conforme proposto por G. S. T. ARMER (1968).

O momento normal a uma direção qualquer dado por $\mathrm{M}^{*} \mathrm{x}$ e $\mathrm{M}^{*} \alpha$, sendo $\alpha$ o ângulo medido no sentido anti-horário entre o eixo $\mathrm{x}$ e a direção da armadura resistente a $M^{*} \alpha$ conforme ${ }^{*}$, é:

$$
\begin{aligned}
& \mathrm{Mn}_{\theta, \mathrm{x}} \cdot \mathrm{ds}=\mathrm{M}_{\mathrm{x}}^{*} \cdot \mathrm{ds} \cdot \cos \theta \cdot \cos \theta \\
& \mathrm{Mn}_{\theta, \alpha} \cdot \mathrm{ds}=\mathrm{M}_{\alpha}^{*} \cdot \mathrm{ds} \cdot \cos (\alpha-\theta) \cdot \cos (\alpha-\theta) \\
& \therefore \mathrm{Mn} \theta=\mathrm{M}_{\mathrm{x}}^{*} \cdot \cos ^{2} \theta+\mathrm{M}_{\alpha}^{*} \cdot \cos ^{2}(\alpha-\theta)
\end{aligned}
$$

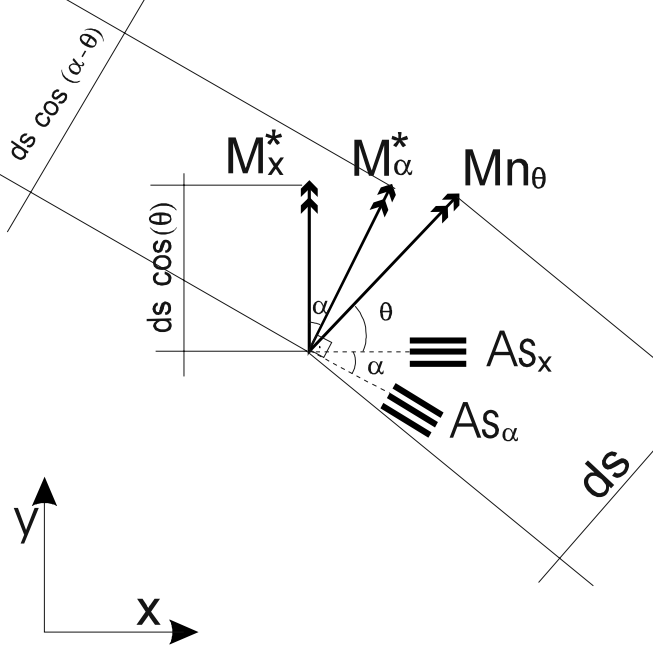

FIGURA 2.9 - Momentos para armaduras paralelas ao eixo x e à $\alpha$

Desta forma a função $f(\theta)$ relativa ao excesso de momento normal será:

$$
\begin{aligned}
f(\theta)= & M_{x}^{*} \cdot \cos ^{2} \theta+M_{\alpha}^{*} \cdot \cos ^{2}(\alpha-\theta)-M_{x} \cdot \cos ^{2} \theta-M_{y} \cdot \operatorname{sen}^{2} \theta- \\
& -2 \cdot M_{x y} \cdot \operatorname{sen} \theta \cdot \cos \theta \geq 0
\end{aligned}
$$




\section{Como:}

$\cos (\alpha-\theta)=\cos \theta \cdot \cos \alpha+\operatorname{sen} \theta \cdot \operatorname{sen} \alpha$

$\Rightarrow \cos ^{2}(\alpha-\theta)=\cos ^{2} \theta \cdot \cos ^{2} \alpha+2 \cdot \cos \theta \cdot \cos \alpha \cdot \operatorname{sen} \theta \cdot \operatorname{sen} \alpha+\operatorname{sen}^{2} \theta \cdot \operatorname{sen}^{2} \alpha$,

pode-se simplificar a expressão dividindo por $\cos ^{2} \theta$ e chamando (tan $\theta)$ de $k$.

Desta forma tem-se:

$$
\begin{aligned}
f(k)= & M^{*} x+M^{*} \alpha \cdot\left(\cos ^{2} \alpha+2 \cdot k \cdot \cos \alpha \cdot \operatorname{sen} \alpha+k^{2} \cdot \operatorname{sen}^{2} \alpha\right)- \\
& -M x-M y \cdot k^{2}-M x y \cdot 2 \cdot k \geq 0
\end{aligned}
$$

Derivando-se a função tem-se:

$$
\frac{d f(k)}{d k}=2 \cdot M^{*} \alpha \cdot\left(\cos \alpha \cdot \operatorname{sen} \alpha+k \cdot \operatorname{sen}^{2} \alpha\right)-2 \cdot M y \cdot k-2 \cdot M x y=0
$$

Portanto:

$$
\begin{array}{r}
M^{*} \alpha=\frac{M y \cdot k-M x y}{\cos \alpha \cdot \operatorname{sen} \alpha+k \cdot \operatorname{sen}^{2} \alpha}=\frac{1}{\operatorname{sen}^{2} \alpha} \cdot\left(\frac{M y \cdot k-M x y}{\cot \alpha+k}\right) \\
K_{\text {crítico }}=-\frac{M^{*} \alpha \cdot \cos \alpha \cdot \operatorname{sen} \alpha+M x y}{M^{*} \alpha \cdot\left(1-\cos ^{2} \alpha\right)-M y}=-\frac{M^{*} \alpha \cdot \cos \alpha \cdot \operatorname{sen} \alpha+M x y}{M^{*} \alpha \cdot \operatorname{sen}^{2} \alpha-M y}
\end{array}
$$

Com a transformação:

$$
\frac{\mathrm{k}}{\cot \alpha+\mathrm{k}}=\frac{\mathrm{k}+\cot \alpha-\cot \alpha}{\cot \alpha+\mathrm{k}}=1-\frac{\cot \alpha}{\cot \alpha+\mathrm{k}}
$$

pode-se rescrever a equação (2.18) como:

$$
M^{*} \alpha=\frac{1}{\operatorname{sen}^{2} \alpha} \cdot\left(M y-\frac{M x y+M y \cdot \cot \alpha}{\cot \alpha+k}\right)
$$

Substituindo a eq. (2.20) na eq. (2.16) e igualando a zero, obtém-se: 
$M^{*} x=M x+2 \cdot M x y \cdot \cot \alpha+M y \cdot \cot ^{2} \alpha-(\cot \alpha+k) \cdot(M x y+M y \cdot \cot \alpha)$

A segunda derivada da função é:

$$
\begin{aligned}
& \frac{d^{2} f(k)}{{d k^{2}}^{2}}=2 \cdot M^{*} \alpha \cdot \operatorname{sen}^{2} \alpha-2 \cdot M y>0 \\
\therefore \quad & M^{*} \alpha>\frac{M y}{\operatorname{sen}^{2} \alpha} \quad \ldots(2.22)
\end{aligned}
$$

Analisando-se as eqs. (2.20) e (2.22) chega-se à conclusão que $\frac{M x y+M y \cdot \cot \alpha}{\cot \alpha+k}$ deve ser negativo, portanto, pode-se fazer $K=|\cot \alpha+k| e$ substituir Mxy $+M y \cdot \cot \alpha$ por $(-|M x y+M y \cdot \cot \alpha|)$.

Desta forma:

$$
\begin{aligned}
& M^{*} \alpha=\frac{1}{\operatorname{sen}^{2} \alpha} \cdot\left(M y+\frac{|M x y+M y \cdot \cot \alpha|}{K}\right) \\
& M^{*} x=M x+2 \cdot M x y \cdot \cot \alpha+M y \cdot \cot ^{2} \alpha+K \cdot|M x y+M y \cdot \cot \alpha|
\end{aligned}
$$

Minimizando-se a soma de $M^{*} x$ e $M^{*} \alpha$ em função de $K$, tem-se:

$$
\begin{aligned}
& \frac{d\left(M^{*} x+M^{*} \alpha\right)}{d K}=-|M x y+M y \cdot \cot \alpha| \cdot \frac{1+K^{2} \cdot \operatorname{sen}^{2} \alpha}{K^{2} \cdot \operatorname{sen}^{2} \alpha}=0 \\
& \therefore \quad K=\frac{1}{|\operatorname{sen} \alpha|}
\end{aligned}
$$

Substituindo a eq. (2.25) em (2.23) e (2.24) pode-se escrever as equações para determinação de momentos equivalentes em duas direções oblíquas para o caso de momentos positivos:

$$
M^{\star} \alpha=\frac{M y}{\operatorname{sen}^{2} \alpha}+\left|\frac{M x y+M y \cdot \cot \alpha}{\operatorname{sen} \alpha}\right|
$$




$$
M^{*} x=M x+2 \cdot M x y \cdot \cot \alpha+M y \cdot \cot ^{2} \alpha+\left|\frac{M x y+M y \cdot \cot \alpha}{\operatorname{sen} \alpha}\right|
$$

Estas equações se reduzem às equações dadas anteriormente para $M^{*} x$ e $M^{*} y$ fazendo-se $\alpha=90^{\circ}$.

As equações para o caso de momentos estritamente negativos e momentos positivo e negativo em conjunto podem ser obtidas de maneira análoga ao caso de $\mathrm{M}^{*} \mathrm{x}$ e $\mathrm{M}^{*} \mathrm{y}$.

Resumidamente tem-se:

i) momentos equivalentes positivos:

$$
\begin{aligned}
& M^{*} x=M x+2 M x y \cdot \cot \alpha+M y \cdot \cot ^{2} \alpha+\left|\frac{M x y+M y \cdot \cot \alpha}{\operatorname{sen} \alpha}\right| \\
& M^{*} \alpha=\frac{M y}{\operatorname{sen}^{2} \alpha}+\left|\frac{M x y+M y \cdot \cot \alpha}{\operatorname{sen} \alpha}\right|
\end{aligned}
$$

se $M^{*} x$ resultar negativo; adotar $M^{*} x=0$ e recalcular $M^{*} \alpha$ com a expressão:

$$
M^{*} \alpha=\frac{1}{\operatorname{sen}^{2} \alpha}\left(M y+\mid \frac{(M x y+M y \cdot \cot \alpha)^{2}}{\left(M x+2 M x y \cdot \cot \alpha+M y \cdot \cot ^{2} \alpha\right)}\right)
$$

caso $\mathrm{M}^{*} \alpha$ resulte negativo, adotar $\mathrm{M}^{*} \alpha=0$ e recalcular $\mathrm{M}^{*} \mathrm{x}$ :

$$
M^{*} x=M x+2 M x y \cdot \cot \alpha+M y \cdot \cot ^{2} \alpha+\left|\frac{(M x y+M y \cdot \cot \alpha)^{2}}{M y}\right|
$$

caso ambos $M^{*} x$ e $M^{*} \alpha$ resultem negativos não há necessidade de armadura positiva; 
ii) momentos equivalentes negativos:

$$
\begin{aligned}
& M^{*} x=M x+2 M x y \cdot \cot \alpha+M y \cdot \cot ^{2} \alpha-\left|\frac{M x y+M y \cdot \cot \alpha}{\operatorname{sen} \alpha}\right| \\
& M^{*} \alpha=\frac{M y}{\operatorname{sen}^{2} \alpha}-\left|\frac{M x y+M y \cdot \cot \alpha}{\operatorname{sen} \alpha}\right|
\end{aligned}
$$

se $\mathrm{M}^{*} \mathrm{x}$ resultar positivo; adotar $\mathrm{M}^{*} \mathrm{x}=0$ e recalcular $\mathrm{M}^{*} \alpha$ com a expressão:

$$
\left.M^{*} \alpha=\frac{1}{\operatorname{sen}^{2} \alpha}\left(M y-\mid \frac{(M x y+M y \cdot \cot \alpha)^{2}}{\left(M x+2 M x y \cdot \cot \alpha+M y \cdot \cot ^{2} \alpha\right)}\right)\right)
$$

caso $\mathrm{M}^{*} \alpha$ resulte positivo, adotar $\mathrm{M}^{*} \alpha=0$ e recalcular $\mathrm{M}^{*} \mathrm{x}$ :

$$
M{ }^{*} x=M x+2 M x y \cdot \cot \alpha+M y \cdot \cot ^{2} \alpha-\left|\frac{(M x y+M y \cdot \cot \alpha)^{2}}{M y}\right|
$$

caso ambos $M^{*} x$ e $M^{*} \alpha$ resultem positivos não há necessidade de armadura negativa.

Vale observar que as equações para cálculo de $M^{*} x$ quando $M^{*} \alpha$ é feito igual a zero, podem ser substituídas pelas equações para o cálculo de $M^{*} x$ para armaduras ortogonais, quando $M^{*} y$ é nulo, uma vez que, em ambos os casos, existe a necessidade apenas de armadura segundo a direção $X$. 


\section{RESISTÊNCIA DO CONCRETO AO MOMENTO VOLVENTE}

\subsection{Introdução}

O cisalhamento desenvolvido em uma peça de concreto armado sujeita a um momento torçor é, em parte, resistido pelo próprio concreto. Para determinar qual o máximo momento volvente resistido pelo concreto é necessário determinar-se a máxima tensão cisalhante de torção que pode ser resistida pelo concreto.

Existem, na bibliografia especializada, uma série de estudos que procuram determinar o valor dessa tensão. Esses estudos revelam que o valor da máxima tensão cisalhante resistida pelo concreto em uma peça sujeita à torção pura é significantemente maior do que em peças sujeitas à torção combinada com flexão, força cortante ou forças axiais.

Nos itens seguintes serão discutidos os procedimentos para se determinarem as tensões cisalhantes aplicadas em uma peça sujeita a esforços de torção, flexão e força cortante e as resistências do concreto a essas tensões, levando-se em conta as interações existentes entre cada tipo de esforço.

A maior parte do trabalhos feitos sobre este assunto, se referem a vigas. Deste forma, serão discutidas inicialmente vigas de concreto armado 
e em seguida as analogias que podem ser feitas para uma laje de concreto armado.

\subsection{Tensões Cisalhantes Devidas à Força Cortante em Vigas}

Uma seção sujeita a força cortante possui tensões cisalhantes, distribuídas ao longo de sua área. A integração destas tensões na seção resulta na força cortante.

As tensões cisalhantes desenvolvidas ao longo da altura da peça podem ser calculadas pela seguinte expressão clássica da resistência dos materiais [encontrada em extensa bibliografia, como por exemplo SCHIEL (1984)], válida para material homogêneo:

$\tau=\frac{V \cdot M s}{b \cdot I} ; \quad$ onde $V$ é a força cortante;

Ms = é o momento estático a uma altura y;

b é a largura da seção na altura y e

l é o momento de inércia de flexão da seção.

Para uma seção retangular tem-se a seguinte distribuição de tensões:

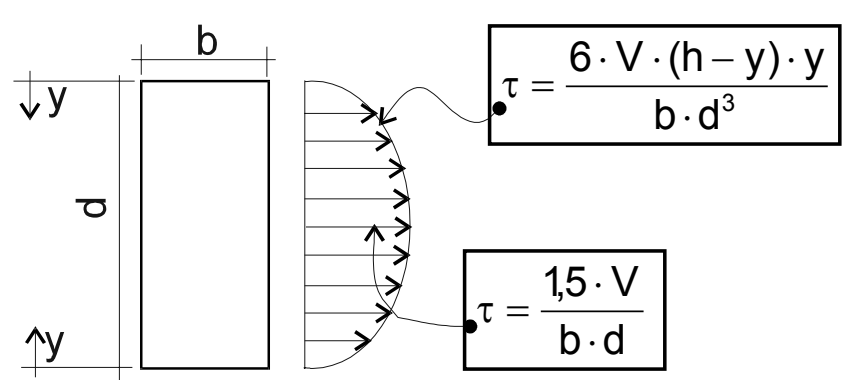

FIGURA 3.1 - Tensões cisalhantes devidas à força cortante

Em muitas normas de concreto, incluindo o $\mathrm{ACl}$ e a norma brasileira de concreto (NB1), é adotado um valor convencional da tensão cisalhante $\left(\tau_{w}\right)$ igual a $\frac{V}{b_{w} \cdot d}$, que corresponde ao valor médio desta tensão. 
Esse valor será usado no presente trabalho, pois a máxima tensão cisalhante resistida pelo concreto, de acordo com o $\mathrm{ACl}$ e com a NB1, discutida nos itens seguintes, utilizam-no como referência.

A norma americana de concreto (ACl 318-89, revised 1992) permite considerar a resistência do concreto às tensões cisalhantes devidas à força cortante igual $\mathrm{a}^{2}$ :

$$
\tau_{c}=\Phi \cdot 2,0 \cdot \sqrt{f c k}(\mathrm{psi}) \text { ou } \tau_{\mathrm{c}}=\Phi \cdot 0,166 \cdot \sqrt{\mathrm{fck}}(\mathrm{Mpa}) ; \operatorname{com} \Phi=0,85
$$

Este valor previne contra a ruptura, levando em conta a possibilidade de combinação com momentos fletores de diferentes intensidades. Um estudo detalhado sobre o assunto pode ser encontrado em ACI-ASCE Committee 426 (1973) e, mais resumidamente, em PARK \& PAULAY (1975).

O anexo da NB116/89 considera o seguinte valor para resistência do concreto às tensões cisalhantes devidas à força cortante em peças sujeitas a flexão simples:

$$
\tau_{c}=0,15 \cdot \sqrt{f c k}(\mathrm{Mpa})
$$

Considerações sobre o tratamento de elementos fletidos sujeitos a força cortante, de acordo com as normas brasileiras, podem ser encontradas em GIONGO \& TOTTI JR.(1994).

Comparando-se os dois valores, percebe-se que o limite do $\mathrm{ACl}$ é $6 \%$ menor que o da NB1, ressaltando que, na comparação entre as normas, é importante levar em conta, também, as diferenças existentes entre os coeficientes de segurança. $\mathrm{O} \mathrm{ACl}$ adota coeficientes de majoração iguais a 1,4 para cargas permanentes ("dead loads") e 1,7 para cargas acidentais

\footnotetext{
${ }^{2}$ As notações utilizadas no $\mathrm{ACl}$ estão adaptadas para as equivalentes da NB1. Desta forma, a notação para a resistência específica do concreto, f'c no $\mathrm{ACl}$, será adotada fck e assim por diante.
} 
("live loads"). A NB1 adota coeficiente de majoração igual a 1,4 para cargas permanentes $(\mathrm{g})$ e acidentais $(\mathrm{q})$.

Para um caso idealizado com g igual a $80 \%$ da carga total, tem-se:

- NB1: carga majorada $=1,4 \times(g+q)$;

- AC1: carga majorada $=1,4 \times 0,80 \times g+1,7 \times 0,20 \times q=1,46 \times(g+q)$.

Na recomendação para cálculo do momento volvente (descrita no final deste capítulo) utilizou-se idéias do ACl e da NB1 para cálculo das tensões de referência, porém, os limites máximos das tensões de cisalhamento foram adotados de acordo com as prescrições da NB1, devendo-se, portanto, utilizar-se os coeficientes de segurança da norma brasileira.

Embora o concreto possua resistência ao cisalhamento, a maioria dos autores recomenda uma armadura mínima quando $\tau_{\mathrm{w}}$ é menor que $\tau_{\mathrm{c}}$, exceção feita em NAWY (1990), que recomenda vigas sem estribos quando $\tau_{\mathrm{w}}$ é menor que $50 \%$ de $\tau_{\mathrm{c}}$.

\subsection{Tensões Cisalhantes Devidas à Torção em Vigas}

Uma seção sujeita à torção possui tensões cisalhantes distribuídas em contornos de tensão constante conforme a n, sendo maiores as tensões próximas ao perímetro externo. 


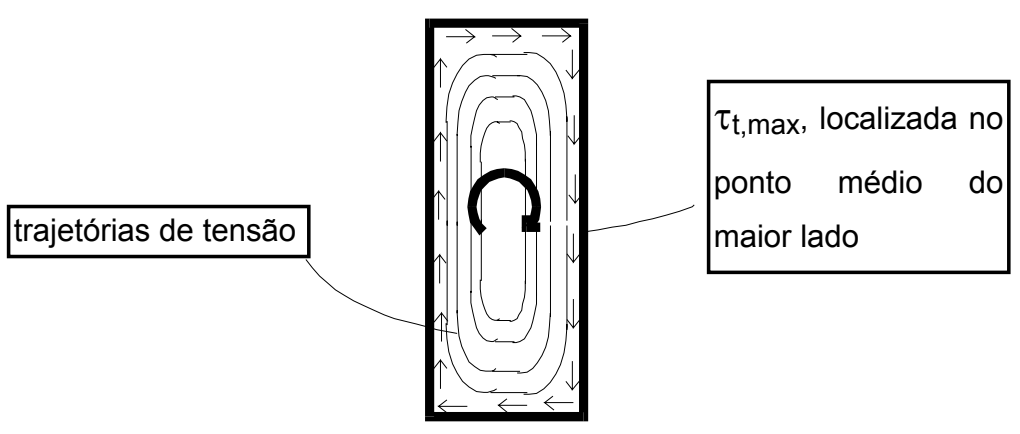

FIGURA 3.2 - Tensões cisalhantes de torção

O valor de $\tau_{t, \max }$ é dado pela expressão:

$$
\tau_{\mathrm{t}, \max }=\frac{T}{w \cdot b^{2} \cdot h}
$$

onde $\mathrm{b}$ é o menor lado do retângulo e $\mathrm{h}$ é o maior.

T é o momento torçor.

O valor do parâmetro adimensional $\mathbf{w}$ varia de 0,208 a 0,333 na teoria elástica e de 0,333 a 0,5 na teoria plástica. Em ACI COMMITTEE 438 (1969) e em NAWY (1990) são feitas referências ao trabalho $\mathrm{HSU}^{3}$, confirmado por outros, estabelecendo que w pode ser tomado como 0,333 . O ACl adota este valor. Para seções compostas de retângulos pode-se fazer a somatória de $b^{2} \cdot h$.

A NB1 utiliza, para determinação da máxima tensão cisalhante devida à torção, a fórmula de Bredt, válida para peças com tensões compatíveis com o estádio II (seção fissurada). Em LEONHARDT \& MÖNNIG (1977) e em GIONGO (1994ª) podem ser encontradas maiores informações de como tratar vigas sujeitas à torção segundo a norma brasileira.

Estudos feitos pelo ACl, relatados em ACl COMMITTEE 438 (1969), OSBRUN et al. (1969) e HSU \& HWANG (1977), determinam o valor máximo

\footnotetext{
${ }^{3}$ HSU, T.T.C. (1968). Torsion of structural concrete - plain concrete rectangular sections. Torsion of structural concrete. SP-18, American Concrete Institute.
} 
da tensão cisalhante devida à torção igual a $6 \cdot \sqrt{f c k}$ (psi) ou $0,5 \cdot \sqrt{f c k}$ (Mpa) para peças sujeitas a torção pura.

Para peças sujeitas a flexão e torção existe uma redução grande na resistência do concreto a torção. Em VICTOR \& FERGUSON (1968), HSU (1968), LAMPERT \& COLLINS (1972) e KIRK \& LASH (1971) podem ser encontradas expressões que relacionam torção e flexão. Por facilidade de cálculo o $\mathrm{ACl}$ prefere levar em conta esta interação de modo indireto, reduzindo a resistência à torção do concreto para peças sujeitas a torção e flexão para $40 \%$ do valor verificado para peças sujeitas a torção pura. Segundo o $\mathrm{ACl}$ esta redução é segura para todos os possíveis casos de combinação de torção e flexão.

Desta forma, o valor da máxima tensão cisalhante associada à torção e resistida pelo concreto $\left(\tau_{\mathrm{tc}}\right)$, será igual a $0,4 \cdot\left(0,5 \cdot \sqrt{f_{c k}}\right)=0,2 \cdot \sqrt{f_{c k}}(\mathrm{Mpa})$.

A NB1 (1982) não prevê resistência do concreto à torção.

\subsection{Interação Entre Força Cortante e Momento Torçor}

Na bibliografia pesquisada são encontradas várias referências a ensaios feitos procurando-se estudar a interação entre força cortante e torção. Dentre esses trabalhos pode-se citar HSU (1968) para vigas sem estribos e OSBURN et al. (1969) e LIAO \& FERGUSON (1969) para vigas com estribos.

A partir destes ensaios são sugeridas curvas de interação entre entes dois tipos de solicitação. A I, extraída de HSU (1968), mostra a superfície de interação entre torção, força cortante e flexão. 


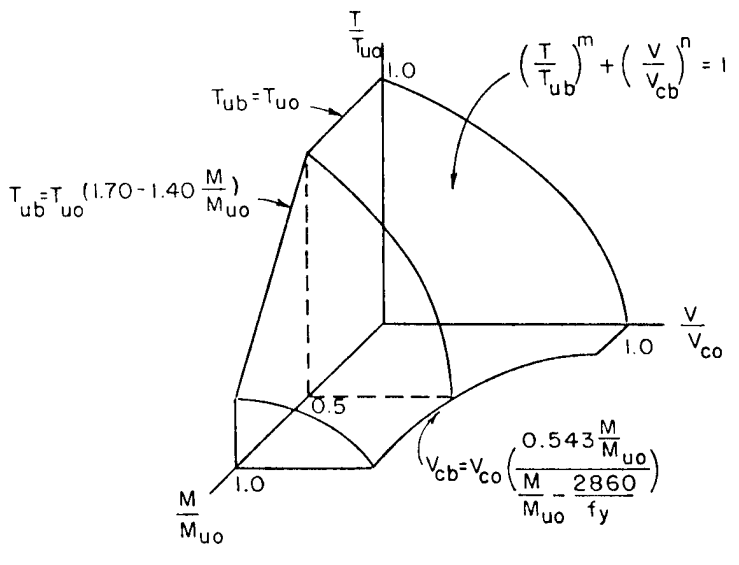

a) FORMA GERAL

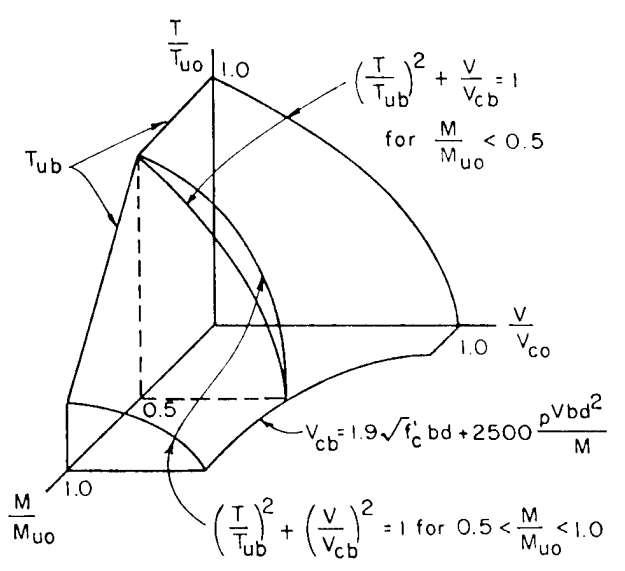

b) FORMA SIMPLIFICADA PARA PROJETO

FIGURA 3.3 - Superfície de interação entre torção, flexão e força cortante [ HSU (1968) ]

De uma maneira geral pode-se representar a interação entre força cortante e momento torçor pela seguinte equação:

$$
\left(\frac{T}{T u}\right)^{m}+\left(\frac{V}{V u}\right)^{n}=1
$$

Os fatores $\mathbf{m}$ e $\mathbf{n}$ dependem do valor do momento fletor. Conforme visto na I, HSU (1968) adota $m=2$ e $n=1$ para valores de momento fletor baixos, e $\mathrm{m}=2$ e $\mathrm{n}=2$ para momentos fletores médio a altos.

O ACl (1992) e o EUROCODE (1992) adotam $m=n=2$. A NB1 adota $m=n=1$, sendo a mais conservadora das normas neste assunto. Ensaios experimentais feitos em vigas L, relatados em LIAO \& FERGUSON (1969), determinam um erro máximo de $10 \%$ para a curva de interação com m=n=2.

Para verificar-se a necessidade de armadura de combate à torção em vigas de concreto armado, basta substituir os esforços últimos, Tu e Vu, pelos esforços resistidos pelo concreto, Tc e Vc (obtidos a partir de $\tau_{\mathrm{tc}} \mathrm{e} \tau_{\mathrm{c}}$ ).

O ACl possui uma recomendação geral para a necessidade de armadura de combate à torção em vigas. Momentos torçores menores que $T_{c}=0,85 \cdot\left(\frac{\sqrt{f c k}}{20} \cdot \sum\left(b^{2} \cdot h\right)\right)$, fck em Mpa, b e h em mm (ACl 318M-83), não necessitam de armadura. Este valor corresponde a $25 \%$ do momento torçor 
resistido pelo concreto em peças sujeitas a torção pura. Segundo o $\mathrm{ACl}$, a resistência do concreto às tensões cisalhantes devidas à força cortante não sofre grande influência de momentos torçores dessa magnitude.

\subsection{Tensões Cisalhantes Devidas à Força Cortante em Lajes}

O procedimento para cálculo da tensão cisalhante devida à força cortante média é idêntico ao de vigas.

O $\mathrm{ACl}$ determina que a máxima tensão cisalhante resistida pelo concreto em lajes é um valor entre $\Phi \cdot 2 \cdot \sqrt{f_{c k}} \leq \tau_{c} \leq \Phi \cdot 4 \cdot \sqrt{f c k}$ (psi) ou $\Phi \cdot 0,17 \cdot \sqrt{f_{c k}} \leq \tau_{c} \leq \Phi \cdot 0,33 \cdot \sqrt{f_{c k}}$, sendo este valor discutido com maiores detalhes em ASCE-ACI COMMITTE 426 (1974) e em PARK \& GAMBLE (1980).

A NB1 permite tensões cisalhantes em lajes até o valor de $\tau_{\text {wu1 }}$. Podese calcular $\tau_{\text {wu1 }}$ segundo o anexo da NBR 7197 / 1989:

$$
\tau_{\text {wu1 }}=\psi_{4} \cdot \sqrt{f c k} \leq 1,0(\mathrm{Mpa})
$$

$\psi_{4}$ tem um dos seguintes valores:

I) $\psi_{4}=0,12 \cdot \frac{\alpha \cdot k}{1-3 \cdot \frac{d}{L}}$ para cargas distribuídas, podendo adotar-se $\psi_{4}=0,14 \cdot \alpha \cdot k$ quando $d \leq L / 20$, sendo $L$ o menor vão teórico das lajes apoiadas ou o dobro do comprimento teórico das lajes em balanço;

II) $\psi_{4}=0,08 \cdot \alpha \cdot \mathrm{k}$ para cargas lineares paralelas ao apoio, permitindo-se a redução, na proporção $a / 2 d$, da parcela da força cortante decorrente de cargas cujo afastamento a do eixo do apoio seja inferior ao dobro da altura útil d; 
III) quando há cargas distribuídas e cargas lineares paralelas ao apoio $\psi_{4}$ é obtido por interpolação proporcionalmente às parcelas de força cortante decorrentes desses dois tipos de carregamento.

Os coeficientes $\alpha$ e $\mathbf{k}$ são dados pelas expressões:

$k=1,6-d \geq 1$, com $d$ em metros

$\alpha=1+50 \cdot \rho_{1} \leq 1,5$

limitando-se o produto $\alpha \cdot k$ ao valor 1,75 , sendo $\rho_{1}$ a taxa geométrica de armadura longitudinal de tração afastada de $2 \mathrm{~h}$ da face interna do apoio, considerando-se apenas as barras de aço prolongadas até o apoio e aí corretamente ancoradas. A taxa geométrica $\left(\rho_{1}\right)$ deve ser menor que $2 \%$.

Nesse procedimento são levadas em conta as influências da armadura longitudinal, da altura útil da peça e da resistência do concreto para diferentes tipos de carga. Explicação detalhada sobre a influência de cada fator no cálculo de $\tau_{\text {wu1 }}$ pode ser encontrada em FUSCO (1982).

Com a finalidade de facilitar o uso destas expressões fez-se as seguintes simplificações:

a) $\rho_{1}$ adotado 0,0012 (utilizando uma taxa de armadura mínima de $0,12 \%)$, desta forma $\alpha$ terá valor constante de 1,06 ;

b) para cargas distribuídas $\psi_{4}$ será adota igual a $0,14 \alpha \mathrm{k}$, por se entender que na maioria dos casos d será menor que L/20 e por esta simplificação ser a favor da segurança;

c) adotado o coeficiente $C$ como sendo a relação entre a parcela de força cortante decorrente de cargas distribuídas e o valor total da força cortante na laje. Para laje com cargas distribuídas somente, $\mathrm{C}=1$.

Desta forma tem-se:

$$
\tau_{c}=\tau_{\mathrm{wu} 1}=(0,06 \cdot C+0,08) \cdot 1,06 \cdot(1,6-d) \cdot \sqrt{f c k} \leq 1,0(\mathrm{Mpa}) \quad \ldots(3.3)
$$




\subsection{Tensões Cisalhantes Devidas à Torção em Lajes}

As tensões cisalhantes nas lajes se desenvolvem segundo contornos semelhantes aos descritos em vigas. Porém, como as lajes possuem, em geral, b>>h, as tensões se distribuem horizontalmente na maior parte da laje, existindo alguma pertubação nos cantos. A r ilustra esta situação.

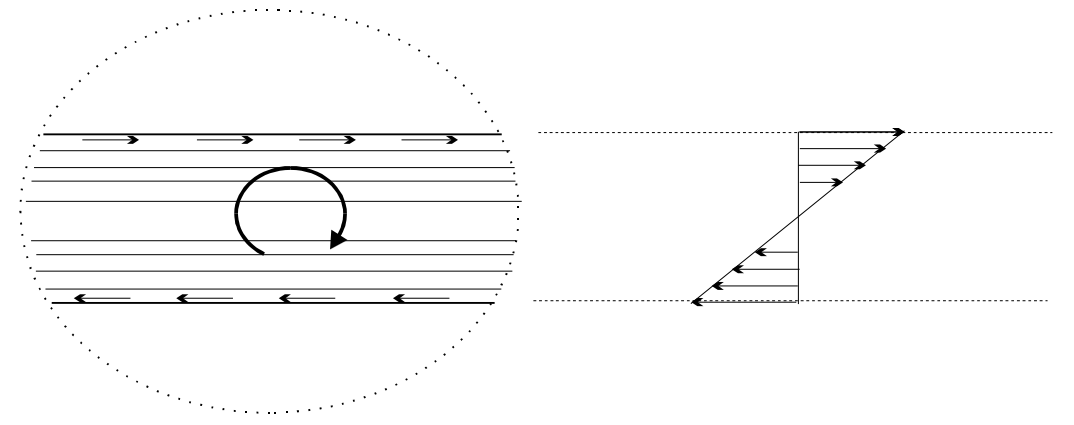

FIGURA 3.4 - Tensões cisalhantes de torção em lajes

No presente trabalho será adotada a idéia do método do $\mathrm{ACl}$ para cálculo de $\tau_{t, \max }$, por entender-se que este é mais adequado à verificação a ser feita.

O método da NB1 é baseado na hipótese de que a parte interna da seção de concreto armado estará fissurada e os esforços de torção serão resistidos pela armadura somente, não levando em conta a resistência do concreto à torção. Desta forma a seção é tratada como uma seção vazada. Como se está verificando a resistência do concreto à torção, deve-se tratar a seção cheia.

Além disto, as lajes são, na grande maioria do casos, elementos de seção retangular com $h / b \rightarrow \infty$ e portanto com o valor de w da eq. (3.1) igual a 0,333 [vide TIMOSHENKO \& GOODIER (1980)].

Segundo PARK \& GAMBLE (1980) a máxima tensão cisalhante de torção resistida pelo concreto em lajes pode ser admitida como duas vezes a mesma tensão para vigas. 
Desta forma tem-se $\tau_{t c}=\Phi \cdot 0,4 \cdot \sqrt{f c k}=0,34 \cdot \sqrt{f c k}(\mathrm{Mpa})$.

Ensaios relatados em KANOH \& YOSHIZAKI (1979) determinam a resistência a torção em lajes como sendo cinco vezes maior que o valor adotado.

O valor de $\tau_{\text {tc }}$ será comparado com $\tau_{\text {wu } 1}$

\subsection{Recomendação Para o Cálculo do Máximo Momento Volvente}

Em PARK \& GAMBLE (1979) é apresentada uma expressão para o cálculo do máximo momento volvente resistido pelo concreto em lajes, de acordo com o ACl. Adaptada para as unidades do sistema internacional de medidas (S.I.), esta expressão é:

$$
\mathrm{Mxy}_{\mathrm{c}}=\phi \cdot \frac{\mathrm{h}^{2}}{3} \cdot \frac{0,4 \cdot \sqrt{\mathrm{fck}}}{\sqrt{1+\left(1,2 \cdot \tau_{\mathrm{w}} / \tau_{\mathrm{t}}\right)}}, \quad \mathrm{h} \text { em metros e fck em MPa }
$$

Nesta recomendação estão assumidas resistências do concreto a tensões cisalhantes iguais a $0,33 \cdot \sqrt{f c k}$ para força cortante e $0,4 \cdot \sqrt{f c k}$ para momentos torçores e interação circular entre força cortante e torção, equivalente a adotar-se $m=n=2$ na eq. (3.2). Exprimindo em função das tensões, obtém-se:

$$
\left(\frac{\tau_{\mathrm{wd}}}{\Phi \cdot \tau_{\mathrm{c}}}\right)^{2}+\left(\frac{\tau_{\mathrm{td}}}{\Phi \cdot \tau_{\mathrm{tc}}}\right)^{2} \leq 1 \Rightarrow\left(\frac{\tau_{\mathrm{wd}}}{0,85 \cdot 0,33 \cdot \sqrt{\mathrm{fck}}}\right)^{2}+\left(\frac{\tau_{\mathrm{td}}}{0,85 \cdot 0,4 \cdot \sqrt{\mathrm{fck}}}\right)^{2} \leq 1
$$

De acordo com a NB1, $\tau_{\text {wu1 }}$ é a máxima tensão cisalhante resistida pelo concreto. Como não existe nenhuma recomendação para resistência do 
concreto a torção, $\tau_{\text {wu1 }}$ será adotada também como tensão cisalhante resistida pelo concreto neste caso.

Desta forma, de maneira semelhante, chega-se a:

$$
\left(\frac{\tau_{w d}}{\tau_{w u 1}}\right)^{2}+\left(\frac{\tau_{t d}}{\tau_{w u 1}}\right)^{2} \leq 1
$$

A consideração acima equivale a, supondo-se verticais as tensões devidas à força cortante e horizontais as tensões de torção, calcular-se uma tensão cisalhante resultante e compara-la com $\tau_{\text {wu1 }}$.

Essa tensão resultante será igual à soma vetorial entre a tensão cisalhante devida à força cortante convencional com a máxima tensão cisalhante devida momento torçor, sendo importante lembrar que essa simplificação só é possível porque foram adotados coeficientes $m=n=2$ na eq. (3.2) e resistência do concreto às tensões cisalhante devidas à torção também igual a $\tau_{w u 1}$. A n ilustra esta situação.

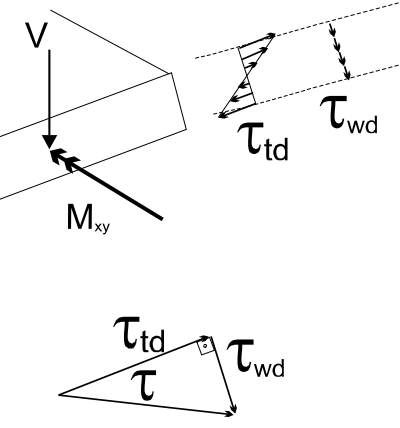

$$
\tau=\sqrt{\tau_{w d}^{2}+\tau_{t d}^{2}} \leq \tau_{w u 1}
$$

FIGURA 3.5 - Combinação de tensões cisalhantes em lajes

Escrevendo-se a eq. (3.4) em função dos esforços, tem-se, para lajes maciças: 


$$
\begin{aligned}
& \left(\frac{\frac{V_{d}}{d}}{\tau_{w u 1}}\right)^{2}+\left(\frac{\frac{3 \cdot M x y_{d}}{h^{2}}}{\tau_{w u 1}}\right)^{2} \leq 1 \\
& \Rightarrow M x y_{d} \leq M x y_{c}=\sqrt{1-\left(\frac{V_{d}}{d \cdot \tau_{w u 1}}\right)^{2}} \cdot \frac{h^{2} \cdot \tau_{w u 1}}{3}
\end{aligned}
$$

Para outras tipologias de lajes, como por exemplo lajes nervuradas, pode-se calcular as tensões cisalhantes devidas à força cortante e ao momento volvente e fazer a verificação na forma de tensões, utilizando a eq. (3.4), ressaltando-se a necessidade de comprovação experimental para o valor de $\tau_{\mathrm{wu} 1}$, no caso de lajes nervuradas.

O valor do máximo momento volvente resistido pelo concreto determinado por este critério é menor do que o determinado pelo critério anterior. Para uma laje maciça com $\mathrm{d}=6 \mathrm{~cm}$ e cargas distribuídas tem-se, adotando-se as simplificações descritas anteriormente, $\tau_{\mathrm{wu} 1}=0,2285 \cdot \sqrt{f_{c k}}$, que equivale a $81 \%$ do valor adotado em PARK \& GAMBLE (1980) para força cortante e a $67 \%$ do valor adotado para momento torçor.

Utilizando os conceitos descritos neste capítulo, pode-se, de maneira criteriosa, levar em conta a resistência do concreto ao momento volvente no dimensionamento das armaduras de lajes de concreto armado.

Valores de momentos volventes menores que $\mathrm{Mxy}_{\mathrm{c}}$, calculado com a eq. (3.5) para o caso de lajes maciças, podem ser desprezados no detalhamento. Para valores de $\mathrm{Mxy}$ maiores que $\mathrm{Mxy}_{\mathrm{c}}$, pode-se diminuir o valor do momento volvente resistido pelo concreto do valor do momento volvente de cálculo. 


\section{SOFTWARE BÁSICO E DE ANÁLISE}

\subsection{Introdução}

Para que se pudesse estudar, de um ponto de vista prático, as implicações que a utilização dos conceitos descritos nos capítulos 2 e 3 trazem ao cálculo de lajes, foram criados modelos matemáticos de lajes e pavimentos em elementos finitos. Estes modelos e a análise dos resultados são descritos no capítulo seguinte.

Para facilitar o processo de criação de modelos de pavimentos em elementos finitos, existem algoritmos de geração automática de malhas. $O$ programa GM utiliza estes algoritmos para gerar uma malha a partir de dados do contorno do pavimento e de pontos e barras principais (pilares e vigas), determinados num arquivo de dados padrão ASCII. Uma descrição mais detalhada do procedimento empregado pode ser encontrado em BAPTISTA (1994).

A fim de facilitar a entrada de dados para o programa GM desenvolveu-se o programa CADGM, com o qual, a partir de um desenho de forma produzida com o AUTOCAD, o projetista pode marcar os pontos necessários à geração e o programa automaticamente cria um arquivo com as coordenadas nodais, extraídos das informações gráficas.

Gerada a malha, existe a necessidade de se intervir no modelo a fim de acertar espessuras e carregamentos dos elementos e restrições nodais. 
Para tanto foi desenvolvido o programa LAJEEF que permite ao projetista conferir e modificar malhas de elementos finitos.

O modelo criado é processado utilizando-se o programa de elementos finitos LS5H, desenvolvido nos trabalhos CORREAA (1991) e RAMALHO (1990).

Processado o modelo, tem-se como resultado os momentos Mx, My e Mxy segundo o eixo de coordenadas adotado. O programa MLAJE analisa estes resultados e calcula momentos equivalentes segundo as direções $\mathrm{X} \mathrm{e}$ $\mathrm{Y}$, segundo a teoria descrita anteriormente, e as áreas de armadura necessárias para resistir a estes momentos.

A partir da análise feita, pode-se traçar curvas de momento e áreas de armadura, utilizando o programa CPLS, de acordo com LISERRE (1993).

\subsection{O Programa CADGM}

Para modelar o pavimento é necessário informar ao programa gerador de malhas as coordenadas dos pontos que formam o contorno do pavimento e pontos especiais. Para tanto se faz necessário adotar um eixo de coordenadas na forma e, a partir deste, medir as coordenadas $\mathrm{X}$ e $\mathrm{Y}$ de cada ponto.

A partir das cotas da forma pode-se fornecer, para cada ponto, as coordenadas, anotá-las no desenho e depois digitar estes dados no arquivo de entrada do gerador de malhas. Este é um procedimento lento, além de estar sujeito a erros de medição, principalmente quando a forma do pavimento é irregular.

O programa CADGM facilita este procedimento pois permite ao projetista obter estas coordenadas a partir do desenho da forma feita em AUTOCAD, agilizando a entrada de dados e minimizando a incidência de erros.

Para tanto, o projetista deve acessar o desenho da forma do pavimento no programa AUTOCAD. Em seguida deve marcar, em uma 
"layer" de nome GM, os ponto desejados através de textos no desenho. A coordenada do texto indicará a coordenada do ponto e o texto propriamente dito deve ser o número do nó. Deve-se, então, utilizar a função "dxfout" do programa para criar um arquivo DXF que servirá de interface.

O programa CADGM irá analisar o arquivo DXF, procurar os pontos anotados e criar um novo arquivo contendo as informações dos nós. Informações sobre o formato de arquivos .DXF podem ser encontradas em AUTODESK (1989).

No programa existem recursos que permitem a geração das coordenadas em uma unidade de comprimento diferente da existente no desenho original, a imposição de um critério de proximidade para alinhamento de nós, mudança na origem dos eixos e determinação da aproximação decimal desejada.

A seguir, tem-se um exemplo de um arquivo gerado pelo programa CADGM (ה).

$\begin{array}{rrrrrr}1 & 0.00 & 0.63 & 23 & 14.31 & 9.54 \\ 2 & 5.90 & 0.63 & 24 & 14.31 & 7.69 \\ 3 & 5.90 & 0.00 & 25 & 0.00 & 1.07 \\ 4 & 8.24 & 0.00 & 26 & 0.00 & 7.26 \\ 5 & 8.24 & 0.63 & 27 & 3.23 & 7.26 \\ 6 & 14.00 & 0.63 & 28 & 3.23 & 7.69 \\ 7 & 14.00 & 0.00 & 29 & 5.90 & 1.07 \\ 8 & 16.33 & 0.00 & 30 & 5.06 & 3.75 \\ 9 & 16.33 & 0.63 & 31 & 5.96 & 3.75 \\ 10 & 22.22 & 0.63 & 32 & 11.12 & 0.63 \\ 11 & 22.22 & 7.69 & 33 & 11.12 & 1.07 \\ 12 & 19.13 & 7.69 & 34 & 11.12 & 3.81 \\ 13 & 19.13 & 10.46 & 35 & 11.12 & 4.51 \\ 14 & 10.76 & 10.46 & 36 & 14.31 & 8.54 \\ 15 & 10.76 & 7.69 & 37 & 16.33 & 1.07 \\ 16 & 7.97 & 7.69 & 38 & 16.27 & 3.75 \\ 17 & 7.97 & 10.46 & 39 & 17.17 & 3.75 \\ 18 & 5.85 & 10.46 & 40 & 19.13 & 7.26 \\ 19 & 5.85 & 7.69 & 41 & 22.22 & 1.07 \\ 20 & 0.00 & 7.69 & 42 & 22.22 & 7.26 \\ 21 & 12.47 & 7.69 & 43 & 7.97 & 8.74 \\ 22 & 12.47 & 9.54 & & & \end{array}$

FIGURA 4.1 - Arquivo de saída do programa CADGM

A I mostra o desenho da forma do pavimento tipo de Ed. Portal dos Pássaros (projeto de propriedade da TECSOF Engenharia de Estruturas) os nós necessários à geração anotados. 


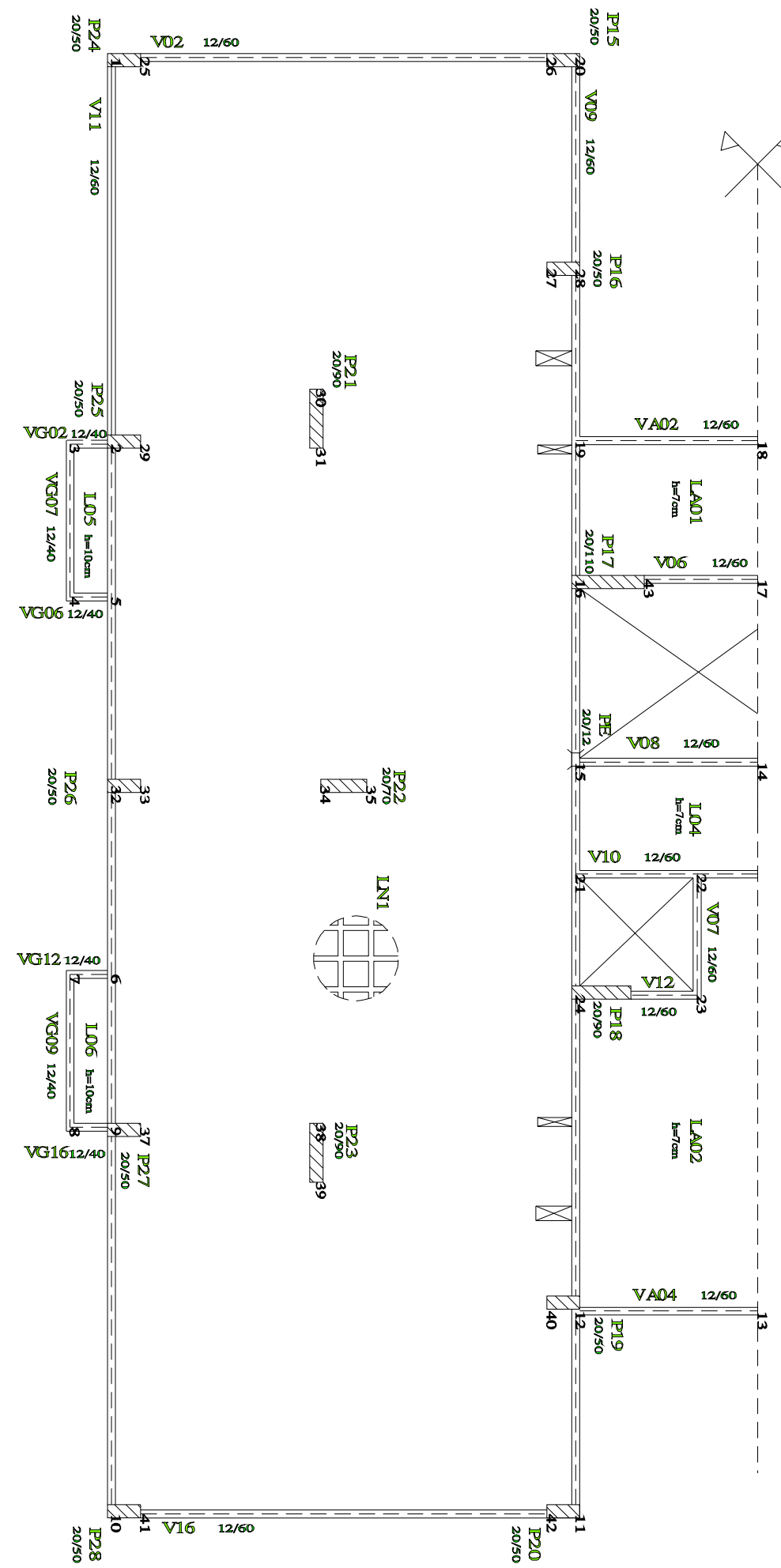

FIGURA 4.2 - Forma do pavimento tipo a ser modelado

\subsection{O Programa LAJEEF}


Com as coordenadas dos pontos obtidas, monta-se o arquivo de entrada de dados do gerador de malhas. A malha é gerada com elementos de espessura e carregamento constante e sem restrições nos nós segundo a translação em $Z$, e rotação em torno de $\mathrm{X} \mathrm{e} \mathrm{Y}$.

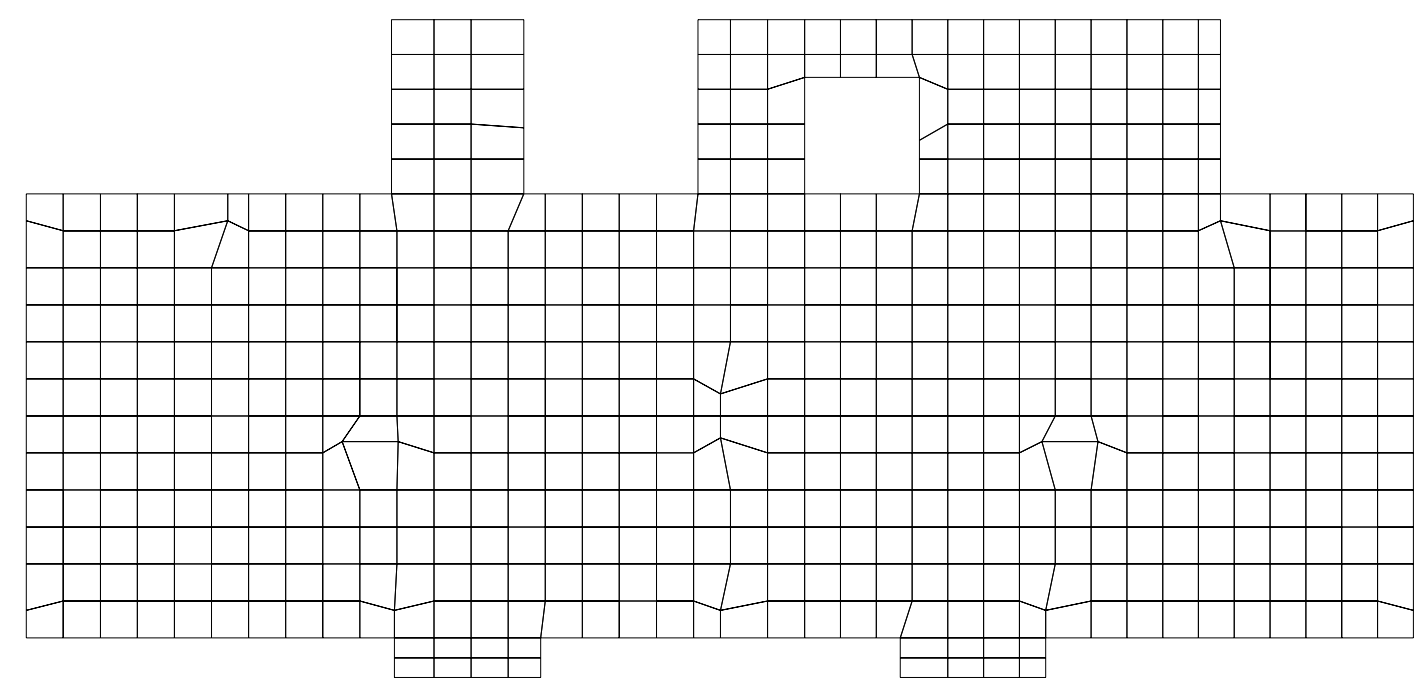

FIGURA 4.3 - Malha gerada pelo programa GM

Há necessidade de se intervir na malha, para determinar regiões de espessuras e carregamentos diferentes e restrições nodais. Além disto, existe a necessidade de conferir a malha gerada e suas alterações.

O programa LAJEEF é utilizado para alterar e conferir as malhas geradas, possuindo os recursos descritos acima e ainda a possibilidade de eliminação de elementos e nós da malha. É um programa de interface gráfica com recursos de "zoom" e utilização de "mouse", o que torna seu uso fácil. Os arquivos de entrada de dados dos modelos são formatados de acordo com ALGOR SUPERDRAW SYSTEM (1987).

Na tela inicial do programa é perguntado o nome do arquivo de dados. Depois do arquivo lido é mostrada uma tela gráfica com os comandos possíveis e o desenho da malha. Os recursos do programa são:

i) visualização dos elementos;

ii) visualização dos números dos elementos;

iii) visualização dos nós; 
iv) visualização dos números dos nós;

v) "zoom" no desenho a partir de coordenadas fornecidas;

vi) "zoom" a partir de janela definida com a utilização do "mouse";

vii) regulagem da dimensão dos caracteres utilizados para desenhar os números dos nós e elementos;

viii) visualização dos carregamentos adotados em cada elemento;

ix) visualização das espessuras de cada elemento;

x) restauração da tela inicial do programa;

xi) conferência das restrições adotadas em cada nó;

xii) alteração de linha de restrições;

xiii) alteração dos carregamentos dos elementos;

xiv) alteração das espessuras dos elementos;

xv) eliminação de elementos e nós da malha.

xvi) gravação das alterações;

A utilização deste programa facilita o trabalho do projetista pois fornece ferramentas que agilizam o processo de modelagem do pavimento e oferece uma maior confiabilidade ao modelo, permitindo que sejam conferidas várias das suas características.

Um projetista que possuísse as ferramentas de geração de malha e não dispusesse de um "software" de alteração e visualização desta malha teria que imprimir os dados do modelo e, com a ajuda de um editor de textos, modificar um a um cada elemento e/ou nó. Em seguida teria que reimprimir os dados para conferir as alterações, sendo este um procedimento demorado e de baixa confiabilidade. 


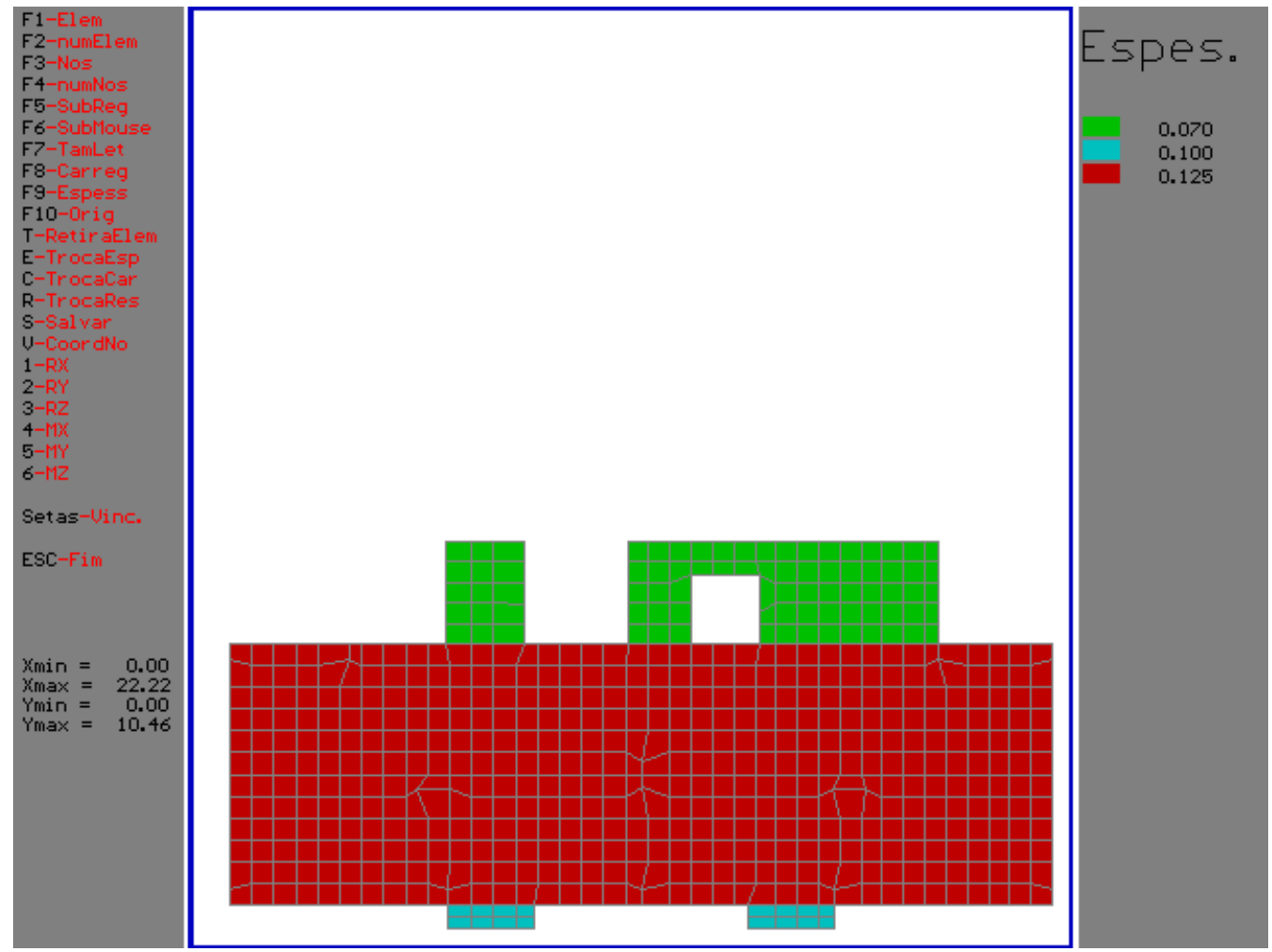

FIGURA 4.4 - Tela do programa LAJEEF mostrando as espessuras dos elementos placa

As ferramentas de eliminação de nós e elementos permitem uma agilidade ainda maior ao cálculo de pavimentos. Em um edifício de andares múltiplos é comum existirem pavimentos semelhantes. A eliminação de nós e elementos permite aproveitar a malha de um pavimento para a modelagem de outro. Permite, também, que alterações na forma do pavimento sejam facilmente impostas ao modelo.

\subsection{O Programa MLAJE}

Depois de processado o pavimento, existe a necessidade de se analisarem os esforços resultantes, e determinarem-se os momentos positivos e negativos equivalentes em cada ponto da laje.

O programa MLAJE calcula os momentos equivalentes e as áreas de armadura necessárias em cada ponto da laje, a partir dos esforços calculados. Para tanto, o usuário deve informar ao programa as unidades 
utilizadas, a resistência do concreto e do aço, a característica do carregamento e as seções de laje utilizadas. As armaduras são assumidas dispostas segundo os eixos $\mathrm{X}$ e $\mathrm{Y}$.

Foi prevista a possibilidade de haverem espessuras de lajes diferentes no pavimento, devendo o usuário determinar contornos diferentes para cada espessura de laje.

$\mathrm{O}$ arquivo de entrada de dados tem o seguinte formato:

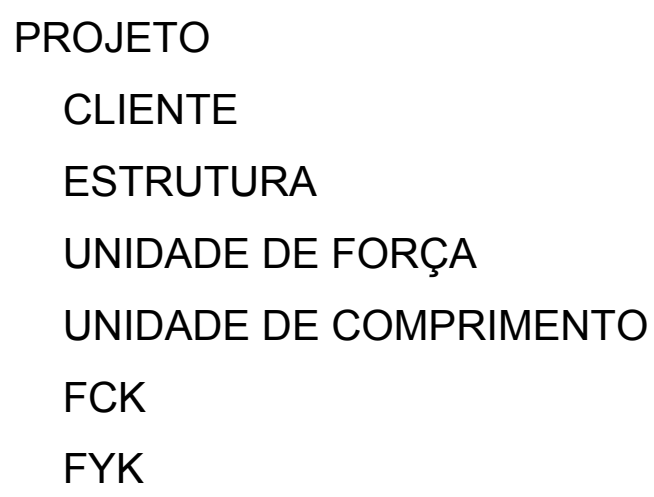
total de cargas na laje (de acordo com item 3.4),

0 = opção para considerar a resistência do concreto ao momento volvente $(O=0$, considerar; $O=1$, não considerar) momento resistido pela armadura mínima positiva momento resistido pela armadura mínima negativa

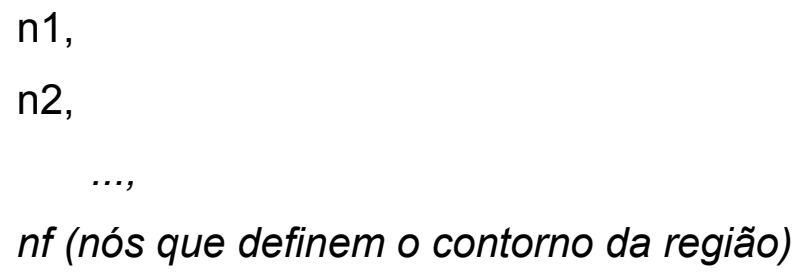


FIM

Inicialmente é determinado o máximo momento volvente resistido pelo concreto de acordo com as eqs. (3.3) e (3.5):

$$
\begin{gathered}
\tau_{\mathrm{wu} 1}=(0,06 \cdot C+0,08) \cdot 1,06 \cdot(1,6-d) \cdot \sqrt{f c k} \leq 1,0 \\
M x y_{c}=\sqrt{1-\left(\frac{V_{d}}{d \cdot \tau_{w u 1}}\right)^{2}} \cdot \frac{h^{2} \cdot \tau_{w u 1}}{3 \cdot 1,4}
\end{gathered}
$$

$\mathrm{O}$ valor das cortante segundo as direções $\mathrm{X}$ e $\mathrm{Y}$ podem ser obtidos a partir das derivadas dos momentos.

Se o valor de Mxy for menor ou igual a $\mathrm{Mxy}_{\mathrm{c}}$, os momentos equivalentes são iguais aos momentos $M x$ e My. Se não for, subtrai-se o valor $\mathrm{Mxy}_{\mathrm{c}}$ de $\mathrm{Mxy}$, e calculam-se os momentos equivalentes positivos $\mathrm{e}$ negativos:

i) momentos equivalentes positivos [eqs. (2.7)]:

$$
\begin{aligned}
& M_{x}^{*}=M_{x}+\left|M_{x y}\right| \\
& M_{y}^{*}=M_{y}+\left|M_{x y}\right|
\end{aligned}
$$

se ambos $\mathrm{M}^{*} \mathrm{x}$ e $\mathrm{M}^{*} \mathrm{y}$ resultarem negativos, não há necessidade de armadura positiva e os momentos equivalentes positivos são feitos iguais a zero. Caso contrário,

se ambos $M^{*} x$ e $M^{*} y$ resultarem em valores menores que $\mathrm{M}_{\text {min }}^{+}$, estes são feitos iguais ao momento mínimo, 
se apenas $\mathrm{M}^{*} \mathrm{x}$ for menor que $\mathrm{M}_{\text {min }}^{+}$; adota-se $\mathrm{M}^{*} \mathrm{x}=\mathrm{M}_{\min }^{+}$, calcula-se $\mathrm{K}$ com a eq. (2.5) e recalcula-se $M^{*} y$ com a segunda das eqs. (2.6):

$$
\begin{aligned}
& K=\left|\frac{M_{x}^{*}-M_{x}}{M_{x y}}\right| \\
& M_{y}^{*}=M_{y}+\frac{1}{K} \cdot\left|M_{x y}\right|
\end{aligned}
$$

caso somente $\mathrm{M}^{*} \mathrm{y}$ seja menor que $\mathrm{M}^{+}{ }_{\min }$, então adota-se $\mathrm{M}^{*} \mathrm{y}=\mathrm{M}^{+}{ }_{\min }$, calcula-se $\mathrm{K}$ com a eq. (2.4) e recalcula-se $M^{*} x$ com a primeira das eqs. (2.6);

$$
\begin{aligned}
& K=\left|\frac{M_{x y}}{M_{y}^{*}-M_{y}}\right| \\
& M_{x}^{*}=M_{x}+K \cdot\left|M_{x y}\right|
\end{aligned}
$$

ii) momentos equivalentes negativos [eqs. (2.8)]:

$$
\begin{aligned}
& M_{x}^{*}=M_{x}-\left|M_{x y}\right| \\
& M_{y}^{*}=M_{y}-\left|M_{x y}\right|
\end{aligned}
$$

se ambos $M^{*} x$ e $M^{*} y$ resultarem positivos, não há necessidade de armadura negativa e os momentos equivalentes negativos são feitos iguais a zero. Caso contrário,

se ambos $M^{*} x$ e $M^{*} y$ resultarem em valores maiores que $\mathrm{M}_{\text {min }}^{-}$(valor negativo), estes são feitos iguais ao momento mínimo.

se apenas $M^{*} x$ for maior que $M_{\text {min }}^{-}$, adota-se $M^{*} x=M_{\text {min }}^{-}$, calcula-se $\mathrm{K}$ e recalcula-se $M^{*} y$ : 


$$
\begin{aligned}
& K=\left|\frac{M_{x}^{*}-M_{x}}{M_{x y}}\right| \\
& M_{y}^{*}=M_{y}-\frac{1}{K} \cdot\left|M_{x y}\right|
\end{aligned}
$$

caso somente $M^{*} y$ seja maior que $M^{+}{ }_{\text {min }}$, então adota-se $M^{*} y=M_{\text {min }}^{+}$, calcula-se $\mathrm{K}$ e recalcula-se $\mathrm{M}^{*} \mathrm{x}$;

$$
\begin{aligned}
& \mathrm{K}=\left|\frac{\mathrm{M}_{\mathrm{xy}}}{\mathrm{M}_{\mathrm{y}}^{*}-\mathrm{M}_{\mathrm{y}}}\right| \\
& \mathrm{M}_{\mathrm{x}}^{*}=\mathrm{M}_{\mathrm{x}}-\mathrm{K} \cdot\left|\mathrm{M}_{\mathrm{xy}}\right|
\end{aligned}
$$

Nesse roteiro de cálculo procurou-se determinar os menores momentos equivalentes (e conseqüentemente menores armaduras) possíveis, de acordo com os critérios discutidos nos capítulos 2 e 3.

Desta forma houve uma preocupação em levar em conta a resistência do concreto ao Mxy e em verificar a possibilidade dos momentos equivalentes serem menores que o momento resistido pela armadura mínima.

Com os valores dos momentos equivalentes positivos e negativos são calculadas as armaduras necessárias em cada ponto da laje.

A sub-rotina do programa MLAJE para cálculo dos momentos equivalentes está descrita no Anexo A. 


\section{EXEMPLOS}

\subsection{Introdução}

Procurando ilustrar os conceitos anteriormente descritos, são mostrados a seguir exemplos da utilização desses conceitos.

Nos exemplos 1 e 2 foram calculados os esforços em alguns pontos de uma laje quadrada apoiada e engastada em seus quatro lados, respectivamente. A partir dos esforços calculados é mostrado como tratar o terno de esforços Mx, My e Mxy, considerando-se a armadura disposta em duas direções ortogonais.

No item 5.4 é ilustrado como tratarem-se casos em que um momento calculado é menor que o momento resistido pelo armadura mínima e o outro é maior.

Nos dois itens seguintes são mostrados exemplos com armaduras dispostas em duas direções oblíquas.

Em seguida é feito um estudo em algumas lajes retangulares apoiadas nos quatro lados, procurando avaliar as recomendações existentes em normas para as armaduras de canto dessas lajes.

Finalmente é feito um estudo comparando-se o detalhamento das lajes de um pavimento tipo, calculado pelo método das charneiras plásticas, por elementos finitos sem a consideração do momento volvente e por elementos finitos, considerando-se o momento volvente. 


\subsection{Exemplo 1}

Laje maciça apoiada em quatro lados indeslocáveis, conforme ו e ה.

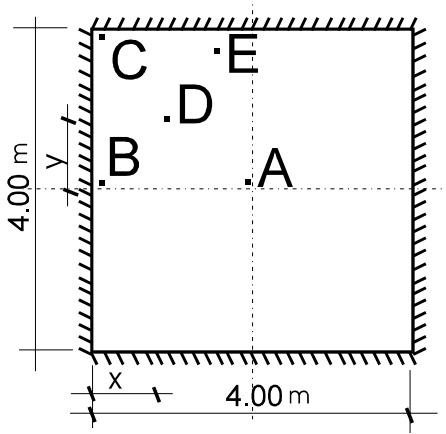

$$
\begin{aligned}
& \mathrm{h}=7 \mathrm{~cm} \\
& \mathrm{~d}=6 \mathrm{~cm} \\
& \text { concreto } \mathrm{C} 20 \\
& v=0,20 \\
& q=3,0 \mathrm{KN} / \mathrm{m}^{2}
\end{aligned}
$$

FIGURA 5.1 - Laje do Exemplo 1

TABELA 5.1 - Posição dos pontos analisados no Exemplo 1

\begin{tabular}{|c|c|c|c|c|c|}
\hline & A & B & C & D & E \\
\hline $\mathbf{X}(\mathbf{m})$ & 1,909 & 0,091 & 0,091 & 1,000 & 1,546 \\
\hline $\mathbf{Y}(\mathbf{m})$ & 0,091 & 0,091 & 1,546 & 1,000 & 1,727 \\
\hline
\end{tabular}

Para calculo dos esforços na laje, foi criada uma malha de 121 elementos quadrados, modelando o quadrante superior esquerdo. Processado o modelo, obtiveram-se os resultados mostrados na $r^{4}$.

TABELA 5.2 - Esforços do Exemplo 1

\begin{tabular}{|c|c|c|c|c|c|}
\hline Ponto & Mx & My & Mxy & Vx & Vy \\
\hline A & 3,87 & 3,87 & $-0,01$ & 0,07 & 0,15 \\
\hline B & 0,45 & 0,32 & $-0,19$ & 2,51 & 0,21 \\
\hline
\end{tabular}

${ }^{4}$ No presente capítulo, quando não indicadas são adotadas as unidades $\mathrm{kN}$ e m para representar as grandezas de força e de comprimento 


\begin{tabular}{|c|c|c|c|c|c|}
\hline C & 0,05 & 0,05 & $-3,22$ & 0,48 & 0,48 \\
\hline D & 2,38 & 2,38 & $-1,34$ & 2,24 & 2,24 \\
\hline E & 0,90 & 1,21 & $-0,95$ & 0,15 & 5,57 \\
\hline
\end{tabular}

Empregando um procedimento simples, utilizando as eqs. (2.7) e (2.8) sem verificar a armadura mínima e a resistência do concreto, tem-se:

ponto A:

armadura positiva: $\mathrm{M}^{*} \mathrm{x}=\mathrm{M}^{*} \mathrm{y}=3,87+0,01=3,88$

armadura negativa: $M^{*} x=M^{*} y=3,87-0,01=3,86$

$>0$, não há necessidade de armadura negativa

ponto B:

armadura positiva: $\mathrm{M}^{*} \mathrm{x}=0,45+0,19=0,64$

$M^{*} y=0,32+0,19=0,51$

armadura negativa: $\mathrm{M}^{*} \mathrm{x}=0,45-0,19=0,26$

$M^{*} y=0,32-0,19=0,13$

não há necessidade de armadura negativa.

ponto C:

armadura positiva: $\mathrm{M}^{*} \mathrm{x}=\mathrm{M}^{*} \mathrm{y}=0,05+3,22=3,27$

armadura negativa: $\mathrm{M}^{*} \mathrm{x}=\mathrm{M}^{*} \mathrm{y}=0,05-3,22=-3,17$

ponto D:

armadura positiva: $\mathrm{M}^{*} \mathrm{x}=\mathrm{M}^{*} \mathrm{y}=2,38+1,34=3,72$

armadura negativa: $M^{*} x=M^{*} y=2,38-1,34=1,04$ 
não há necessidade de armadura negativa.

ponto E:

armadura positiva: $\mathrm{M}^{*} \mathrm{x}=0,90+0,95=1,85$

$M^{*} y=1,21+0,95=2,16$

armadura negativa: $\mathrm{M}^{*} \mathrm{x}=0,90-0,95=-0,05$

$M^{*} y=1,21-0,95=0,26$

A partir dos momentos equivalentes foram determinadas as armaduras necessárias em cada ponto da laje, considerando uma armadura mínima de $0,12 \%$ de $\mathrm{h}$, igual a $0,84 \mathrm{~cm}^{2} / \mathrm{m}$. A $\mathrm{n}$ mostra as áreas de armadura calculadas.

TABELA 5.3 - Armaduras do Exemplo $1\left(\mathrm{~cm}^{2} / \mathrm{m}\right)$

\begin{tabular}{|c|c|c|c|c|}
\hline Ponto & $\mathrm{As}_{\mathrm{x}}{ }^{+}$ & $\mathrm{As}_{\mathrm{v}}{ }^{+}$ & $\mathrm{As}_{\mathrm{x}}{ }^{-}$ & $\mathrm{As}_{\mathrm{v}}{ }^{-}$ \\
\hline $\mathrm{A}$ & 2,23 & 2,23 & 0 & 0 \\
\hline $\mathrm{B}$ & 0,84 & 0,84 & 0 & 0 \\
\hline $\mathrm{C}$ & 1,86 & 1,86 & 1,79 & 1,79 \\
\hline $\mathrm{D}$ & 2,14 & 2,14 & 0 & 0 \\
\hline $\mathrm{E}$ & 1,02 & 1,20 & 0,84 & 0 \\
\hline
\end{tabular}

No ponto B são necessárias apenas armaduras mínimas, não sendo eficiente fazer verificações mais detalhadas. Para os demais pontos é interessante a verificação da resistência do concreto ao momento volvente, procurando diminuir a quantidade de armadura necessária para resistir aos esforços. Desta forma, utilizando a eq. (3.3), tem-se:

$$
\tau_{w u 1}=(0,06 \cdot 1+0,08) \cdot 1,06 \cdot(1,60-0,06) \cdot \sqrt{20}=1,02=1,0 \mathrm{MPa}
$$

ponto A:

$\mathrm{V}_{\max }=0,15 \mathrm{KN} / \mathrm{m}$ 
$\begin{aligned} \mathrm{Mxy}_{\mathrm{c}} & =\sqrt{1-\left(\frac{1,4 \cdot 0,15 \times 10^{-3}}{0,06 \cdot 1,0}\right)^{2}} \cdot \frac{0,07^{2} \cdot 1,0}{3 \cdot 1,4} \quad \text { [de acordo com eq. (3.5)] } \\ & =0,00117 \mathrm{MN} \cdot \mathrm{m} / \mathrm{m}\end{aligned}$

$\mathrm{Mxy}_{\mathrm{c}}=1,17 \mathrm{KN} \cdot \mathrm{m} / \mathrm{m}$

$\mathrm{Mxy}=0,01<\mathrm{Mxy}_{\mathrm{c}}=1,17$

$\therefore M^{*} \mathrm{x}=\mathrm{Mx}=\mathrm{M}^{*} \mathrm{y}=\mathrm{My}=3,87$

como verificado anteriormente, não há necessidade de armadura negativa ponto C:

$\mathrm{V}_{\max }=0,48$

$\mathrm{Mxy}_{\mathrm{c}}=1,17$

Mxy $=3,22>1,17$

- $M x y=3,22-1,17=2,05$

armadura positiva: $M^{*} x=M^{*} y=0,05+2,05=2,10$

armadura negativa: $M^{*} x=M^{*} y=0,05-2,05=-2,00$

ponto D:

$\mathrm{V}_{\text {max }}=2,24$

$\mathrm{Mxy}_{\mathrm{c}}=1,17$

Mxy $=1,34>1,17$

- $M x y=1,34-1,17=0,17$

armadura positiva: $M^{*} x=M^{*} y=2,38+0,17=2,55$

como verificado anteriormente, não há necessidade de armadura negativa

ponto E:

$\mathrm{V}_{\max }=5,57$

$\mathrm{Mxy}_{\mathrm{c}}=1,16$

Mxy $=0,95<1,16$

armadura positiva: $\mathrm{M}^{*} \mathrm{x}=0,90$

$M^{*} y=1,21$

não há necessidade de armadura negativa 
As armaduras em cada ponto passam a ser as descritas na tabela a seguir.

TABELA 5.4 - Armaduras do Exemplo 1 recalculadas $\left(\mathrm{cm}^{2} / \mathrm{m}\right)$

\begin{tabular}{|c|c|c|c|c|}
\hline Ponto & $\mathrm{As}_{\mathrm{x}}{ }^{+}$ & $\mathrm{As}_{\mathrm{y}}{ }^{+}$ & $\mathrm{As}{ }_{\mathrm{x}}{ }^{-}$ & $\mathrm{As}{ }_{\mathrm{y}}{ }^{-}$ \\
\hline $\mathrm{A}$ & 2,22 & 2,22 & 0 & 0 \\
\hline $\mathrm{B}$ & 0,84 & 0,84 & 0 & 0 \\
\hline $\mathrm{C}$ & 1,20 & 1,20 & 1,14 & 1,14 \\
\hline $\mathrm{D}$ & 1,47 & 1,47 & 0 & 0 \\
\hline $\mathrm{E}$ & 0,84 & 0,84 & 0 & 0 \\
\hline
\end{tabular}

Com a consideração da resistência do concreto ao momento volvente, pode-se notar uma diminuição considerável das áreas de armaduras necessárias nos pontos $C$ e D. No ponto $E$, a armadura negativa não se faz mais necessária.

\subsection{Exemplo 2}

Laje anterior, considerada engastada em 4 lados indeslocáveis, conforme r.

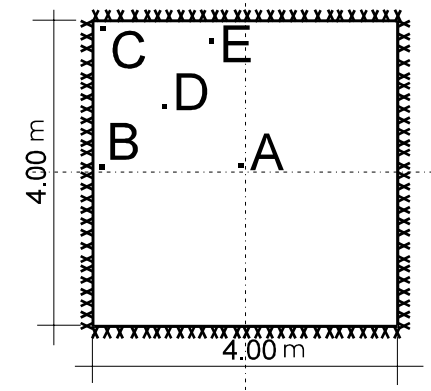

FIGURA 5.2 - Laje do Exemplo 2 
TABELA 5.5 - Esforços do Exemplo 2

\begin{tabular}{|c|c|c|c|c|c|}
\hline Ponto & Mx & My & Mxy & Vx & Vy \\
\hline A & 1,84 & 1,84 & $-0,01$ & 0,16 & 0,16 \\
\hline B & $-3,67$ & $-0,71$ & $-0,02$ & 3,10 & 0,07 \\
\hline C & $-0,08$ & $-0,08$ & $-0,06$ & 0,23 & 0,23 \\
\hline D & 0,52 & 0,52 & $-0,75$ & 1,68 & 1,68 \\
\hline E & $-0,31$ & $-2,07$ & $-0,26$ & 0,84 & 6,90 \\
\hline
\end{tabular}

Sem verificar a necessidade de armadura mínima e a resistência do concreto, tem-se:

ponto A:

armadura positiva: $\mathrm{M}^{*} \mathrm{x}=\mathrm{M}^{*} \mathrm{y}=1,84+0,01=1,85$

armadura negativa: $\mathrm{M}^{*} \mathrm{x}=\mathrm{M}^{*} \mathrm{y}=1,84-0,01=1,83$

não há necessidade de armadura negativa.

ponto B:

armadura positiva: $\mathrm{M}^{*} \mathrm{x}=-3,67+0,02=-3,65$

$M^{*} y=-0,71+0,02=-0,69$

armadura negativa: $\mathrm{M}^{*} \mathrm{x}=-3,67-0,02=-3,69$

$M^{*} y=-0,71-0,02=-0,73$

não há necessidade de armadura positiva.

ponto C:

armadura positiva: $M^{*} x=M^{*} y=-0,08+0,06=-0,02$

armadura negativa: $M^{*} x=M^{*} y=-0,08-0,06=-0,14$

não há necessidade de armadura positiva. 
ponto D:

armadura positiva: $M^{*} x=M^{*} y=0,52+0,75=1,27$

armadura negativa: $M^{*} x=M^{*} y=0,52-0,75=-0,23$

ponto E:

armadura positiva: $\mathrm{M}^{*} \mathrm{x}=-0,31+0,26=-0,05$

$M^{*} y=-2,07+0,26=-1,81$

armadura negativa: $M^{*} x=-0,31-0,26=-0,57$

$M^{*} y=-2,07-0,26=-2,33$

não há necessidade de armadura positiva.

As armaduras necessárias são mostradas na.

TABELA 5.6 - Armaduras do Exemplo $2\left(\mathrm{~cm}^{2} / \mathrm{m}\right)$

\begin{tabular}{|c|c|c|c|c|}
\hline Ponto & $\mathrm{As}_{\mathrm{x}}{ }^{+}$ & $\mathrm{As}_{\mathrm{y}}{ }^{+}$ & $\mathrm{As}_{\mathrm{x}}{ }^{-}$ & $\mathrm{As}_{\mathrm{y}}{ }^{-}$ \\
\hline $\mathrm{A}$ & 1,02 & 1,02 & 0 & 0 \\
\hline $\mathrm{B}$ & 0 & 0 & 2,12 & 0,84 \\
\hline $\mathrm{C}$ & 0 & 0 & 0,84 & 0,84 \\
\hline $\mathrm{D}$ & 0,84 & 0,84 & 0,84 & 0,84 \\
\hline $\mathrm{E}$ & 0 & 0 & 0,84 & 1,30 \\
\hline
\end{tabular}

Nos pontos A, B e C os valores do momento volvente são pequenos, sendo a consideração da resistência do concreto ao momento volvente pouco relevante. Para os demais pontos, tem-se:

ponto D:

$\mathrm{V}_{\max }=1,68$ 


$$
\begin{aligned}
& \begin{array}{l}
M x y_{c} \\
M x y
\end{array}=0,75<1,17 \\
& -M x y=0 \\
& \quad \text { armadura positiva: } M^{*} x=M^{*} y=0,52=>A s^{+}=0,84 \\
& \text { não há necessidade de armadura negativa. }
\end{aligned}
$$

$$
\begin{aligned}
& \text { ponto } \mathrm{E} \text { : } \\
& \mathrm{V}_{\max }=6,90 \\
& M_{x y}=1,16 \\
& M x y=0,26<1,16 \\
& \text { - } M x y=0 \\
& \text { armadura negativa: } \mathrm{M}^{*} \mathrm{x}=-0,31=>\mathrm{As}_{\mathrm{x}}{ }^{-}=0,84 \\
& M^{*} y=-2,07=>A s_{y}{ }^{-}=1,15
\end{aligned}
$$

Não ocorreu nenhum ponto onde seria interessante a verificação de armadura mínima, uma vez que, em todos os pontos, os momentos volventes são baixos e resistidos pelo próprio concreto. Desta forma os momentos equivalentes resultaram sempre iguais aos momentos calculados nas direções $\mathrm{X}$ e $\mathrm{Y}$.

\subsection{Verificação de Momento Mínimo}

Podem existir pontos em uma laje onde um momento equivalente é menor que o momento resistido pela armadura mínima e o outro é maior. Neste caso é interessante um cálculo mais detalhado, utilizando-se a possibilidade de impor um momento igual ao momento mínimo para diminuir o valor do outro momento. 
Imaginando-se um ponto da laje anterior sujeito ao terno de esforços $M x=0,40 ; M y=3,00$ e $M x y=1,50$ e com $M x y_{c}=1,16$, tem-se:

\subsection{1 $M x y>M x y_{c}=>M x y=1,50-1,16=0,34$}

armadura positiva:

$M^{*} x=0,40+0,34=0,74=>A s_{x, \min }=0,84\left(M_{\min }=1,53\right)$

$M^{*} y=3,00+0,34=3,34=A s_{y}=1,93$

modificando o ângulo critico $\left(\neq 45^{\circ}\right)$ para $K$ equivalente a $M^{*} x=1,53$ :

$\mathrm{K}=\frac{1,53-0,40}{0,34}=3,3 \quad$ [conforme a eq. (2.5)]

$$
M^{*} y=3,00+\frac{1}{3,3} \cdot 0,34=3,10 \quad[\text { conforme a eq. (2.3) }]=>A_{y}=1,77
$$

(8\% menos)

A mostra que os momentos equivalentes $M^{*} x=1,53$ e $M^{*} y=3,10$ são suficientes para cobrir o terno de esforços inicial.

TABELA 5.7 - Momentos Mn1 e Mn2

\begin{tabular}{|c|c|c|c|c|}
\hline$\theta\left(^{\circ}\right)$ & $\mathrm{k}$ & $\mathrm{Mn} 2$ & $\mathrm{Mn} 1$ & $\mathrm{f}(\mathrm{k})$ \\
\hline & $\tan \theta$ & $\begin{array}{c}\mathrm{Mx}=0,40 \\
\mathrm{My}=3,00 \\
\mathrm{Mxy}=0,34\end{array}$ & $\begin{array}{c}\mathrm{M}^{*} \mathrm{x}=1,53 \\
\mathrm{M}^{*} \mathrm{y}=3,10\end{array}$ & $\mathrm{Mn2-Mn1}$ \\
\hline 0 & 0,000 & 0,40 & 1,53 & 1,13 \\
\hline 20 & 0,364 & 0,92 & 1,71 & 0,79 \\
\hline 40 & 0,839 & 1,81 & 2,18 & 0,37 \\
\hline 60 & 1,732 & 2,64 & 2,71 & 0,06 \\
\hline $\mathbf{7 3 , 1 4}$ & $\mathbf{3 , 3 0 0}$ & $\mathbf{2 , 9 7}$ & $\mathbf{2 , 9 7}$ & $\mathbf{0 , 0 0}$ \\
\hline 80 & 5,671 & 3,04 & 3,05 & 0,01 \\
\hline 100 & 5,671 & 2,81 & 3,05 & 0,25 \\
\hline 120 & 1,732 & 2,06 & 2,71 & 0,65 \\
\hline 140 & 0,839 & 1,14 & 2,18 & 1,04 \\
\hline 160 & 0,364 & 0,49 & 1,71 & 1,23 \\
\hline 180 & 0,000 & 0,40 & 1,53 & 1,13 \\
\hline
\end{tabular}


Não há necessidade de armaduras negativas.

Esse caso tende a ocorrer quando a razão entre os lados, e conseqüentemente dos momentos, da laje aumenta.

\subsection{Armadura Oblíqua - Exemplo 3}

Pretende-se calcular momentos equivalentes a uma direção $X$ e a uma direção $\alpha=60^{\circ}$, conforme $n$, dado o terno de esforços $M x=0,50$, $M y=1,50$ e $M x y=0,70$.

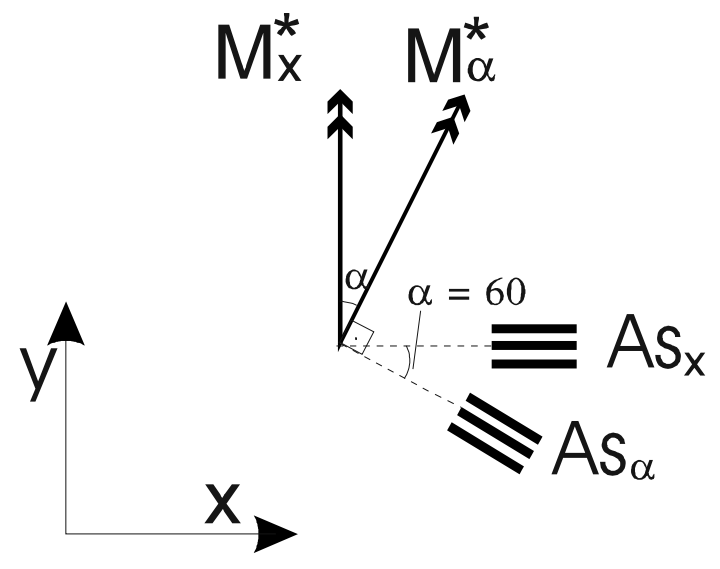

FIGURA 5.3 - Disposição das armaduras do Exemplo 3

Calculando-se as armaduras positivas com a eq. (2.26), tem-se:

$M_{\alpha}^{*}=\frac{1,50}{\operatorname{sen}^{2} 60^{\circ}}+\left|\frac{0,70+1,50 \cdot \cot 60^{\circ}}{\operatorname{sen} 60^{\circ}}\right|=3,81$

Da eq. (2.27), obtém-se: 


$$
M_{x}^{\star}=0,50+2 \cdot 0,70 \cdot \cot 60^{\circ}+1,50 \cdot \cot ^{2} 60^{\circ}+\left|\frac{0,70+1,50 \cdot \cot 60^{\circ}}{\operatorname{sen} 60^{\circ}}\right|=3,62
$$

Apenas para ilustrar, pode-se calcular o valor de K com a eq. (2.19):

$$
K=\left|\frac{3,81 \cdot \cos 60^{\circ} \cdot \operatorname{sen} 60^{\circ}+0,70}{3,81 \cdot \operatorname{sen}^{2} 60^{\circ}-1,50}\right|=1,73
$$

$\mathrm{Na}$ ג, são comparados os momentos normais calculados com Mx, My e $M x y$ e com $M^{*} x$ e $M^{*} \alpha$.

TABELA 5.8 - Momentos Mn1 e Mn2 para o Exemplo 3

\begin{tabular}{|c|c|c|c|c|}
\hline$\theta\left(^{\circ}\right)$ & $\mathrm{k}$ & $\mathrm{Mn} 2$ & $\mathrm{Mn} 1$ & $\mathrm{f}(\mathrm{k})$ \\
\hline & $\tan \theta$ & $\begin{array}{c}\mathrm{Mx}=0,50 \\
\mathrm{My}=1,50 \\
\mathrm{Mxy}=0,70\end{array}$ & $\begin{array}{c}\mathrm{M}^{*} \mathrm{x}=3,62 \\
\mathrm{M}^{*} \alpha=3,81\end{array}$ & \\
\hline 0 & 0,000 & 0,50 & 4,57 & 4,07 \\
\hline 20 & 0,364 & 1,07 & 3,31 & 2,24 \\
\hline 40 & 0,839 & 1,60 & 2,24 & 0,64 \\
\hline 60 & 1,732 & 1,86 & 1,86 & 0,00 \\
\hline 80 & 5,671 & 1,71 & 2,34 & 0,63 \\
\hline 100 & 5,671 & 1,23 & 3,47 & 2,24 \\
\hline 120 & 1,732 & 0,64 & 4,71 & 4,07 \\
\hline 140 & 0,839 & 0,22 & 5,49 & 5,27 \\
\hline 160 & 0,364 & 1,07 & 5,43 & 5,26 \\
\hline 180 & 0,000 & 0,50 & 4,57 & 4,07 \\
\hline
\end{tabular}

Momentos negativos:

$$
\begin{aligned}
& M^{*} x=0,50+2 \cdot 0,70 \cdot \cot 60^{\circ}+1,50 \cdot \cot ^{2} 60^{\circ}-\left|\frac{0,70+1,50 \cdot \cot 60^{\circ}}{\operatorname{sen} 60^{\circ}}\right|=0 \\
& M^{*} \alpha=\frac{1,50}{\operatorname{sen}^{2} 60^{\circ}}-\left|\frac{0,70+1,50 \cdot \cot 60^{\circ}}{\operatorname{sen} 60^{\circ}}\right|=0,19
\end{aligned}
$$


Não há necessidade de armadura negativa.

\subsection{Armadura Oblíqua - Exemplo 4}

Momentos equivalentes a uma direção X e a uma direção $\alpha=50^{\circ}$, dado o terno de esforços $M x=-0,70, M y=2,00$ e $M x y=0,50$.

armadura positiva

$$
M^{*} x=4,39 \text { e } M^{*} \alpha=6,25
$$

armadura negativa

$$
M^{*} x=-1,30 \text { e } M^{*} \alpha=0,57
$$

Ao se tentar calcular momentos equivalentes negativos, resultou um valor de $\mathrm{M}^{*} \alpha$ positivo, portanto deve-se adotar $\mathrm{M}^{*} \alpha=0$ e recalcular $\mathrm{M}^{\star} \mathrm{x}$ : $M^{*} x=-0,70+2 \cdot 0,50 \cdot \cot 50^{\circ}+2,00 \cdot \cot ^{2} 50^{\circ}-\left|\frac{\left(0,50+2,00 \cdot \cot 50^{\circ}\right)^{2}}{2,00}\right|=-0,82$

$\mathrm{Na}$ ד pode-se verificar que, no campo de momentos negativos (conforme item 2.2.3), estes momentos são suficientes para cobrir o terno inicial de esforços.

TABELA 5.9 - Momentos Mn1 e Mn2 para o Exemplo 4

\begin{tabular}{|c|c|c|c|c|}
\hline$\theta\left(^{\circ}\right)$ & $\mathrm{k}$ & $\mathrm{Mn2}$ & $\mathrm{Mn} 1$ & $\mathrm{f}(\mathrm{k})$ \\
\hline & & $\begin{array}{c}\mathrm{Mx}=-0,70 \\
\mathrm{My}=2,00 \\
\end{array}$ & $\begin{array}{c}\mathrm{M}^{*} \mathrm{x}=-0,82 \\
\mathrm{M}^{*} \alpha=0\end{array}$ & \\
\hline $\mathbf{0}$ & $\mathbf{0 , 0 0 0}$ & $\mathbf{- 0 , 7 0}$ & $\mathbf{- 0 , 8 2}$ & $\mathbf{0 , 1 2}$ \\
\hline $\mathbf{2 0}$ & $\mathbf{0 , 3 6 4}$ & $\mathbf{- 0 , 0 6}$ & $\mathbf{- 0 , 7 3}$ & $\mathbf{0 , 6 7}$ \\
\hline
\end{tabular}




\begin{tabular}{|c|c|c|c|c|}
\hline 40 & 0,839 & 0,91 & $-0,48$ & $-0,42$ \\
\hline 60 & 1,732 & 1,76 & $-0,21$ & $-1,55$ \\
\hline 80 & 5,671 & 2,09 & $-0,02$ & $-2,06$ \\
\hline 100 & 5,671 & 1,75 & $-0,02$ & $-1,72$ \\
\hline 120 & 1,732 & 0,89 & $-0,21$ & $-0,68$ \\
\hline $\mathbf{1 4 0}$ & $\mathbf{0 , 8 3 9}$ & $\mathbf{- 0 , 0 8}$ & $\mathbf{- 0 , 4 8}$ & $\mathbf{0 , 4 0}$ \\
\hline $\mathbf{1 6 0}$ & $\mathbf{0 , 3 6 4}$ & $\mathbf{- 0 , 7 1}$ & $\mathbf{- 0 , 7 3}$ & $\mathbf{0 , 0 2}$ \\
\hline $\mathbf{1 8 0}$ & $\mathbf{0 , 0 0 0}$ & $\mathbf{- 0 , 7 0}$ & $\mathbf{- 0 , 8 2}$ & $\mathbf{0 , 1 2}$ \\
\hline
\end{tabular}

\subsection{Laje retangular apoiada nos quatro lados}

É interessante o estudo de lajes retangulares apoiadas nos quatro lados, pois este é um caso onde a presença do momento volvente é evidente, sendo recomendada a disposição de armadura de canto, mesmo quando os esforços são calculados desprezando-se a contribuição do momento volvente.

A norma brasileira de concreto armado (NB1-1982), recomenda que as armaduras nos cantos (inferiores e superiores) sejam iguais à metade da máxima área de armadura disposta no vão. Em JIMENEZ MONTOYA (1969) é recomendada uma área de armadura para os cantos igual a $75 \%$ da maior área de armadura do vão. No COMITÉ EURO-INTERNATIONAL DU BÉTON (CEB-1990) e em LEONHARDT \& MÖNNING (1978b) é recomendado que as armaduras dos cantos de lajes apoiadas sejam iguais à maior armadura no vão. A v mostra essas recomendações. 


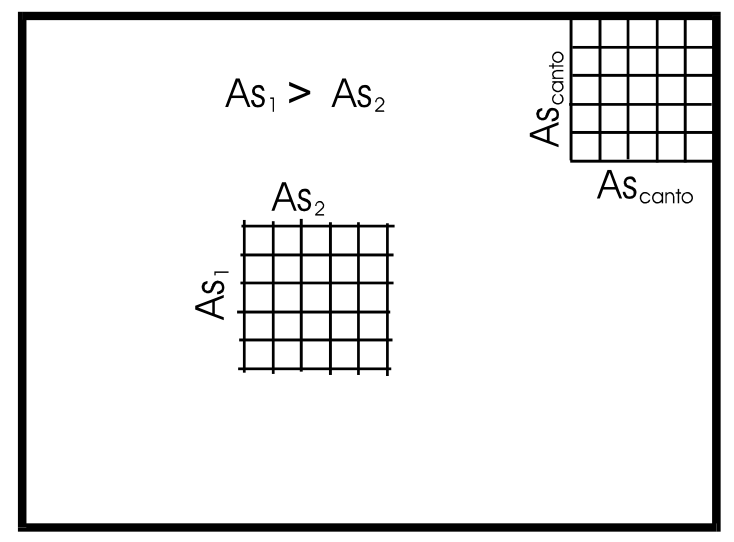

\begin{tabular}{|c|c|}
\hline NB1 / 1982 & $\begin{array}{l}A s_{\text {canto }}= \\
50 \% \times A s_{1}\end{array}$ \\
\hline $\begin{array}{l}\text { JIMENEZ } \\
\text { MONTOYA }\end{array}$ & $\begin{array}{l}A s_{\text {canto }}= \\
75 \% \times A s_{1}\end{array}$ \\
\hline $\begin{array}{l}\text { CEB } 1990 \text { e } \\
\text { LEONHARDT } \\
\& \text { MÖNNIG }\end{array}$ & $\begin{array}{l}A \mathbf{s}_{\text {canto }}= \\
100 \% \times A s_{1}\end{array}$ \\
\hline
\end{tabular}

FIGURA 5.4 - Recomendações encontradas sobre a armadura de canto

A razão entre o valor do momento volvente no canto e o momento fletor no vão de uma laje apoiada nos 4 lados varia conforme a razão entre a maior e menor dimensão da laje $(\lambda)$. Para uma laje com $\lambda=1$, considerando os apoios indeslocáveis e $v=0,20$, obtém-se $\mathrm{Mx} \cong 4,39 \times 10^{-2} \cdot p \cdot l^{2}$ e $\mathrm{Mxy} \cong$ $3,65 \times 10^{-2} \cdot p \cdot l^{2}$. Para $\lambda=2$, tem-se $M x \cong 9,96 \times 10^{-2} \cdot p \cdot l^{2}$ e $M x y \cong$ $5,15 \times 10^{-2} \cdot p \cdot I^{2}$.

O valor do momento volvente resistido pelo concreto depende do fck e da altura da laje. Outro fator que pode modificar o valor de $M x y_{c}$ é o valor da força cortante, que em lajes maciças tem pouca influência.

Mesmo admitindo que $\mathrm{Mxy}_{\mathrm{c}}$ seja constante, a razão entre o valor do momento volvente utilizado para cálculo das armadura e Mxy calculado, varia conforme variam os esforços:

$\Rightarrow$ Mxy é proporcional a $\mathrm{Mx}$, mesmo se $\mathrm{Mxy}_{\mathrm{c}}$ for admitido constante, a razão $\frac{M x y-M x y_{c}}{M x}$ não será constante.

Existem, portanto, diversos fatores que influenciam a razão entre as armaduras de canto e do vão. Desta forma, não é possível determinar com exatidão qual deve ser esta razão. A utilização de computadores para o cálculo de pavimentos pode determinar com maior precisão estas 
armaduras, devendo os esforços serem tratados conforme os conceitos descritos anteriormente.

Procurando verificar se as recomendações para determinar o valor da armadura de canto são seguras, estudaram-se alguns casos de lajes apoiadas nos quatro lados. São utilizados os "softwares" descritos no capítulo 4 para modelar e calcular as lajes, sendo considerada a resistência do concreto ao momento volvente, conforme os conceitos descritos no capítulo 3.

Foram estudadas lajes com dimensões $4 \mathrm{~m} \times 4 \mathrm{~m}$ e $4 \mathrm{~m} \times 8 \mathrm{~m}$, com espessuras variando entre 7 e $12 \mathrm{~cm}$ e adotadas cargas correspondentes a uma flecha de $1,33 \mathrm{~cm}$, que corresponde ao limite normalizado para o deslocamento igual a $\mathrm{l} / 300$.

Utilizou-se fck $=15$ e $20 \mathrm{MPa}$ e $E_{c}=17.884$ e $20.156 \mathrm{MPa}$, respectivamente.

Foi modelado o quadrante superior esquerdo de cada laje em 121 elementos quadrilaterais do tipo placa. Durante o processamento, cada elemento é divido automaticamente em 4 elementos triangulares.

As curvas relativas aos processamentos das lajes L3 e L3A estão reproduzidas no anexo $B$. Para as demais lajes foram obtidas curvas similares.

\subsubsection{Lajes $4 \mathrm{~m} \times 4 \mathrm{~m}$}

Para a dimensão $4 m \times 4 m$, foram estudadas as seguintes lajes:

C-15:
1) $\mathrm{h}=7 \mathrm{~cm} \mathrm{e}(\mathrm{g}+\mathrm{q})=6,80 \mathrm{KN} / \mathrm{m}^{2}$
2) $\mathrm{h}=8 \mathrm{~cm} \mathrm{e}(\mathrm{g}+\mathrm{q})=10,17 \mathrm{KN} / \mathrm{m}^{2}$
3) $\mathrm{h}=9 \mathrm{~cm}$ e $(\mathrm{g}+\mathrm{q})=14,47 \mathrm{KN} / \mathrm{m}^{2}$ C-20:

4) $\mathrm{h}=7 \mathrm{~cm}$ e $(\mathrm{g}+\mathrm{q})=7,67 \mathrm{KN} / \mathrm{m}^{2}$

5) $\mathrm{h}=8 \mathrm{~cm}$ e $(\mathrm{g}+\mathrm{q})=11,46 \mathrm{KN} / \mathrm{m}^{2}$ 
6) $\mathrm{h}=9 \mathrm{~cm} \mathrm{e}(\mathrm{g}+\mathrm{q})=16,31 \mathrm{KN} / \mathrm{m}^{2}$

Considerando-se os apoios indeslocáveis, obtiveram-se os resultados mostrados na tabela abaixo.

TABELA 5.10 - Armaduras encontradas para lajes $4 \mathrm{~m} \times 4 \mathrm{~m}$

\begin{tabular}{|c|c|c|c|}
\hline Laje & As (canto) & As (vão) & As $_{\text {canto }} /$ As $_{\text {vão }}$ \\
\hline $\mathbf{1}$ & 1,65 & 2,90 & $56,9 \%$ \\
\hline $\mathbf{2}$ & 2,24 & 3,78 & $59,2 \%$ \\
\hline $\mathbf{3}$ & 2,92 & 4,77 & $61,2 \%$ \\
\hline $\mathbf{4}$ & 1,84 & 3,20 & $57,5 \%$ \\
\hline $\mathbf{5}$ & 2,48 & 4,14 & $59,9 \%$ \\
\hline $\mathbf{6}$ & 3,22 & 5,22 & $61,7 \%$ \\
\hline
\end{tabular}

\subsubsection{Lajes $4 \mathrm{~m} \times 8 \mathrm{~m}$}

Lajes estudadas:

C-15:

7) $\mathrm{h}=10 \mathrm{~cm} \mathrm{e}(\mathrm{g}+\mathrm{q})=7,94 \mathrm{KN} / \mathrm{m}^{2}$

8) $\mathrm{h}=11 \mathrm{~cm} \mathrm{e}(\mathrm{g}+\mathrm{q})=10,58 \mathrm{KN} / \mathrm{m}^{2}$

9) $\mathrm{h}=12 \mathrm{~cm}$ e $(\mathrm{g}+\mathrm{q})=13,74 \mathrm{KN} / \mathrm{m}^{2}$

C-20:

10) $\mathrm{h}=10 \mathrm{~cm} \mathrm{e}(\mathrm{g}+\mathrm{q})=8,95 \mathrm{KN} / \mathrm{m}^{2}$

11) $h=11 \mathrm{~cm} \mathrm{e}(\mathrm{g}+\mathrm{q})=11,92 \mathrm{KN} / \mathrm{m}^{2}$

12) $\mathrm{h}=12 \mathrm{~cm}$ e $(\mathrm{g}+\mathrm{q})=15,48 \mathrm{KN} / \mathrm{m}^{2}$

Foram obtidos os seguintes resultados (apoios indeslocáveis):

TABELA 5.11 - Armaduras para lajes 4mx8m

\begin{tabular}{|c|c|c|c|c|c|}
\hline Laje & \multicolumn{2}{|c|}{ As (canto) } & \multicolumn{2}{c|}{ As (vão) } & \multirow{2}{*}{\begin{tabular}{c}
$A_{\text {canto }} /$ \\
$A_{\text {max,vão }}$ \\
\hline
\end{tabular}} \\
\hline
\end{tabular}




\begin{tabular}{|c|c|c|c|c|c|}
$\mathbf{7}$ & 1,61 & 1,62 & 5,25 & 1,81 & $30,1 \%$ \\
\hline $\mathbf{8}$ & 2,03 & 2,05 & 6,38 & 2,24 & $32,1 \%$ \\
\hline $\mathbf{9}$ & 2,51 & 2,53 & 7,67 & 2,76 & $33,0 \%$ \\
\hline $\mathbf{1 0}$ & 1,78 & 1,80 & 5,75 & 2,03 & $31,3 \%$ \\
\hline $\mathbf{1 1}$ & 2,25 & 2,27 & 6,99 & 2,49 & $32,4 \%$ \\
\hline $\mathbf{1 2}$ & 2,77 & 2,79 & 8,35 & 3,05 & $33,4 \%$ \\
\hline
\end{tabular}

\subsubsection{Laje 4m x 4m Apoiada em Vigas Deformáveis}

Analisando-se os resultados anteriores, percebe-se que a pior situação, no que diz respeito à relação entre as armaduras de canto e do vão, ocorre em lajes quadradas. Procurando estudar melhor esta forma de laje, foi criado um modelo de uma laje L3A, semelhante à laje 3 , porém apoiada em vigas deformáveis, de acordo com a '.

De maneira idêntica aos processamentos anteriores, as lajes foram modeladas em 121 elementos quadrilaterais do tipo placa. As vigas foram modeladas como elementos do tipo barra, com propriedades relativas às suas seções. O pilar foi considerado como um ponto com a translação transversal impedida e as rotações em torno dos eixos $\mathrm{X}$ e $\mathrm{Y}$ livres.

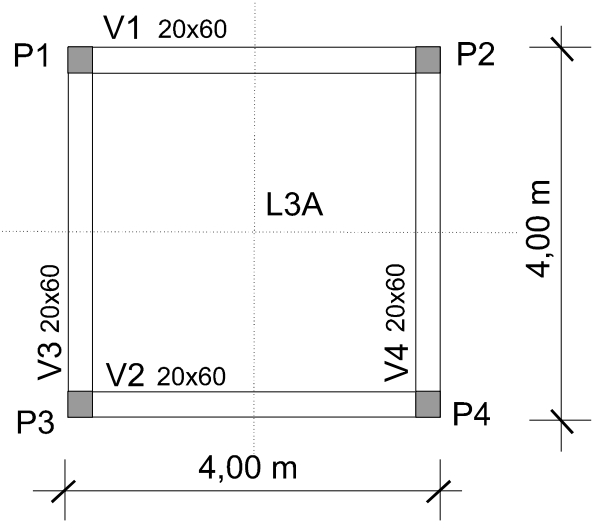

FIGURA 5.5 - Laje quadrada apoiada em vigas 
Nessa laje, chegou-se a armaduras iguais a $4,62 \mathrm{~cm}^{2} / \mathrm{m}$ no centro do vão e $1,95 \mathrm{~cm}^{2} / \mathrm{m}$ no canto, sendo a armadura de canto igual a $42,2 \%$ da armadura do vão. Se não for considerada a resistência do concreto ao momento volvente, chega-se a armaduras iguais a $4,64 \mathrm{~cm}^{2} / \mathrm{m}$ e $2,73 \mathrm{~cm}^{2} / \mathrm{m}$ no centro do vão e no canto, respectivamente. Neste caso, a armadura de canto é igual a $58,8 \%$ da armadura do vão.

\subsubsection{Análise dos Resultados dos Processamentos}

Analisando a laje modelada como apoiada em vigas deformáveis, pode-se perceber que a razão entre as armaduras de canto e a armadura do centro do vão ficou abaixo de $50 \%$. Nesse processamento, o pilar P1 foi considerado um ponto, com apenas a translação transversal impedida. Desta forma, não surgiram momentos negativos na laje na região próxima ao pilar. Se o pilar P1 também fosse modelado, provavelmente apareceriam, de maneira proporcional à rigidez considerada, momentos negativos no canto da laje, o que aumentaria a razão entre a armadura de canto e a armadura do vão.

A consideração de lados rígidos é, para cálculo de Mxy, uma simplificação a favor da segurança. Além disso, é possível existirem casos em que as lajes são apoiadas em lados rígidos, como por exemplo lajes apoiadas em paredes de concreto armado (caso comum em reservatórios) ou lajes de concreto armado em edifícios de alvenaria estrutural.

Dos processamentos feitos considerando as lajes apoiadas em lados rígidos, percebe-se que a recomendação de se estimar as áreas das armaduras de canto como sendo iguais a $50 \%$ da maior área de armadura do vão, não é segura, pois, nos processamentos feitos, foram encontradas áreas de armaduras de canto iguais a até $62 \%$ da maior área do vão. Portanto, pode-se afirmar que a recomendação da NB1 / 1992 pode ser 
segura em alguns casos de laje. Porém, não é possível afirmar que esta recomendação é segura para todos os casos.

Desta forma, dentre as recomendações citadas anteriormente, a que melhor atende a todos os casos estudados é aquela que adota áreas de armaduras de canto iguais a $75 \%$ da maior área do vão.

\subsection{Análise de um Pavimento Tipo}

Procurando avaliar a eficiência da consideração do momento volvente no cálculo de lajes de concreto armado, foi analisado um pavimento tipo calculado de três maneiras distintas:

i) de acordo com o método das charneiras plásticas, [informações sobre o método das charneiras plásticas podem ser obtidas em PINHEIRO (1988)],

ii) por elementos finitos, sem considerar o momento volvente, e

iii) por elemento finitos, considerando o momento volvente.

Foi estudado o pavimento tipo do Ed. Residencial Andaluzia, cujo projeto é propriedade da D. C. Matos Engenharia de Projetos e Consultoria Ltda. A אי mostra a forma do pavimento.

Foi adotado o seguinte carregamento distribuído nas lajes:

- sobrecarga $=1,50 \mathrm{KN} / \mathrm{m}^{2}$

- revestimento do teto (gesso) $=0,20 \mathrm{KN} / \mathrm{m}^{2}$

- contra-piso $=0,02 \times 20=0,40 \mathrm{KN} / \mathrm{m}^{2}$

- piso (cerâmica) $=0,20 \mathrm{KN} / \mathrm{m}^{2}$

Total (exceto peso próprio) $=2,30 \mathrm{KN} / \mathrm{m}^{2}$ 
As cargas de parede foram consideradas, de maneira aproximada, com distribuídas pela área de cada laje no método das charneiras plásticas, e como linhas de carga concentradas, corretamente posicionadas, nos cálculos pelo MEF.

$\mathrm{Na}$ modelagem pelo $\mathrm{MEF}$, não foi considerada a rigidez à torção das vigas.

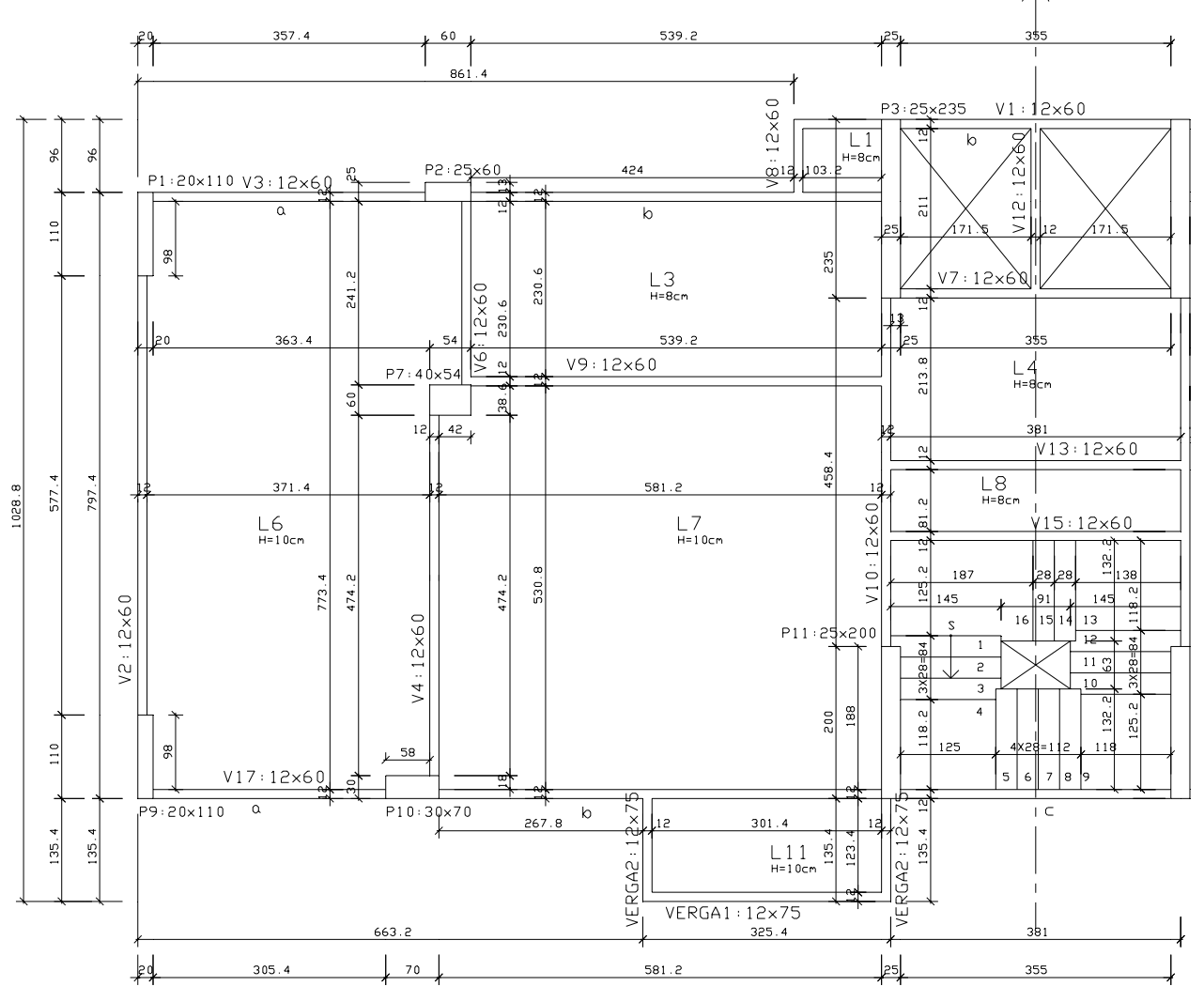

FIGURA 5.6 - Forma do pavimento tipo do Ed. Andaluzia

\subsubsection{Cálculo por Charneiras Plásticas}

Cargas de parede sobre as lajes $(\mathrm{kN})$ :

$\mathrm{L} 1=\mathrm{L} 4=\mathrm{L} 8=0$; $\mathrm{L} 3=15,21 ; \mathrm{L} 6=41,92 ; \mathrm{L} 7=31,24$;

$\mathrm{L} 11=270+100 \mathrm{kN} / \mathrm{m}$ na borda do balanço. 
Vãos teóricos $(\mathrm{cm})$ :

$$
\begin{array}{ll}
\mathrm{L} 1=121,7 \times 96,0 & \mathrm{~L} 3=551,0 \times 242,6 \\
\mathrm{~L} 4=293,0 \times 225,8 & \mathrm{~L} 6=400,0 \times 785,4 \\
\text { L7 }=593,2 \times 542,8 & \mathrm{~L} 8=393,0 \times 93,2 \\
\mathrm{~L} 11=313,4 \times 135,4 &
\end{array}
$$

Sobrecarga de parede sobre as lajes $\left(\mathrm{kN} / \mathrm{m}^{2}\right)$

$$
\begin{aligned}
& \mathrm{L} 1=\mathrm{L} 4=\mathrm{L} 8=0 \quad \mathrm{~L} 3=1,14 \\
& \mathrm{~L} 6=1,33 \quad \mathrm{~L} 7=0,97 \\
& \mathrm{~L} 11=0,64+1,00 \mathrm{KN} / \mathrm{m} \text { na borda do balanço. }
\end{aligned}
$$

Relação entre momentos positivos e negativos $=1$.

Momentos calculados (kN.m/m):

L1: $M x=0,10 ; M y=M ' y=0,20$

L3: $M x=M \prime x=0,63 ; M y=M^{\prime} y=2,11$

$L 4: M x=M \prime x=0,50 ; M y=1,67$

L6: $M x=6,55 ; M y=M ' y=1,96$

L7: $M x=M \prime x=M y=M^{\prime} y=5,30$

L8: $M x=M^{\prime} x=0,08 ; M y=M^{\prime} y=0,27$

L11: M'y $=6,34$

Armaduras calculadas $\left(\mathrm{cm}^{2} / \mathrm{m}\right)$ :

$L 1: A s_{x}=A s_{y}=0,96$

L3: $A s_{x}=0,96 ; A s_{y}=0,99$

$L 4: A s_{x}=A s_{y}=0,96$

L6: $A s_{x}=2,44 ; A s_{y}=1,20$

L7: $A s_{x}=A s_{y}=1,96$ 
L8: $A s_{x}=A s_{y}=0,96$

$L 11: A s_{y}^{\prime}=2,36$

As lajes foram detalhadas seguindo os seguintes critérios:

- área de armadura positiva mínima igual a $0,12 \%$ de b·h.

- área de armadura negativa mínima igual a 0,15\% de b·h.

- $1,5 \mathrm{~cm}$ de cobrimento,

- comprimento das armaduras negativas iguais a $2 \times(0,25 \times 0$ maior dos menores vãos + comprimento de ancoragem) + dobras,

- comprimento da armadura negativa do balanço igual a 2 × vão teórico + al $=1,5 \cdot d+$ comprimento de ancoragem + dobras,

- comprimento da armadura sobre as vigas de borda igual a 0,2 $\times 0$ menor vão, com área igual a $25 \%$ da área de armadura do vão na mesma direção ou $1,5 \mathrm{~cm}^{2} / \mathrm{m}$ (para consideração de seção $T$ nas vigas) e dobra sobre as vigas igual a $10 \varnothing$.

- segunda dobra da armadura do balanço igual a $2 \cdot d$ ou comprimento de ancoragem.

Estas recomendações podem ser encontradas em GIONGO (1994b), em LEONHARDT \& MÖNNIG (1978b) e no texto provisório da NB1 (1993).

Os detalhamentos positivo e negativo são mostrados a seguir. 


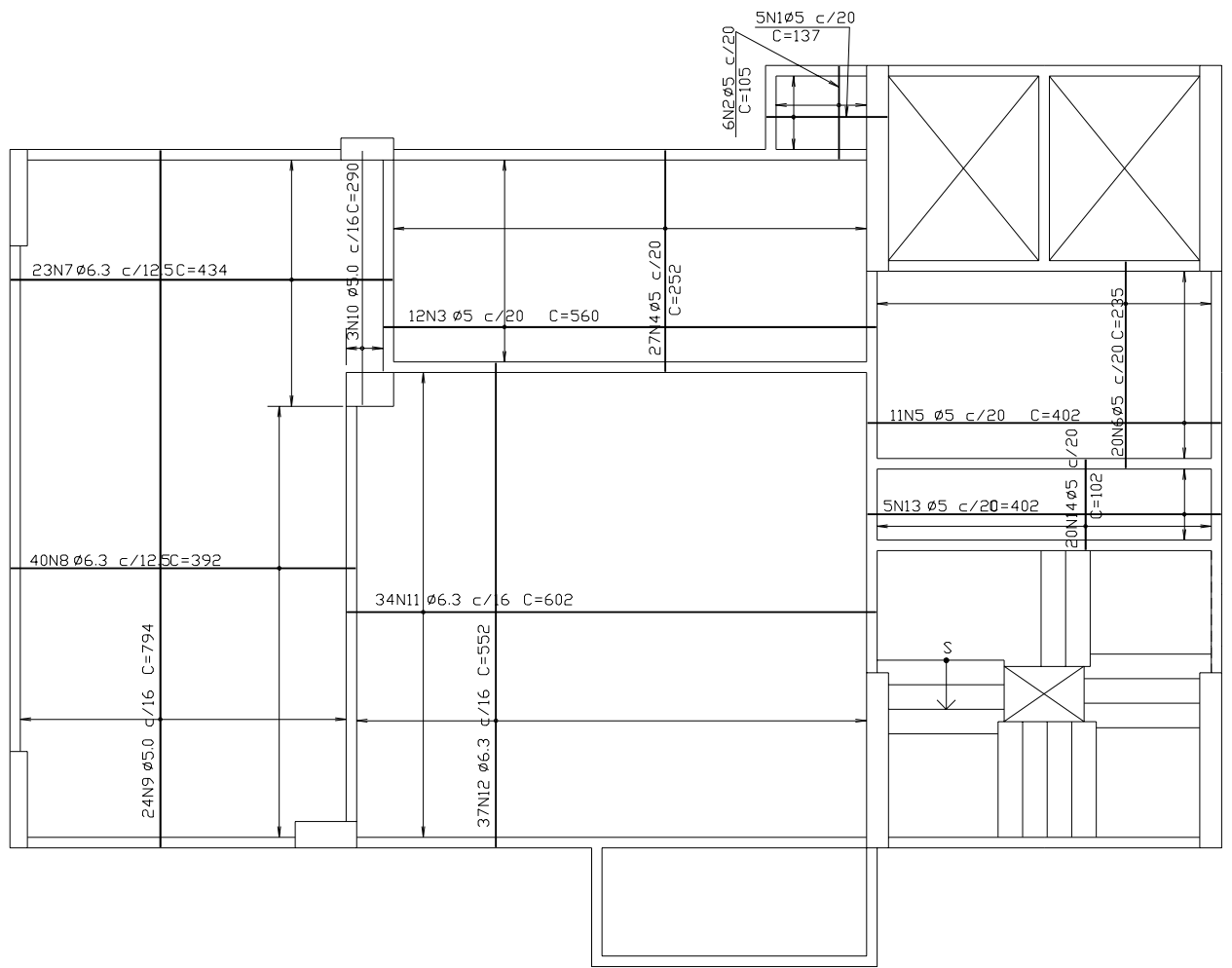

FIGURA 5.7 - Detalhamento das armaduras positivas - método das charneiras pláticas

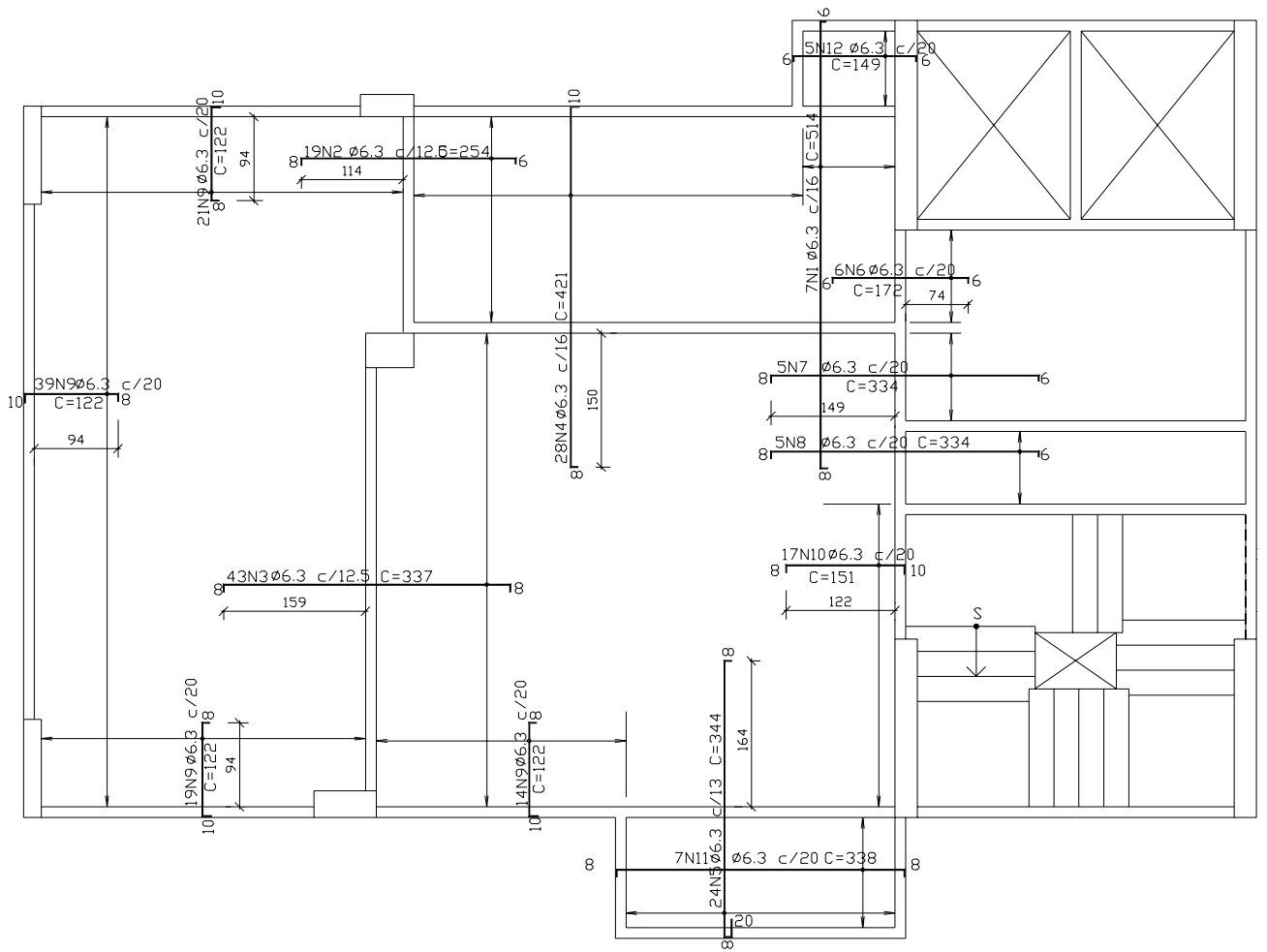

FIGURA 5.8 - Detalhamento das armaduras negativas - método das charneiras plásticas 


\subsubsection{Cálculo por Elementos Finitos (sem Mxy)}

Modelou-se o pavimento anterior em elementos finitos, adotando um valor para G próximo de zero para desconsiderar a contribuição de Mxy e forçar o comportamento da laje como o de uma placa composta de faixas ortogonais fletidas.

Depois de calculados os esforços, foram traçadas curvas com os valores de Mx, My, das áreas de armaduras em $\mathrm{X}$ e $\mathrm{Y}$ e dos deslocamentos verticais do pavimento. A partir destas curvas, mostradas no anexo $\mathrm{C}$, foram detalhadas as armaduras.

Foram utilizados os critérios de detalhamento anteriores, porém ancorando as armaduras negativa no ponto de momento nulo dado pelas curvas de isovalor (deslocado de al), e não a distância de 0,25 × o maior dos menores vãos.

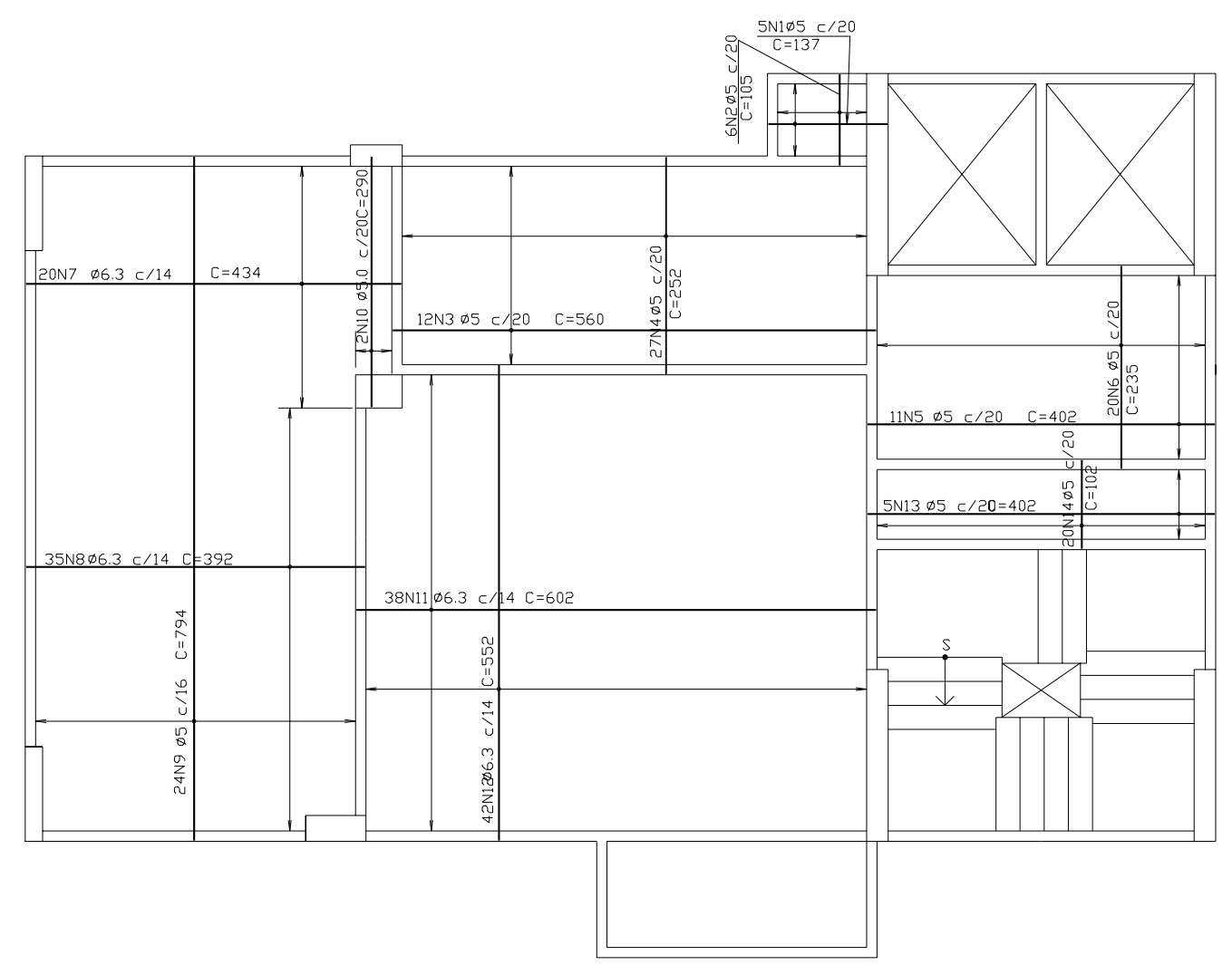

FIGURA 5.9 - Detalhamento das armaduras positivas - MEF sem Mxy 


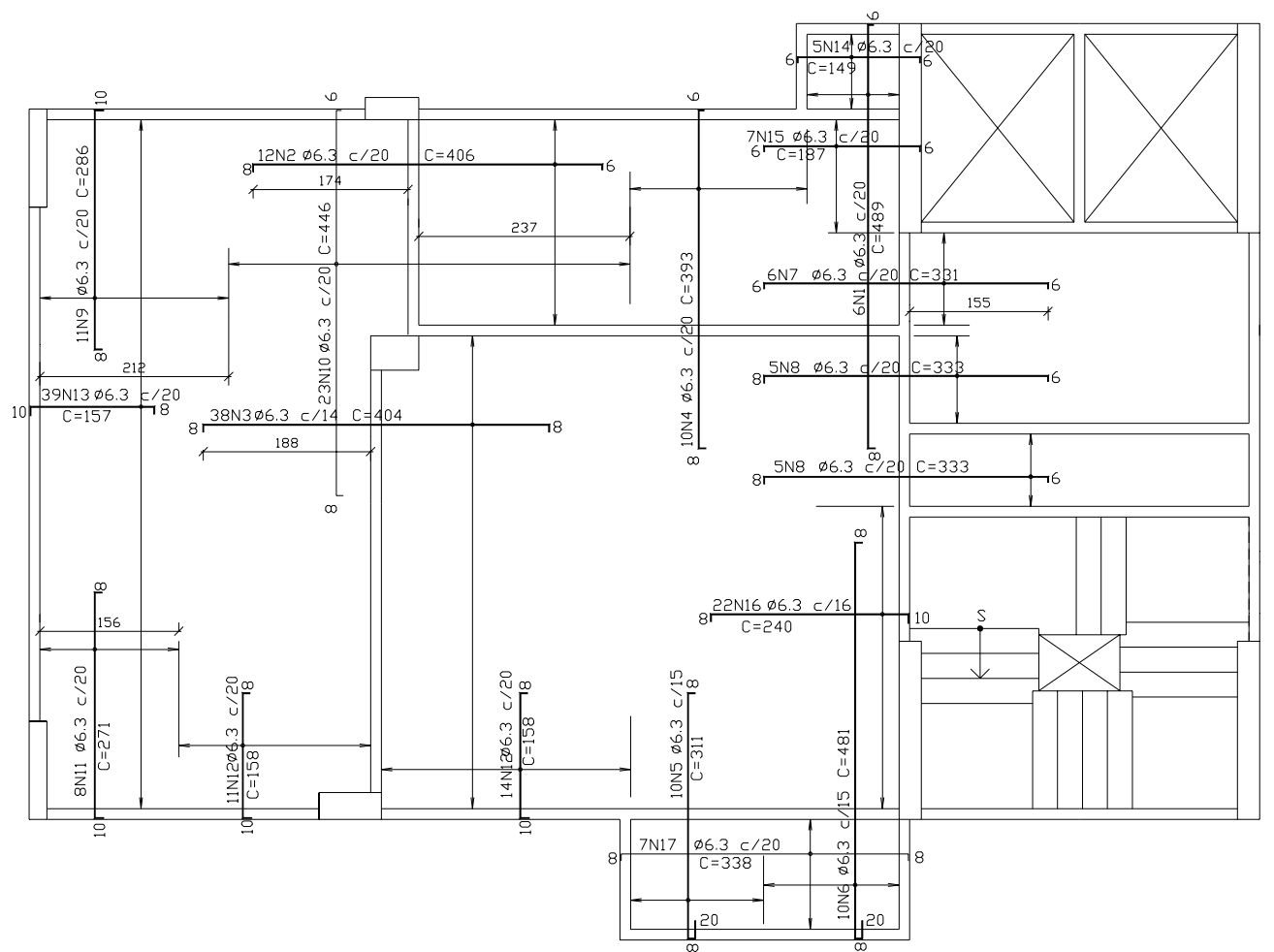

FIGURA 5.10 - Detalhamento das armaduras negativas - MEF sem Mxy

\subsubsection{Cálculo por Elementos Finitos (considerando Mxy)}

Utilizando o modelo anterior, os esforços do pavimento foram recalculados, considerando a rigidez a torção das lajes.

Foram traçadas curvas com os valores de $M x, M y, M x y, M^{*} x$ e $M^{*} y$ positivos e negativos, das áreas de armaduras segundo as direções $X$ e $Y$, positivas e negativas e dos deslocamentos. Estas curvas são mostradas no anexo D.

As figuras a seguir mostram os detalhamentos, feitos a partir das curvas de armaduras, considerando a contribuição do concreto ao Mxy. 


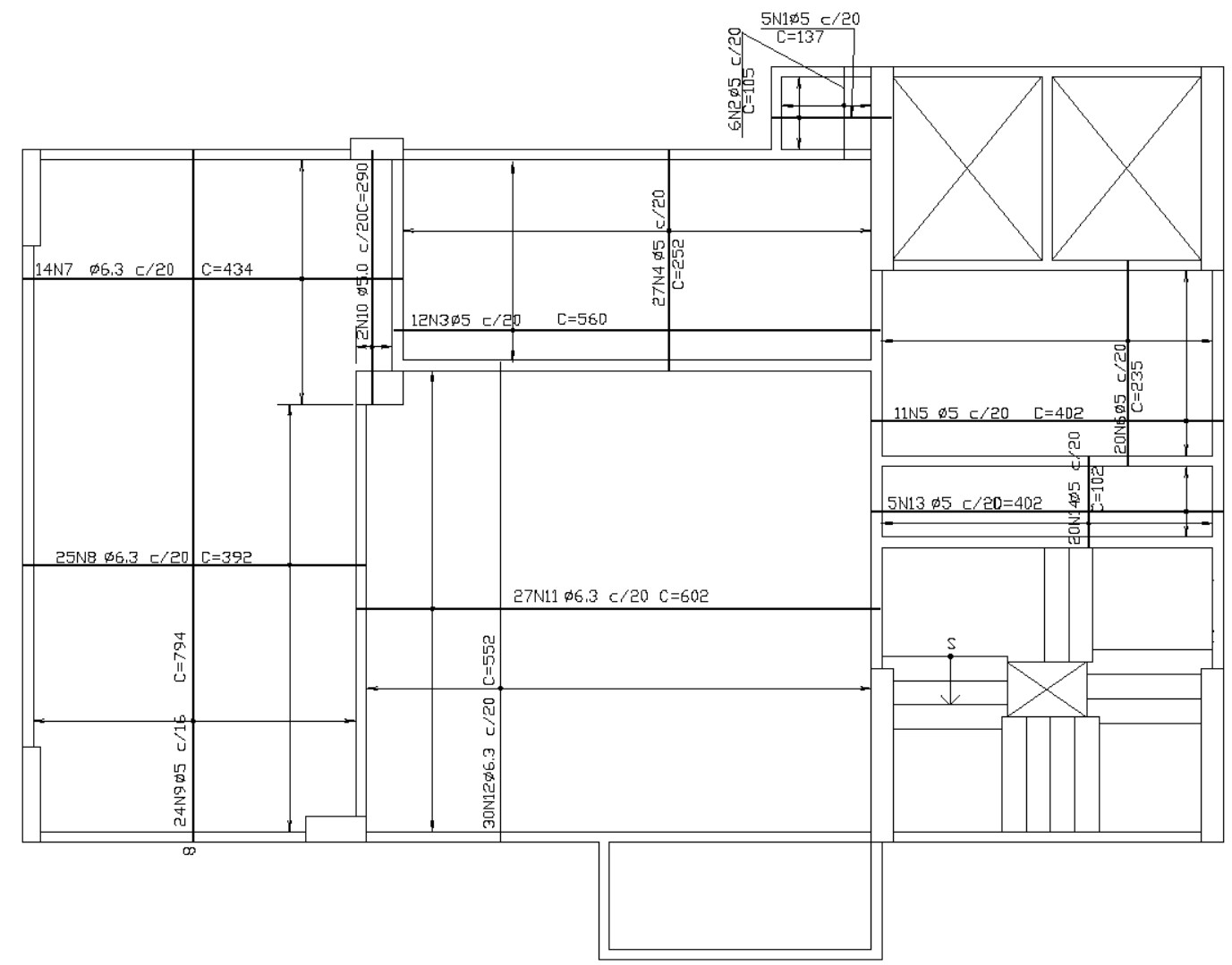

FIGURA 5.11 - Detalhamento das armaduras positivas - MEF com Mxy 


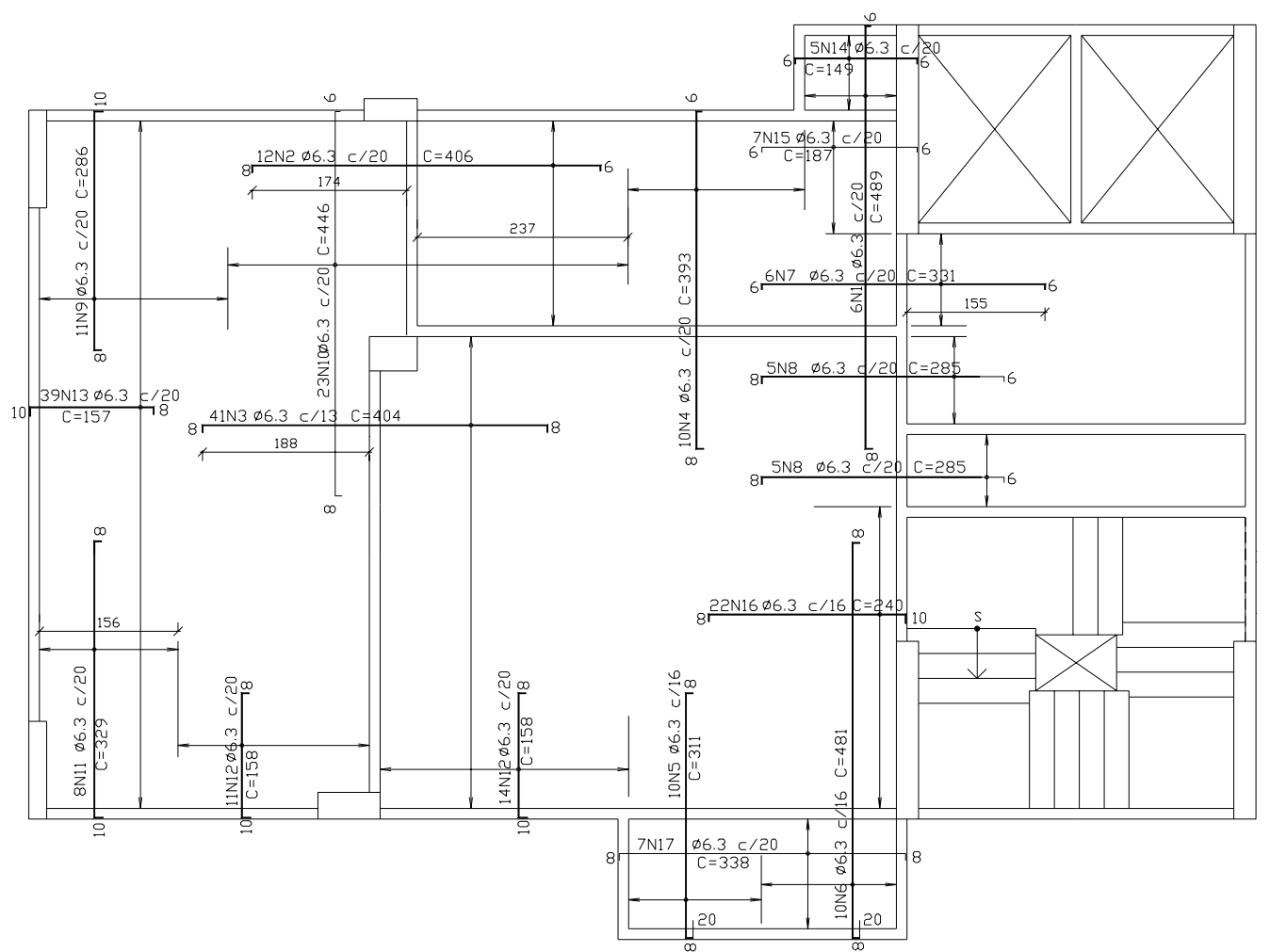

FIGURA 5.12 - Detalhamento das armaduras negativas - MEF com Mxy

\subsubsection{Consumos de Aço}

Para avaliar a eficiência do cálculo considerando-se o momento volvente, foram comparados os consumos de aço, de acordo com cada detalhamento feito. As tabelas a seguir mostram esses consumos. 
TABELA 5.12 - Lista de armaduras - método das charneiras plásticas

\begin{tabular}{|c|c|c|c|c|c|c|c|c|c|}
\hline \multicolumn{5}{|c|}{ Armaduras Positivas } & \multicolumn{5}{|c|}{ Armaduras Neqativas } \\
\hline POS & $\varnothing$ & QUANT & $\begin{array}{l}\text { COMP. } \\
\text { UNIT. }\end{array}$ & $\begin{array}{l}\text { COMP. } \\
\text { TOTAL }\end{array}$ & POS & $\varnothing$ & QUANT & $\begin{array}{l}\text { COMP. } \\
\text { UNIT. }\end{array}$ & $\begin{array}{l}\text { COMP. } \\
\text { TOTAL }\end{array}$ \\
\hline 1 & 5 & 5 & 137 & 685 & 1 & 6,3 & 7 & 514 & 3598 \\
\hline 2 & 5 & 6 & 105 & 630 & 2 & 6,3 & 19 & 254 & 4826 \\
\hline 3 & 5 & 12 & 560 & 6720 & 3 & 6,3 & 43 & 337 & 14491 \\
\hline 4 & 5 & 27 & 252 & 6804 & 4 & 6,3 & 28 & 421 & 11788 \\
\hline 5 & 5 & 11 & 402 & 4422 & 5 & 6,3 & 24 & 344 & 8256 \\
\hline 6 & 5 & 20 & 235 & 4700 & 6 & 6,3 & 6 & 172 & 1032 \\
\hline 7 & 6,3 & 23 & 434 & 9982 & 7 & 6,3 & 5 & 334 & 1670 \\
\hline 8 & 6,3 & 40 & 392 & 15680 & 8 & 6,3 & 5 & 334 & 1670 \\
\hline 9 & 5 & 24 & 794 & 19056 & 9 & 6,3 & 93 & 122 & 11346 \\
\hline 10 & 5 & 3 & 290 & 870 & 10 & 6,3 & 17 & 151 & 2567 \\
\hline 11 & 6,3 & 34 & 602 & 20468 & 11 & 6,3 & 7 & 338 & 2366 \\
\hline 12 & 6,3 & 37 & 552 & 20424 & 12 & 6,3 & 5 & 149 & 745 \\
\hline 13 & 5 & 5 & 402 & 2010 & & & & & \\
\hline 14 & 5 & 20 & 102 & 2040 & & & & & \\
\hline
\end{tabular}

TABELA 5.13 - Lista de armaduras - MEF sem Mxy

\begin{tabular}{|c|c|c|c|c|c|c|c|c|c|}
\hline \multicolumn{5}{|c|}{ Armaduras Positivas } & \multicolumn{5}{|c|}{ Armaduras Neqativas } \\
\hline POS & ø & QUANT & $\begin{array}{l}\text { COMP. } \\
\text { UNIT. }\end{array}$ & $\begin{array}{l}\text { COMP. } \\
\text { TOTAL }\end{array}$ & POS & $\varnothing$ & QUANT & $\begin{array}{l}\text { COMP. } \\
\text { UNIT. }\end{array}$ & $\begin{array}{l}\text { COMP. } \\
\text { TOTAL }\end{array}$ \\
\hline 1 & 5 & 5 & $\begin{array}{r}137 \\
\end{array}$ & 685 & 1 & 6,3 & 6 & 489 & 2934 \\
\hline 2 & 5 & 6 & 105 & 630 & 2 & 6,3 & 12 & 406 & 4872 \\
\hline 3 & 5 & 12 & 560 & 6720 & 3 & 6,3 & 38 & 404 & 15352 \\
\hline 4 & 5 & 27 & 252 & 6804 & 4 & 6,3 & 10 & 393 & 3930 \\
\hline 5 & 5 & 11 & 402 & 4422 & 5 & 6,3 & 10 & 311 & 3110 \\
\hline 6 & 5 & 20 & 235 & 4700 & 6 & 6,3 & 10 & 481 & 4810 \\
\hline 7 & 6,3 & 20 & 434 & 8680 & 7 & 6,3 & 6 & 331 & 1986 \\
\hline 8 & 6,3 & 35 & 392 & 13720 & 8 & 6,3 & 10 & 333 & 3330 \\
\hline 9 & 5 & 24 & 794 & 19056 & 9 & 6,3 & 11 & 286 & 3146 \\
\hline 10 & 5 & 2 & 290 & 580 & 10 & 6,3 & 23 & 446 & 10258 \\
\hline 11 & 6,3 & 38 & 602 & 22876 & 11 & 6,3 & 8 & 271 & 2168 \\
\hline 12 & 6,3 & 42 & 552 & 23184 & 12 & 6,3 & 25 & 158 & 3950 \\
\hline 13 & 5 & 5 & 402 & 2010 & 13 & 6,3 & 39 & 157 & 6123 \\
\hline \multirow[t]{4}{*}{14} & 5 & 20 & 102 & 2040 & 14 & 6,3 & 5 & 149 & 745 \\
\hline & & & & & 15 & 6,3 & 7 & 187 & 1309 \\
\hline & & & & & 16 & 6,3 & 22 & 240 & 5280 \\
\hline & & & & & 17 & 6,3 & 7 & 338 & 2366 \\
\hline
\end{tabular}


TABELA 5.14 - Lista de armaduras - MEF com Mxy

\begin{tabular}{|c|c|c|c|c|c|c|c|c|c|}
\hline \multicolumn{5}{|c|}{ Armaduras Positivas } & \multicolumn{5}{|c|}{ Armaduras Neqativas } \\
\hline POS & $\varnothing$ & QUANT & $\begin{array}{l}\text { COMP. } \\
\text { UNIT. }\end{array}$ & $\begin{array}{l}\text { COMP. } \\
\text { TOTAL }\end{array}$ & POS & $\varnothing$ & QUANT & $\begin{array}{l}\text { COMP. } \\
\text { UNIT. }\end{array}$ & $\begin{array}{l}\text { COMP. } \\
\text { TOTAL }\end{array}$ \\
\hline 1 & 5 & 5 & 137 & 685 & 1 & 6,3 & 6 & 489 & 2934 \\
\hline 2 & 5 & 6 & 105 & 630 & 2 & 6,3 & 12 & 406 & 4872 \\
\hline 3 & 5 & 12 & 560 & 6720 & 3 & 6,3 & 41 & 404 & 16564 \\
\hline 4 & 5 & 27 & 252 & 6804 & 4 & 6,3 & 10 & 393 & 3930 \\
\hline 5 & 5 & 11 & 402 & 4422 & 5 & 6,3 & 10 & 311 & 3110 \\
\hline 6 & 5 & 20 & 235 & 4700 & 6 & 6,3 & 10 & 481 & 4810 \\
\hline 7 & 6,3 & 14 & 434 & 6076 & 7 & 6,3 & 6 & 331 & 1986 \\
\hline 8 & 6,3 & 25 & 392 & 9800 & 8 & 6,3 & 10 & 285 & 2850 \\
\hline 9 & 5 & 24 & 794 & 19056 & 9 & 6,3 & 11 & 286 & 3146 \\
\hline 10 & 5 & 2 & 290 & 580 & 10 & 6,3 & 23 & 446 & 10258 \\
\hline 11 & 6,3 & 27 & 602 & 16254 & 11 & 6,3 & 8 & 329 & 2632 \\
\hline 12 & \begin{tabular}{|l|}
6,3 \\
\end{tabular} & 30 & 552 & 16560 & 12 & 6,3 & 25 & 158 & 3950 \\
\hline 13 & 5 & 5 & 402 & 2010 & 13 & 6,3 & 39 & 157 & 6123 \\
\hline 14 & 5 & 20 & 102 & 2040 & 14 & 6,3 & 5 & 149 & 745 \\
\hline & & & & & 15 & 6,3 & 7 & 187 & 1309 \\
\hline & & & & & 16 & 6,3 & 22 & 240 & 5280 \\
\hline & & & & & 17 & 6,3 & 7 & 338 & 2366 \\
\hline
\end{tabular}

Comparando-se os consumos de aço, percebe-se que o total para o MEF com Mxy é $4 \%$ menor que o total do método das charneiras plásticas e $11 \%$ menor que o total para o MEF sem Mxy. A tabela e o gráfico a seguir mostram a comparação dos consumos totais.

TABELA 5.15 - Consumos de aço $(\mathrm{kg})$

\begin{tabular}{|c|c|c|c|}
\hline & Charneiras & E.F. s/ Mxy & E.F. c/ Mxy \\
\hline As positiva & 243 & 247 & 198 \\
\hline As negativa & 164 & 189 & 192 \\
\hline & & & \\
\hline Total & 404 & 436 & 390 \\
\hline $\begin{array}{c}\text { Comparação } \\
\text { com o método } \\
\text { de charneiras }\end{array}$ & $\mathbf{1 0 0 \%}$ & $\mathbf{1 0 8 \%}$ & $\mathbf{9 6 \%}$ \\
\hline
\end{tabular}




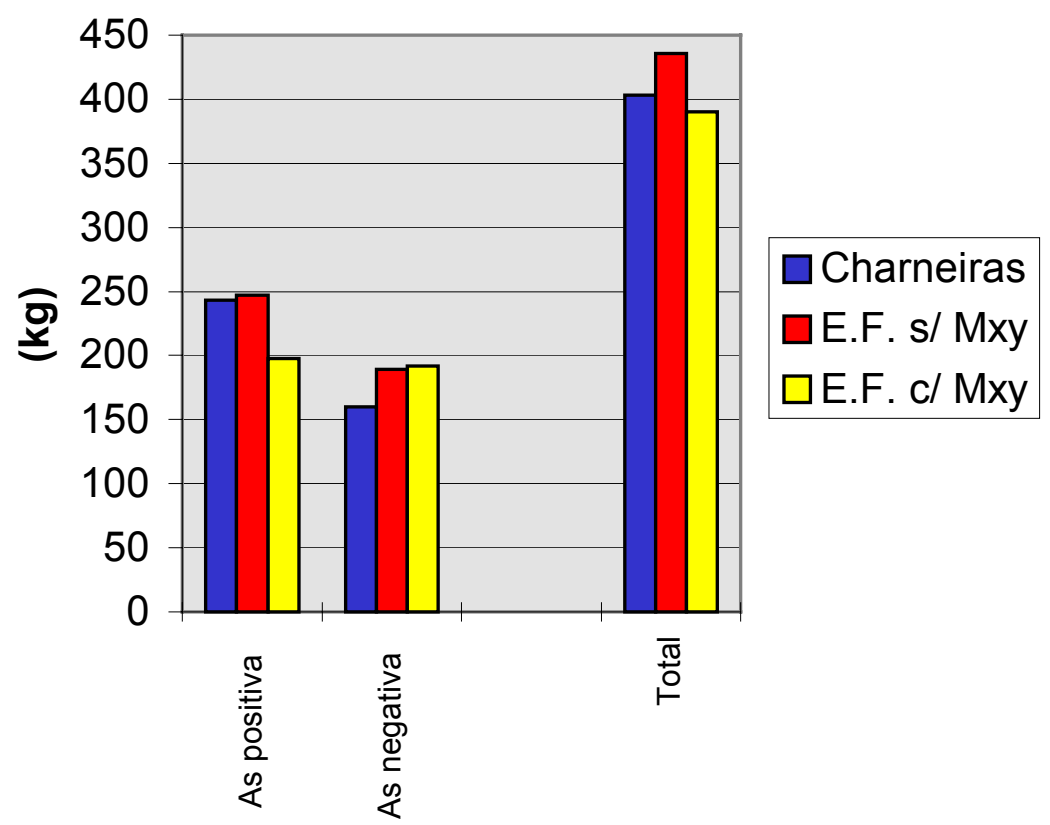

FIGURA 5.13 - Comparação dos consumos de aço

\subsubsection{Análise dos Resultados}

Analisando os detalhamentos das armaduras positivas pode-se perceber que, para lajes de pequena dimensão, o tipo de processamento pouco influencia nos resultados finais. Para lajes de maior dimensão, podese observar uma diminuição na quantidade de armadura necessária para resistir aos esforços na comparação dos resultados do cálculo feito pelo MEF considerando Mxy (1), com o método das charneiras plásticas (2) e com o MEF sem a consideração de Mxy (3).

A área de armadura positiva necessária para resistir aos esforços na L6 (de dimensão 4,00m x 7,85m) foi reduzida em 32\% na menor dimensão, quando comparado o método (1) com o método (2). Na comparação do método (1) com o método (3), obteve-se uma redução de $29 \%$ na menor dimensão. Na maior dimensão os resultados dos três métodos foram iguais (armadura mínima). Na laje L7 (5,51m x 5,43m), obteve-se a uma redução 
de $28 \%$ na comparação do método (1) com o método (3) e de $20 \%$ na comparação do método (1) com o método (2).

Analisando-se os detalhamentos negativos, percebe-se que as armaduras negativas entre duas lajes detalhadas pelos métodos (1) e (3) possuem, de uma maneira geral, áreas de aço menores e comprimentos de barras maiores, em comparação com o método (2).

Entre as lajes L3/L7 e entre L7/L11 o consumo de aço dos métodos (1) e (3) são iguais e cerca de $20 \%$ menores que o consumo do método (2). Entre as lajes L3/L6, L7/L4 e L7/L8, os consumos são praticamente iguais.

Comparando-se as armaduras entre as lajes L6/L7, calculadas pelos métodos (1) e (3), percebe-se que os comprimentos das barras são iguais, porém as áreas de armaduras do método (1) resultaram $7 \%$ menores que as áreas do método (3). Entre essas mesmas lajes, obtém-se uma economia de $12 \%$ na comparação do consumo de aço do método (1) com o método (2).

Entre as lajes L3/L4 verifica-se que as áreas de armaduras indicadas pelos três métodos são iguais, porém o comprimento das barras dos métodos (1) e (3) são cerca de $92 \%$ maiores que do método (2). Como o comprimento das barras é calculado de maneira aproximada no método (2), este é menos confiável que os comprimentos obtidos nos métodos (1) e (3).

Nas vigas de borda, foram dispostas, para o método (2), as armaduras prescritas no texto provisório da NB1 (1993). Nos métodos (1) e (3), os resultados indicam a necessidade de armaduras negativas nestas posições. Estas foram sempre maiores do que o mínimo indicado no referido texto.

No cálculo pelo MEF é considerada a interação entre as lajes e os pilares. Desta forma, a distribuição de momentos nas lajes ocorre de maneira diferente do que é suposto em cálculos aproximados com lajes analisadas individualmente, aparecendo momentos negativos altos próximos aos pilares e havendo uma diminuição dos momentos em outras regiões. Este fato explica a redução de momentos na parte interna do pavimento e o 
aumento das armaduras sobre as vigas de borda, na comparação dos métodos (1) e (3) com o método (2).

No método das charneiras plásticas, os momentos negativos entre duas lajes são compatibilizados de maneira aproximada, enquanto que no MEF estes momentos são compatibilizados automaticamente durante o processamento. Desta forma, é esperado que os momentos negativos calculados pelo método (2) sejam maiores que os calculados pelos métodos (1) e (3).

Examinando os resultados finais, percebe-se que o consumo de aço total do métodos (1) é menor que o do método (3). O cálculo pelo método das charneiras plásticas já tem alguma tradição nos projetos de concreto armado, tendo sido bastante estudado nos últimos tempos. $O$ fato desses consumos terem sido bastante próximos, indica que o método proposto é eficiente para o cálculo de lajes de pavimentos. Além disto, no método (1) são levadas em conta as interações existentes entre as lajes, vigas e pilares do pavimento, o que não ocorre no método (3). Esta diferença pode ser sentida na distribuição dos esforços que, além de levar a distribuições distintas de momentos nas lajes, poderá trazer vantagens no dimensionamento das vigas, pois o carregamento destas ocorrerá de maneira não uniforme, havendo uma tendência de diminuição dos momentos nas vigas.

Outra vantagem do MEF sobre o método das charneiras plásticas é o fato de ser possível posicionar de maneira precisa as cargas de parede, o que torna o cálculo mais rigoroso. $\mathrm{O}$ menor consumo de aço obtido no método (3) em comparação com o método (2), pode ser explicado, em parte, pelo fato das cargas de parede terem sido consideradas (de maneira aproximada) como cargas distribuídas no método (3), enquanto que no método (2) essas são consideradas (de maneira mais rigorosa) como linhas de cargas concentradas.

Além disso, os resultados do MEF representam melhor o comportamento conjunto dos elementos estruturais que compõem o 
pavimento, o que possibilita que os comprimentos e posições das barras das armaduras sejam melhor definidos. Comparando-se os resultados do método (2) com o método (3), pode-se perceber que, em geral, as áreas das armaduras necessárias são menores, porém os comprimentos são maiores. Pode-se perceber, também, posições de armaduras existentes no método (2) que não são definidas no método (3), especialmente em regiões próximas a pilares.

O consumo de aço total do método (1) foi cerca de $10 \%$ menor que no método (2). Além disto, houve uma redução de cerca de $21 \%$ no valor da flecha do pavimento calculada pelo método (1) em comparação à flecha calculada pelo método (2). Essas reduções eram esperadas, pois estão sendo consideradas, de maneira criteriosa, a rigidez a torção das lajes no cálculo dos esforços e a resistência do concreto às tensões cisalhantes no detalhamento das armaduras.

Outra vantagem que a utilização do método (1) traz ao cálculo de pavimentos de concreto armado, é o fato de serem indicadas as regiões onde serão necessárias armaduras devidas à presença de momentos volventes significativos. 


\section{CONCLUSÃO}

Para o cálculo de lajes de concreto armado, principalmente com a utilização do auxílio de microcomputadores para o cálculo, é importante que se conheçam os métodos de detalhamento das armaduras em direções diferentes das direções principais dos esforços.

No presente trabalho, foram estudados dois métodos de cálculo de momentos equivalentes a duas direções diferentes das principais: o método de Wood e o método de Leonhardt \& Mönnig.

Conforme descrito no segundo capítulo deste trabalho, chegou-se à conclusão que o método de Wood e o método de Leonhardt \& Mönnig são equivalentes, sendo o primeiro uma aproximação numérica para o problema e o segundo uma aproximação física.

O método de Wood parte do princípio de que deve haver um equilíbrio entre os momentos normais aplicados e resistentes da laje segundo um plano crítico qualquer. No método de Leonhardt \& Mönnig é feito o equilíbrio dos esforços aplicados e resistentes da laje segundo uma direção admitida fissurada. As equações finais resultantes dos dois métodos são equivalentes.

Buscando uma maior economia no projeto de lajes de concreto armado, procurou-se considerar a resistência do concreto ao momento volvente, determinando um critério para cálculo desta resistência. As tensões cisalhantes produzidas pelo momento volvente, combinadas com as tensões cisalhantes devidas à força cortante, devem ser menores que as tensões cisalhantes resistidas pelo concreto. No capítulo 3 são relatadas as considerações de como deve ser feita esta verificação. 
A norma brasileira de concreto determina o valor de $\tau_{\text {wu1 }}$ como sendo a tensão de referência para a resistência do concreto às tensões cisalhantes devidas à força cortante em lajes, porém não traz nenhuma recomendação de como calcular a resistência do concreto às tensões cisalhantes devidas ao momento volvente.

Analisando-se a bibliografia específica, na qual são relatados vários ensaios práticos, chegou-se à conclusão que o valor de $\tau_{\text {wu1 }}$ é menor que o valor das tensões cisalhantes correspondentes ao Mxy resistidas pelo concreto. Procurando ficar o mais próximo possível das recomendações da norma brasileira, foi adotado, neste trabalho, o valor de $\tau_{\text {wu1 }}$ como referência também para a resistência do concreto às tensões cisalhantes devidas ao Mxy, combinadas com as tensões cisalhantes devidas à força cortante. Resultados de ensaios, citados no capítulo 3, confirmam que esta é uma aproximação segura. Um estudo mais detalhado sobre o assunto pode ser tema de trabalho futuro.

A utilização de computadores para o cálculo de pavimentos permite que os modelos de cálculo sejam aprimorados, podendo ser impostas mais variáveis aos procedimentos de cálculo. Para que estes procedimentos de cálculo possuam agilidade e confiabilidade, existe a necessidade de desenvolvimento de ferramentas que facilitem tanto a confecção de modelos matemáticos para o cálculo, quanto a conferência dos modelos criados.

Os programas CADGM e LAJEEF, detalhados no capítulo 4, facilitam o processo de criação e conferência de malhas de pavimento em elementos finitos.

O programa MLAJE é usado como um pós processador que analisa os esforços resultantes do cálculo e, utilizando os conceitos deste trabalho, calcula os momentos equivalentes e as áreas de armaduras necessárias nas lajes do modelo. É um programa relativamente simples, que pode ser facilmente adaptado para outros sistemas de cálculo de pavimentos, de grande possibilidade de aplicação no cálculo de lajes de concreto armado. 
Analisando-se as lajes apoiadas nos quatro lados, cujos modelos e resultados são analisados no capítulo 5 , chega-se à conclusão que a recomendação da norma brasileira (NB1 / 1982) para a armadura de canto ( $50 \%$ da maior área de armadura do vão) não é suficiente para cobrir todos os casos de lajes, sendo mais adequado, na falta de um cálculo mais rigoroso, considerar a área de armadura no canto igual a $75 \%$ da maior área de armadura do vão. Propõe-se que este seja o critério normalizado.

Analisando-se os detalhamentos feitos do pavimento tipo, chega-se à conclusão que a consideração da rigidez a torção e da resistência do concreto ao momento volvente no cálculo de lajes de concreto armado, além de reproduzir melhor a distribuição dos esforços (e conseqüentemente a disposição de armaduras), pode diminuir, de maneira criteriosa e segura, a quantidade de aço necessária para o detalhamento das lajes em comparação com modelagens simplificadas. Além disto pôde-se verificar uma diminuição (de $21 \%$ no pavimento analisado) no valor da flecha devido à consideração da rigidez à torção. 


\section{ANEXOS}

\subsection{Anexo A - Subrotina Para Cálculo dos Momentos Equivalentes}

procedure processar;

var i,j,nc : word; $\{\mathrm{i}, \mathrm{j}$ - variaveis de controle

nc - numero do contorno\}

erro : boolean; \{erro - variavel de controle\}

$\mathrm{mc}, \mathrm{k}$ : real; $\quad\{\mathrm{mc}$ - momento volvente resistido pelo concreto

$\{\mathrm{k}$ - tangente do angulo critico $\}$

mxt,myt,mxyt,vxt,vyt : real; \{esforcos\}

\{ calculo da area de aco\}

function as (m,d:real):real;

var Bx,Bxlim,C,md, $\{\mathrm{Bx}$, Bxlim - valores de Beta $\mathrm{X}\}$

$\{C$ - variavel auxiliar de calculo $\}$

\{md - momento de projeto

delta,a: real;

erroas : boolean; \{variaveis auxiliares\}

$\{\mathrm{cc}$ - parametro para transformar unidades de comprimento em $\mathrm{m}\}$

\{cf - parametro para transformar unidades de forca em MN\}

begin

erroas := false;

$\left\{A=0,68^{*} d^{\wedge} 2^{*} f c d\right\}$

$c:=0.68^{*} \operatorname{sqr}\left(d^{*} \mathrm{cc}\right)^{*} \mathrm{fck}{ }^{*} \mathrm{cf} / \mathrm{cc} / \mathrm{cc} / 1.4$ 


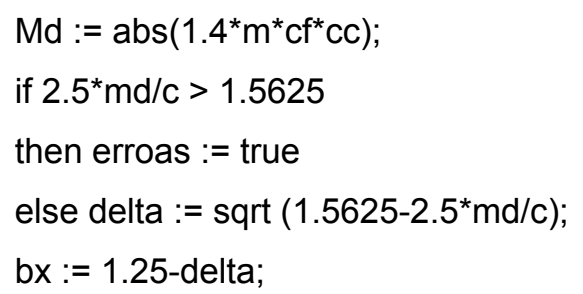

if fyk ${ }^{*} \mathrm{cf} / \mathrm{cc} / \mathrm{cc}>500$ then bxlim $:=0.462$ else bxlim : $=0.628$;

if bx $>$ bxlim

then $\{$ armadura dupla $=>$ erro $\}$ erroas := true

else $a:=c^{*} b x /\left(d^{*} c^{*} f y k / 1.15^{*} \mathrm{cf} / \mathrm{cc} / \mathrm{cc}\right)^{*} 10000$;

if erroas then begin as:=-99999; write (\#7);end

else if $\left(\left(a<12^{*} h[n c]^{*} \mathrm{cc}\right)\right.$ and $\left.(a>0)\right)$

then as: $=12^{*} h[n c]^{*} \mathrm{cc}$ else as:=a;

end;

$\{$ calculo de twu1 [MPa]\}

function twu1(d:real):real;

var t: real;

begin

$t:=\left(0.06^{*} c[n c]+0.08\right)^{*} 1.06^{*}\left(1.6-d^{*} c c\right)^{*} \operatorname{sqrt}\left(f c k^{*} c f / s q r(c c)\right)$;

if $\mathrm{t}>1$ then twu1:=1 else twu1:=t;

end;

\{ calculo de mxy.concreto [unidade utilizada]\}

function mxyc (i:integer;tal:real):real;

var v,m, tv: real;

begin

if vxt > vyt then $v:=1.4^{*} v t^{*} c f$ else $v:=1.4^{*} v y t^{*} c f ;$

tv := sqr (v/(dl[nc $]^{*} \mathrm{cc}^{*}$ tal $\left.)\right)$;

if $((\operatorname{tv}>=1)$ or $(o[n c]=1))$

then $\mathrm{m}:=0$

else $\mathrm{m}:=\operatorname{sqrt}(1-\mathrm{tv})^{*} \mathrm{sqr}\left(\mathrm{h}[\mathrm{nc}]^{*} \mathrm{cc}\right)^{*} \mathrm{tal} / 3$;

$\mathrm{m}:=\mathrm{m} / \mathrm{cc} / \mathrm{cf} / 1.4$

$m x y c:=m$;

end;

begin 
for $i:=1$ to numelem do

begin

\{identificar contorno\}

$\mathrm{nc}:=0$;

erro $:=$ false;

for $\mathrm{j}:=1$ to numcont do

begin

if stat $(\mathrm{j}, \mathrm{i})$ then \{STAT - procedure para identificar se elemento esta

dentro de um contorno\}

begin

if $\mathrm{nc}<>0$ then

\{circulo vermelho identifica mais de 1 contorno\}

begin

erro := true;

setcolor (red);

circulo $\left(\mathrm{xcg}^{\wedge}[\mathrm{i}], \mathrm{ycg}^{\wedge}[\mathrm{i}], 3^{*} \mathrm{dx}\right)$;

end

else $n c:=j$;

end;

end;

if $\mathrm{nc}=0$ then

begin

\{cor amarela -> nenhum contorno foi identificado\}

erro := true;

setcolor (yellow);

circulo $\left(\mathrm{xcg}^{\wedge}[\mathrm{i}], \mathrm{ycg}^{\wedge}[\mathrm{i}], 3^{*} \mathrm{dx}\right)$;

end;

\{calculo do momentos equivalentes\}

if (not erro) then

begin

setcolor (green);

circulo $\left(\mathrm{xcg}^{\wedge}[\mathrm{i}], \mathrm{ycg}^{\wedge}[\mathrm{i}], 3^{*} \mathrm{dx}\right)$;

$m x t:=m x^{\wedge}[i] ;$

myt := my^[i];

$m x y t:=\operatorname{abs}\left(m x y^{\wedge}[i]\right)$; 


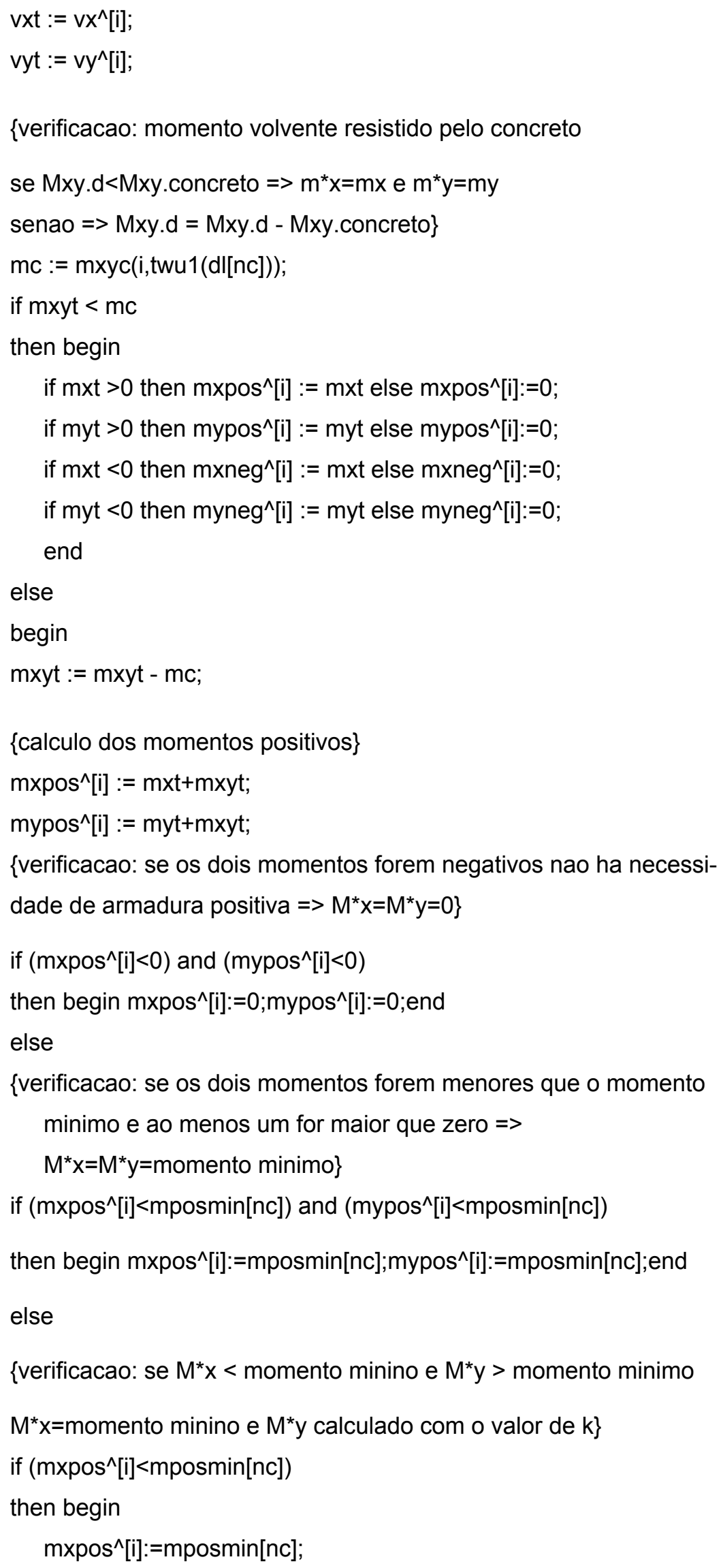




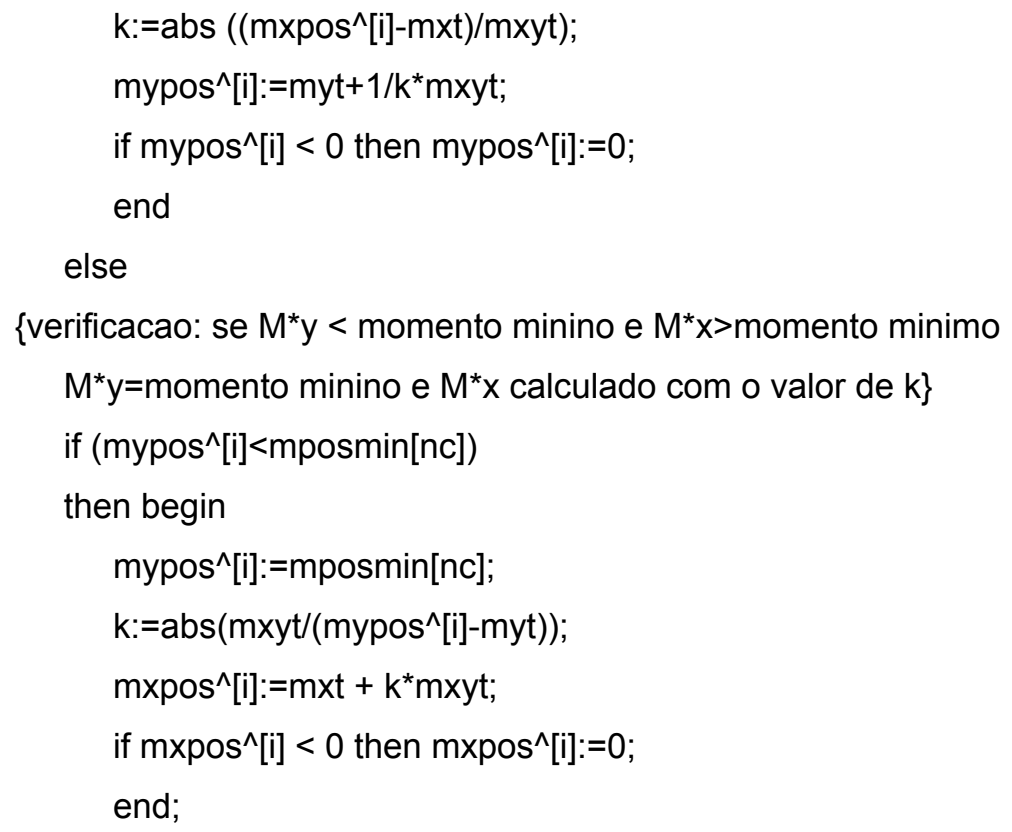




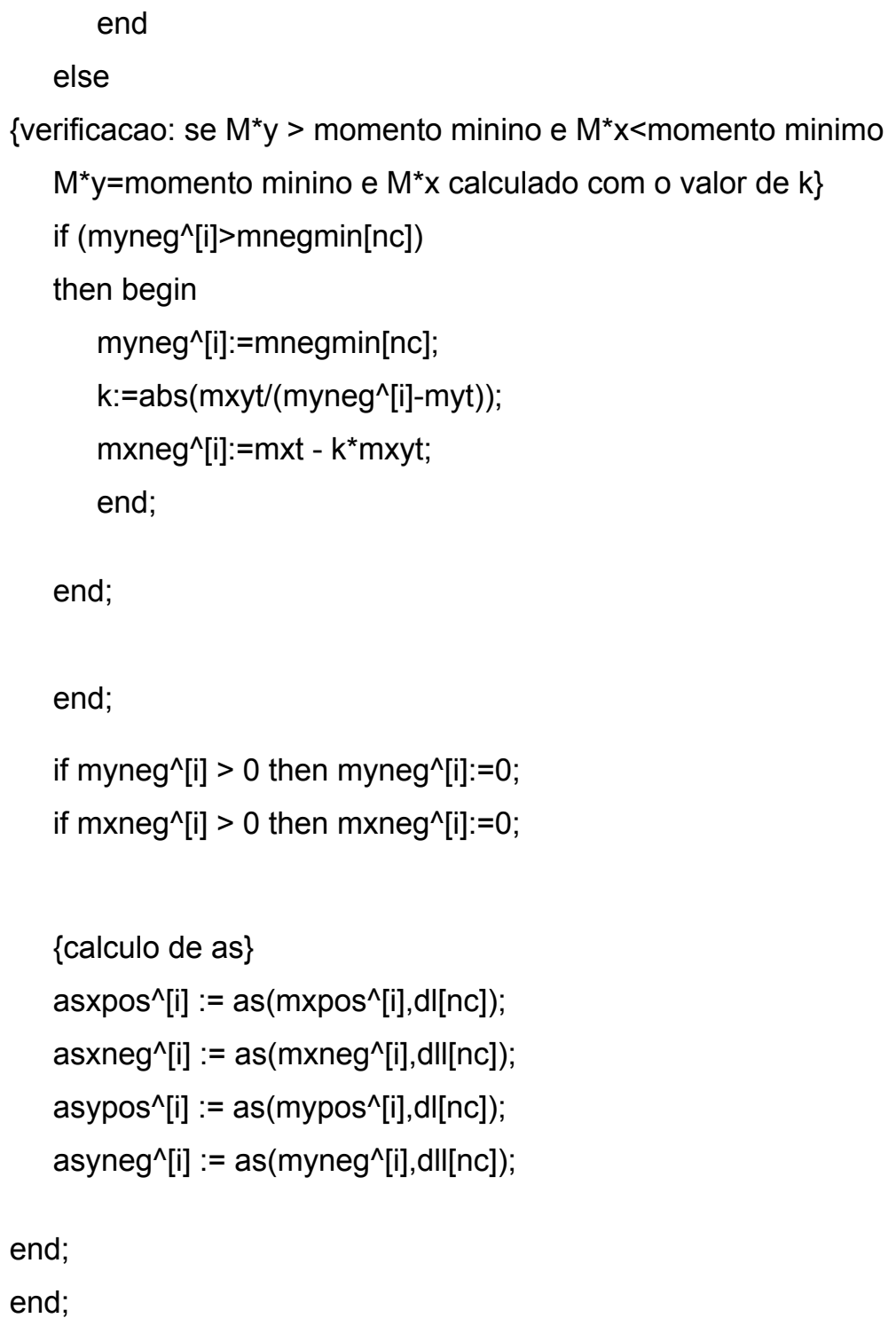


7.2 Anexo B - Curvas de L3 e L3A

\subsubsection{Laje L3}

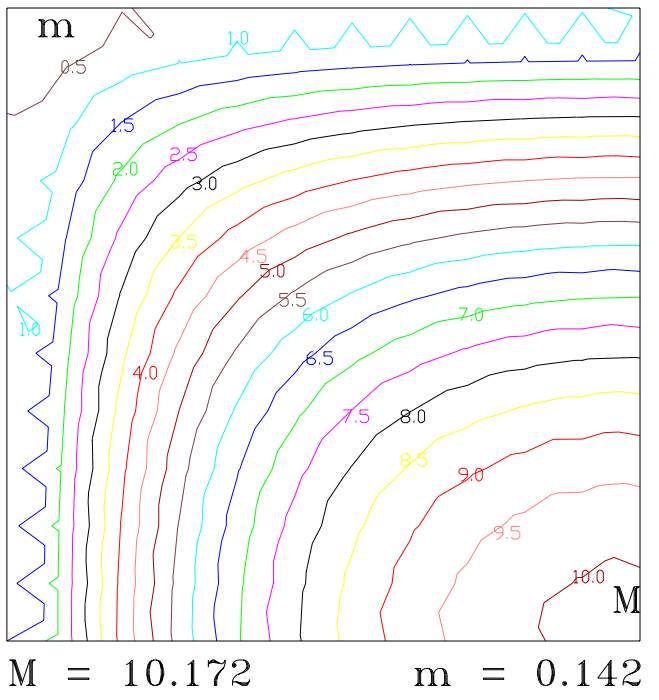

$M x=M y(K N \cdot m / m)$

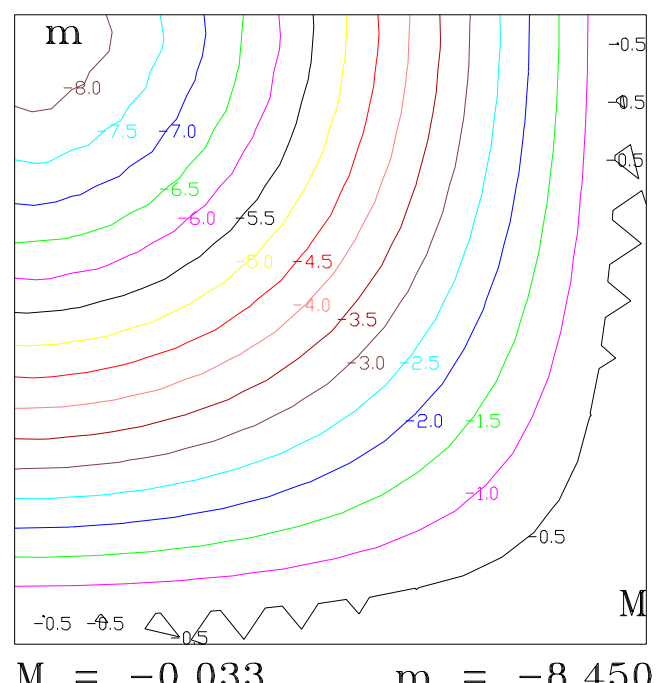

$\operatorname{Mxy}(\mathrm{KN} \cdot \mathrm{m} / \mathrm{m})$

FIGURA 7.1 - Curvas de momentos calculados para L3
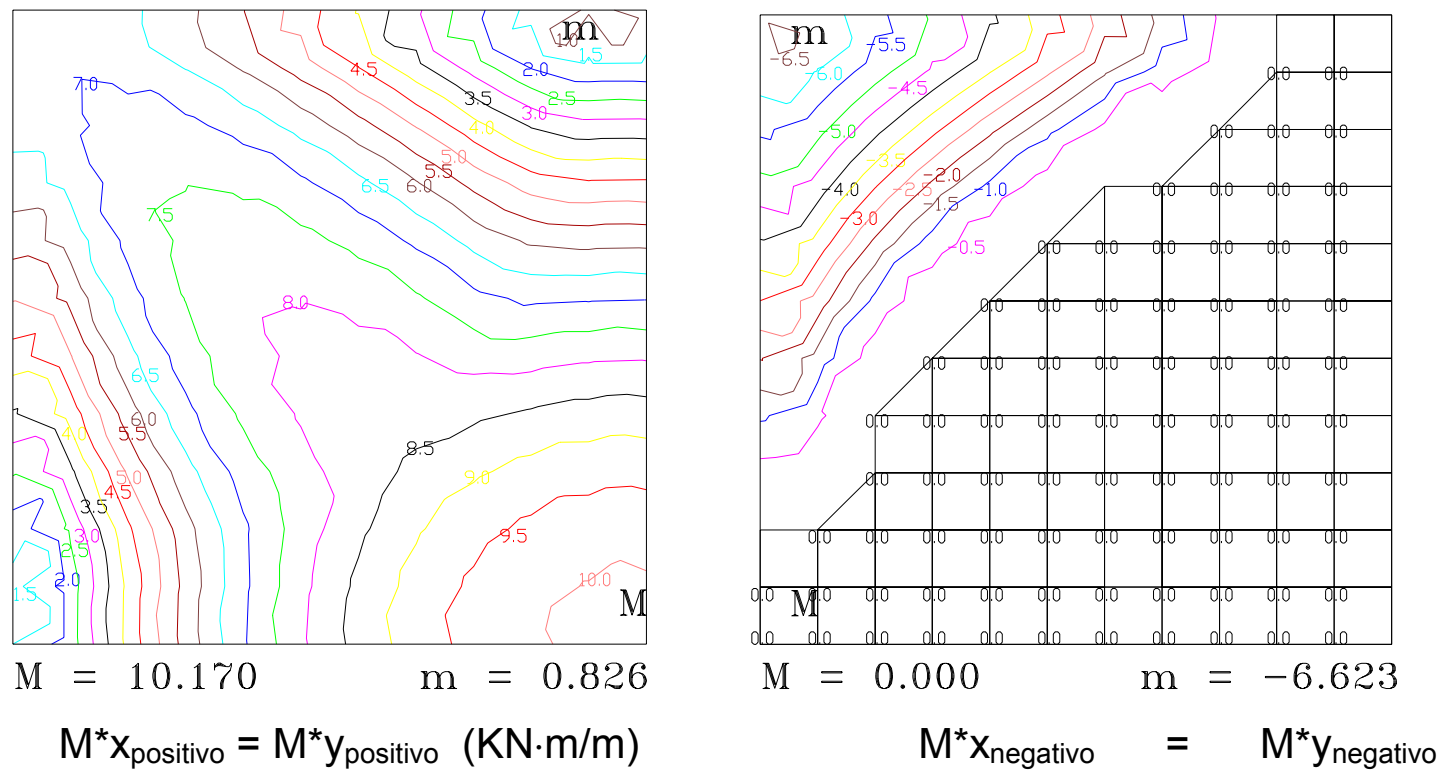

$(\mathrm{KN} \cdot \mathrm{m} / \mathrm{m})$

FIGURA 7.2 - Curvas de momentos equivalentes para L3 

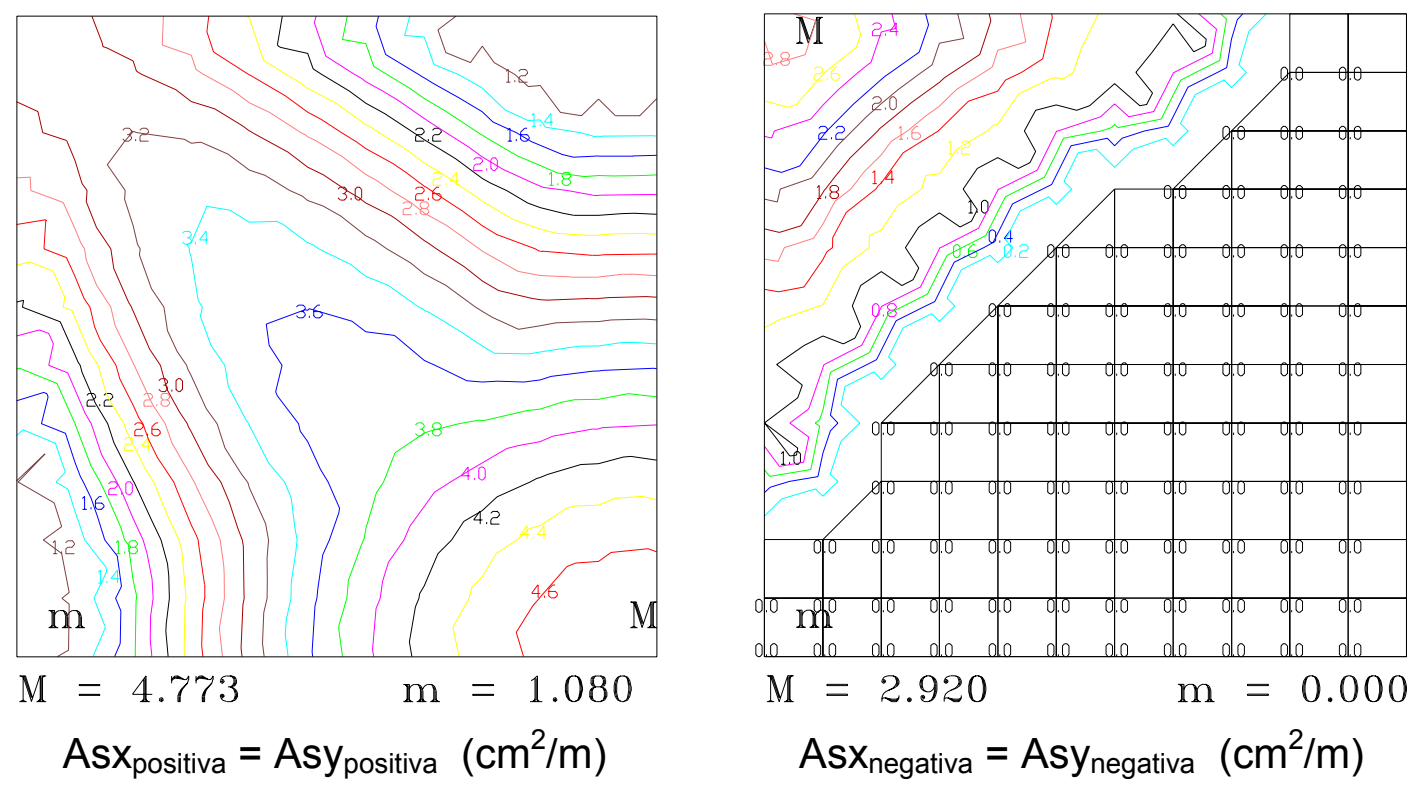

FIGURA 7.3 - Curvas de armaduras calculadas para L3

\subsubsection{Laje L3A}

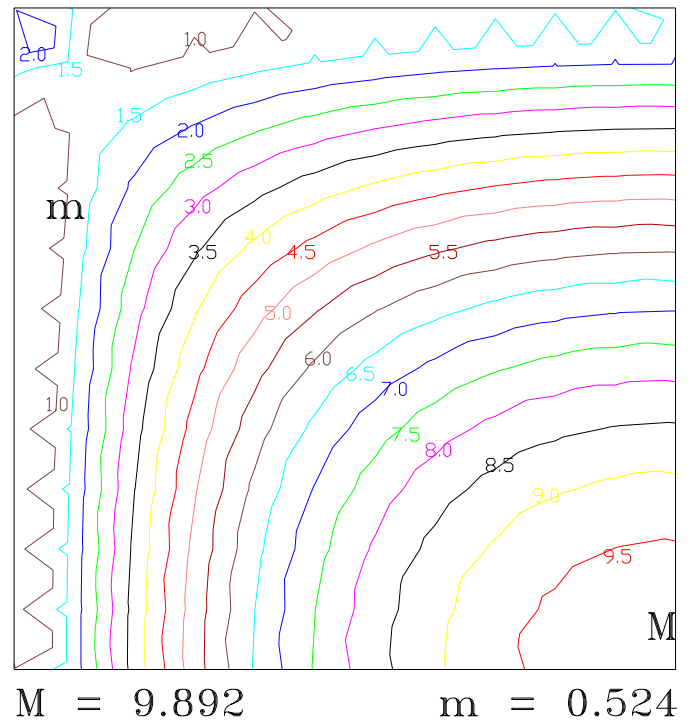

$\mathrm{Mx}=\operatorname{My}(\mathrm{KN} \cdot \mathrm{m} / \mathrm{m})$

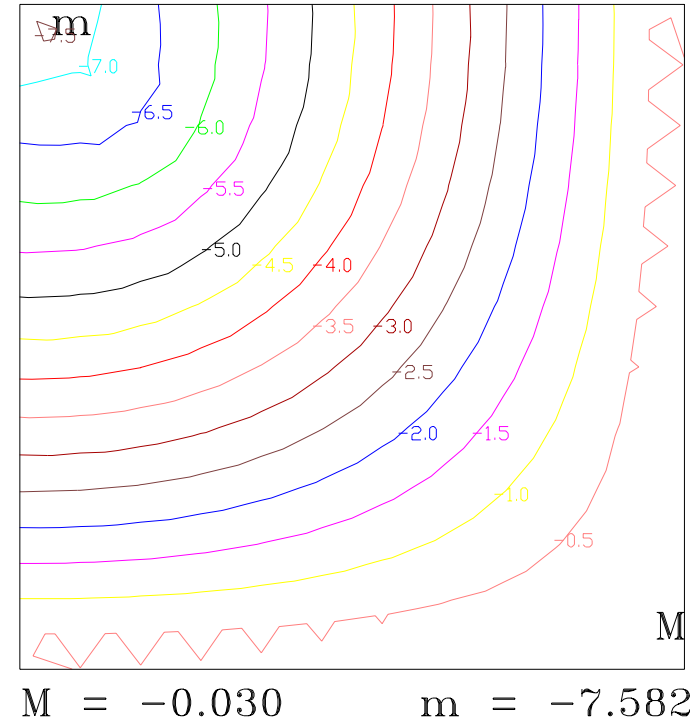

$\operatorname{Mxy}(\mathrm{KN} \cdot \mathrm{m} / \mathrm{m})$

FIGURA 7.4 - Curvas de momentos calculados para L3A 


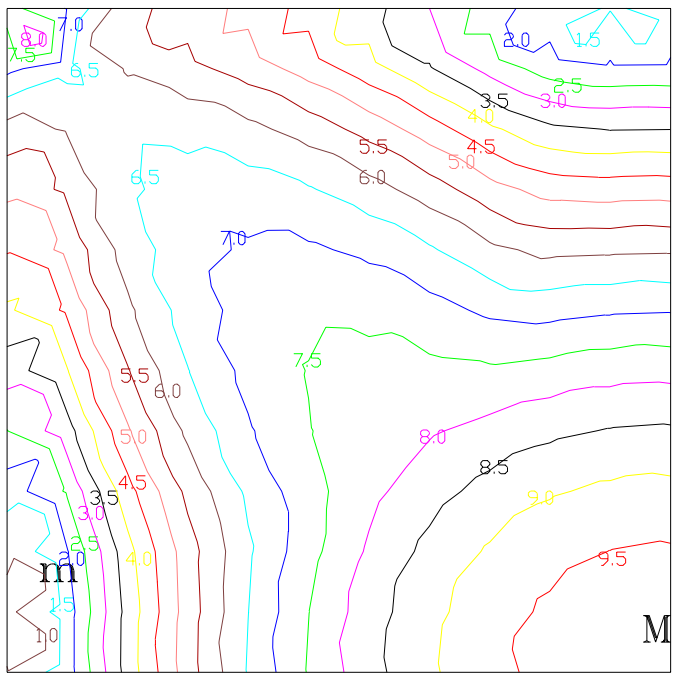

$M=9.892$
0.699

$(\mathrm{KN} \cdot \mathrm{m} / \mathrm{m})$
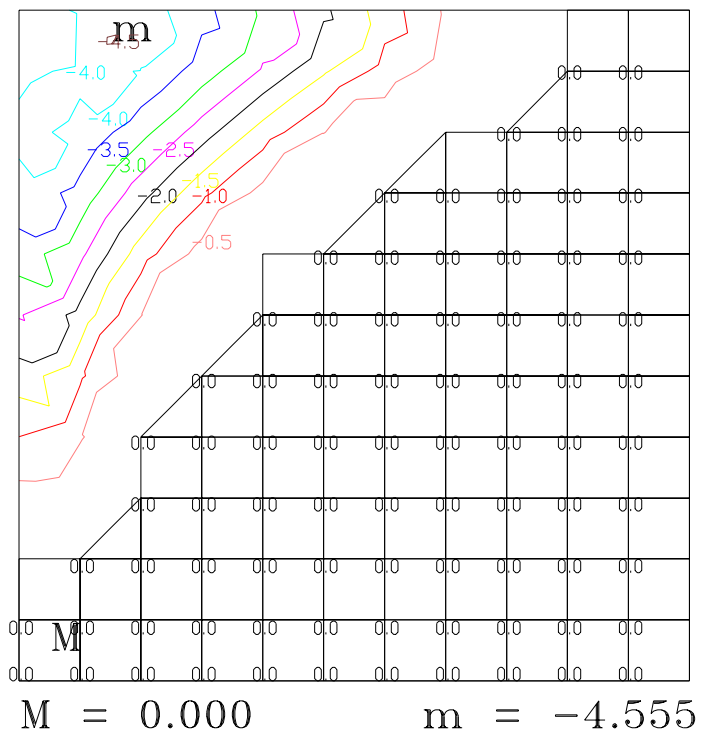

$M^{*} x_{\text {negativo }}=M^{*} y_{\text {negativo }}$

$(\mathrm{KN} \cdot \mathrm{m} / \mathrm{m})$

FIGURA 7.5 - Curvas de momentos equivalentes para L3A considerando Mxy
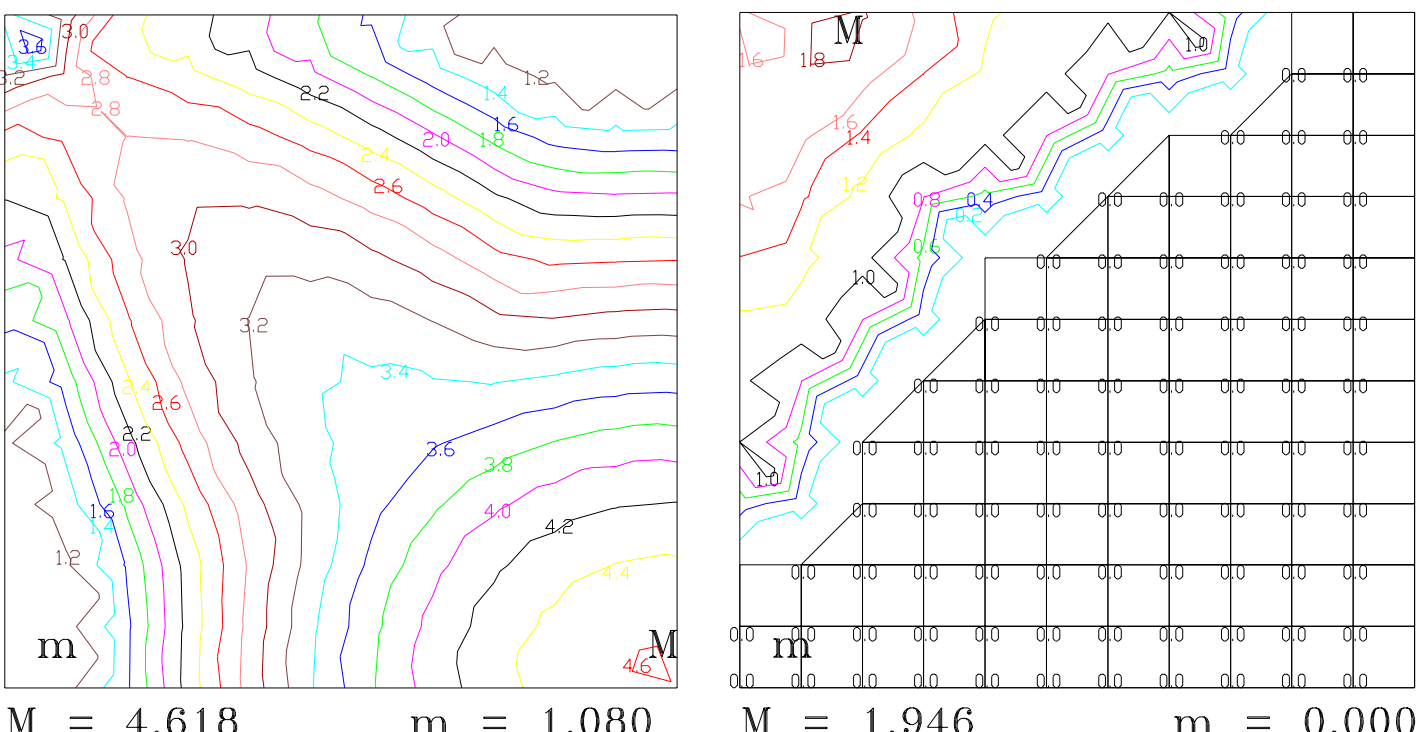

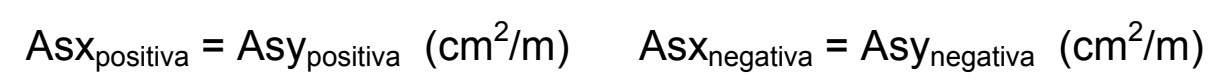

FIGURA 7.6 - Curvas de armaduras calculadas para L3A considerando Mxy 

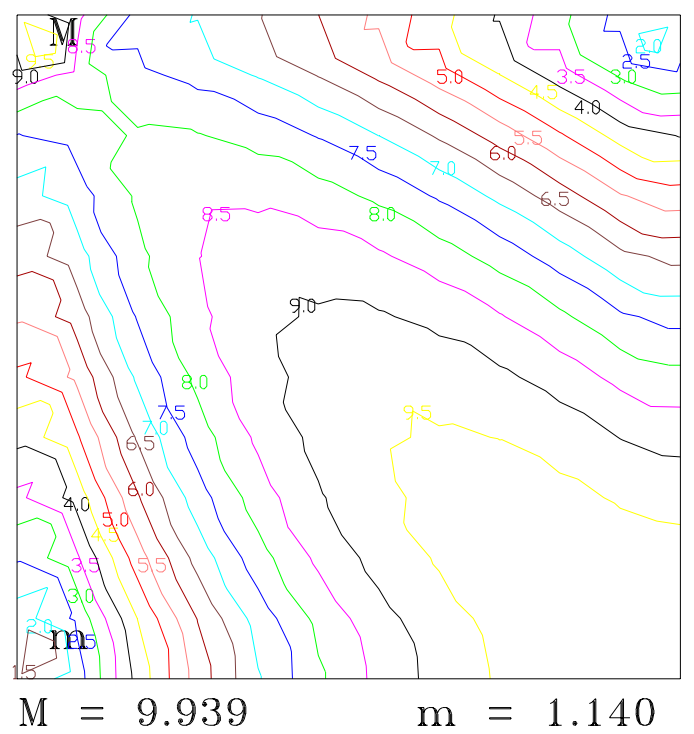

$\mathrm{M}^{*} \mathrm{x}_{\text {positivo }}=\mathrm{M}^{*} \mathrm{y}_{\text {positivo }}(\mathrm{KN} \cdot \mathrm{m} / \mathrm{m})$ $(\mathrm{KN} \cdot \mathrm{m} / \mathrm{m})$
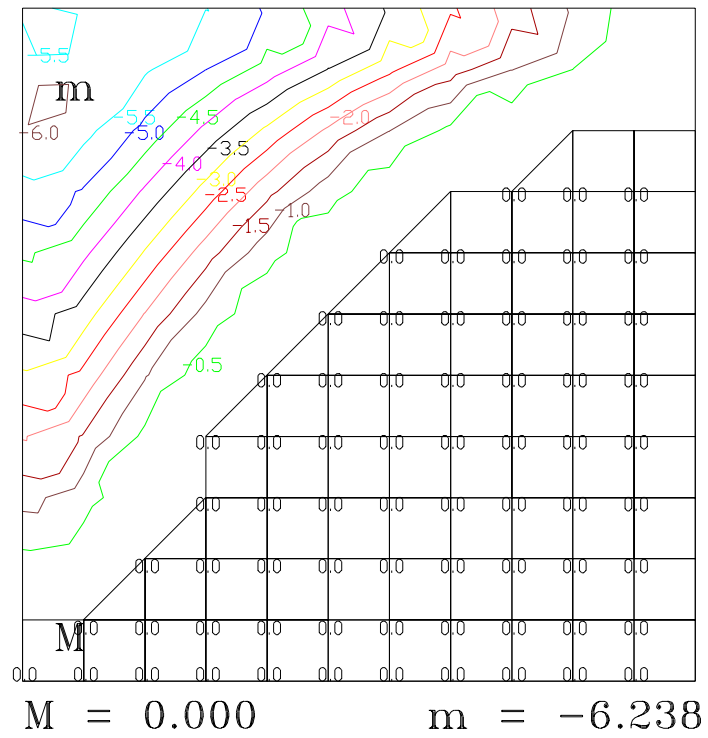

$\mathrm{M}^{*} \mathrm{X}_{\text {negativo }}=\mathrm{M}^{*} \mathrm{y}_{\text {negativo }}$

FIGURA 7.7 - Curvas de momentos equivalentes para L3A sem considerar Mxy ${ }_{c}$
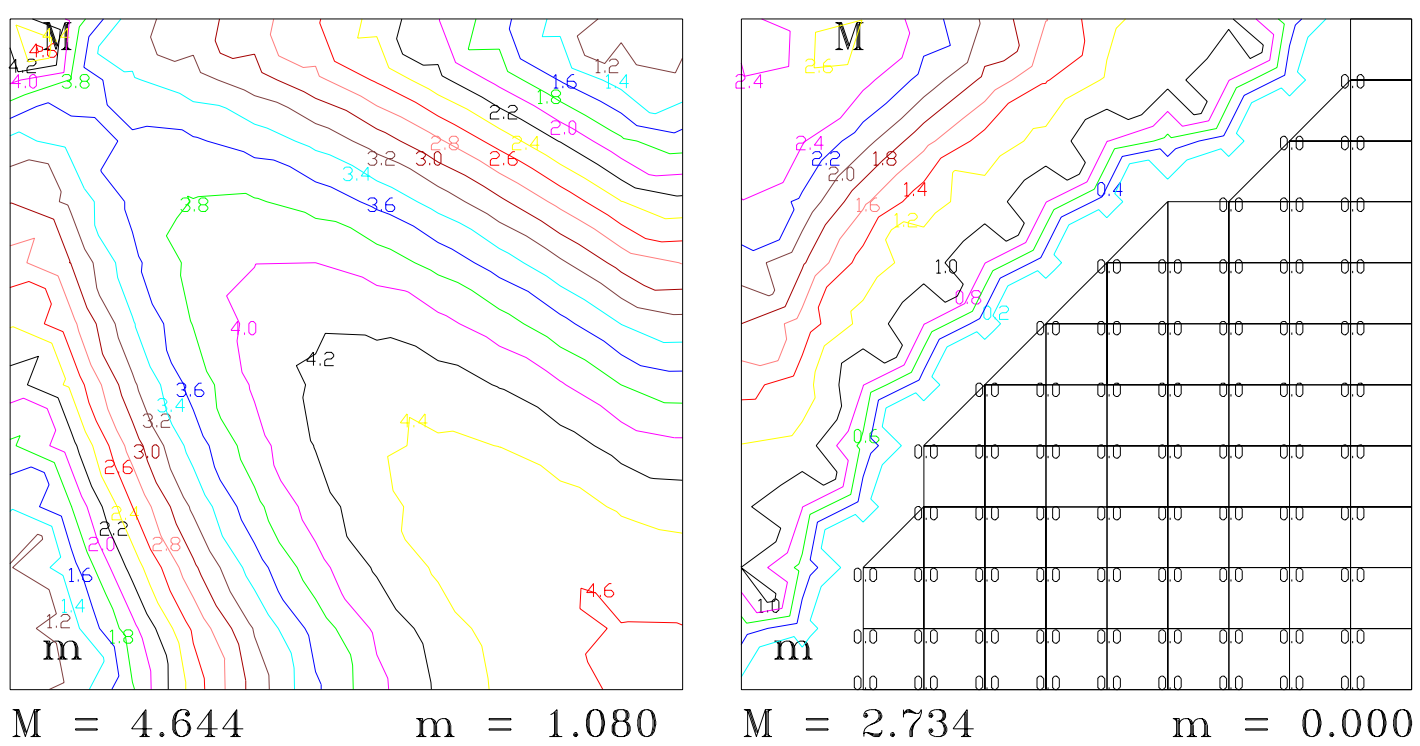

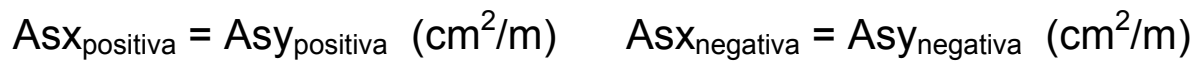

FIGURA 7.8 - Curvas de armaduras calculadas para L3A sem considerar Mxy $\mathrm{C}_{\mathrm{c}}$ 
7.3 Anexo C - Curvas do Pavimento Tipo (sem Mxy)

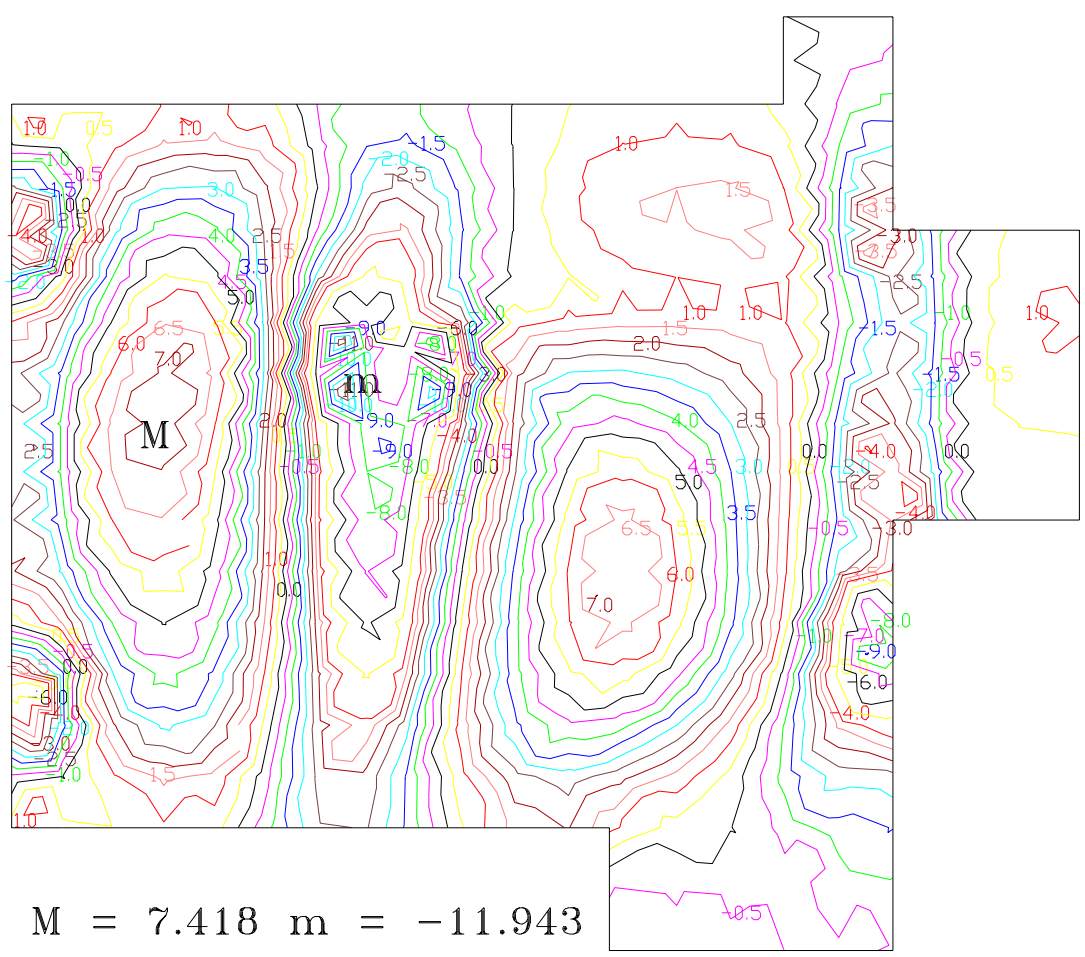

FIGURA 7.9 - Curvas de Mx [MEF sem Mxy $(\mathrm{KN} \cdot \mathrm{m} / \mathrm{m})]$

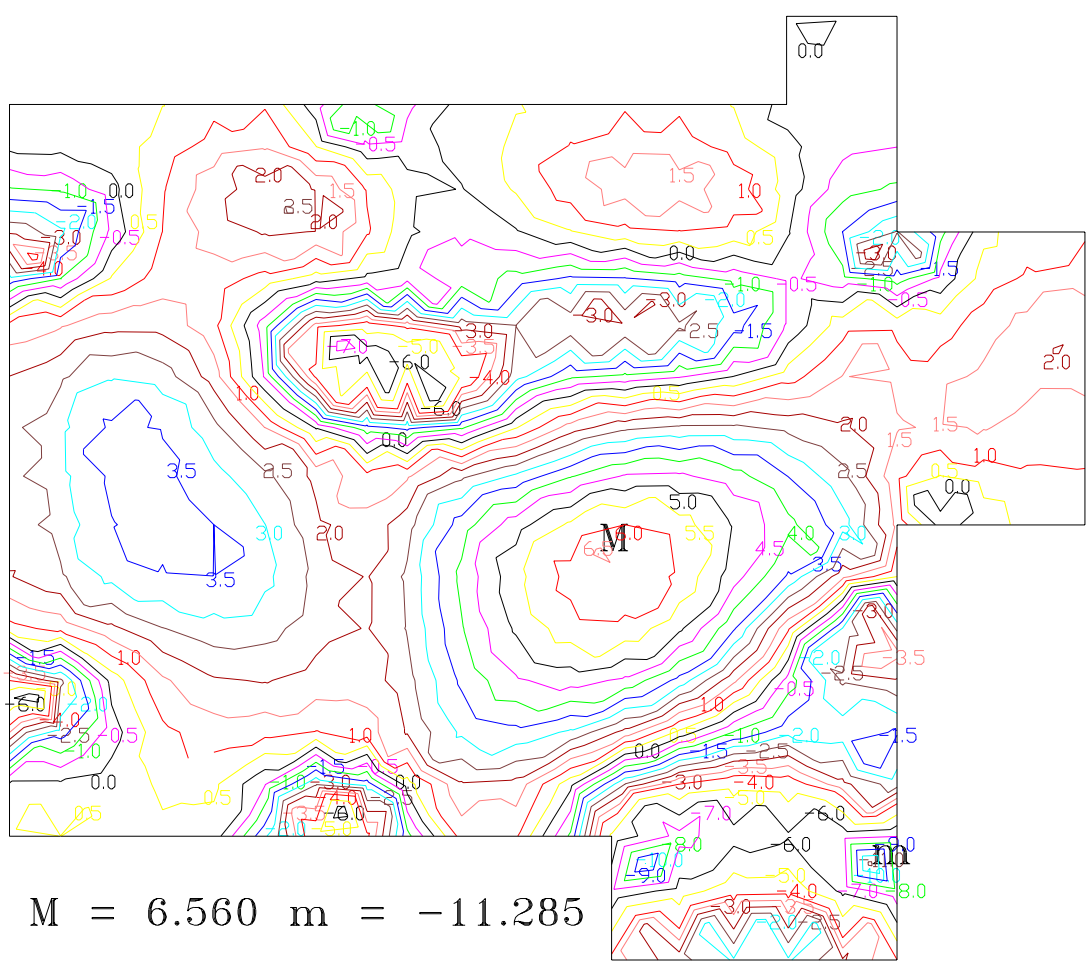

FIGURA 7.10 - Curva de My [MEF sem Mxy $(\mathrm{KN} \cdot \mathrm{m} / \mathrm{m})$ ] 


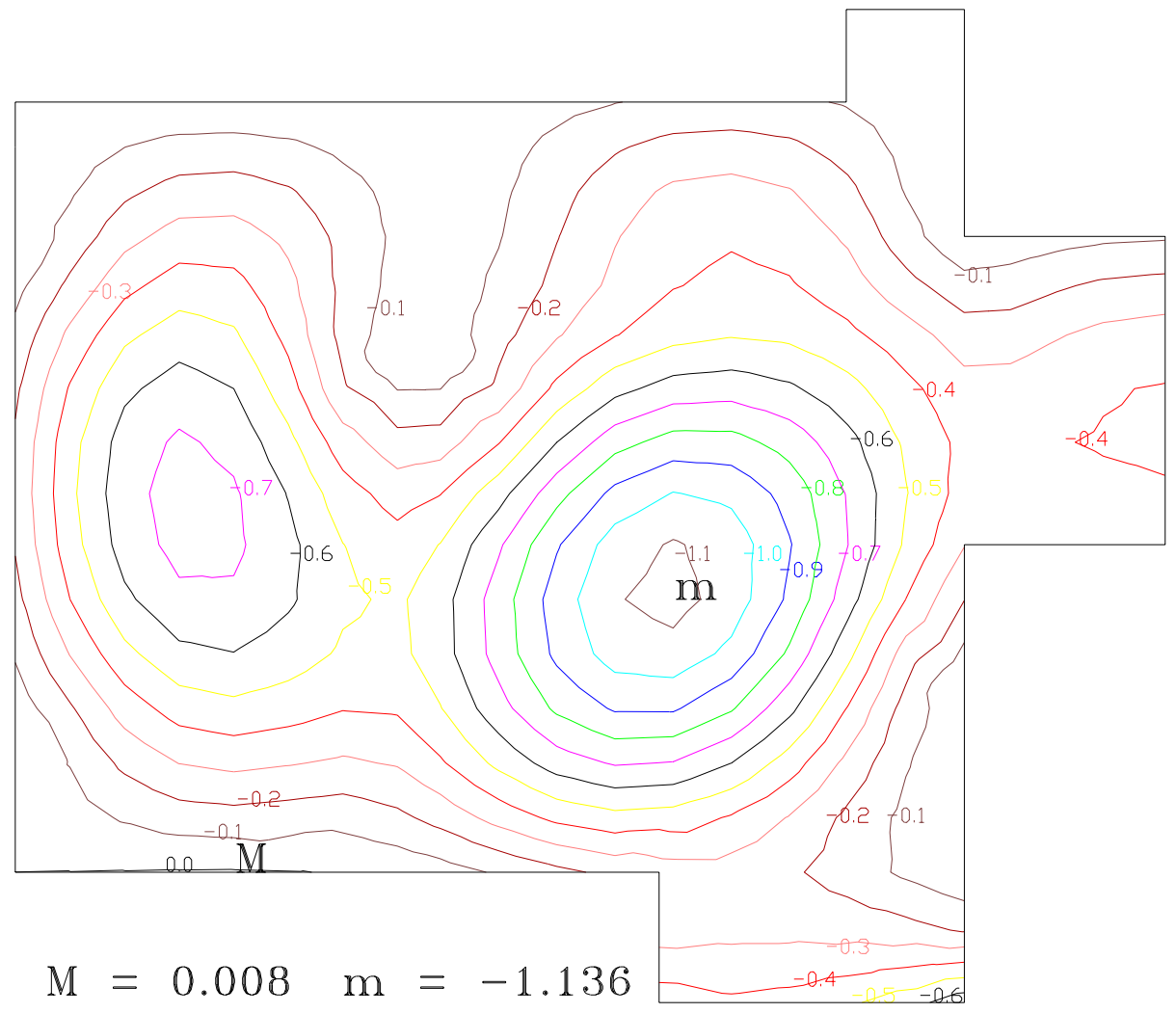

FIGURA 7.11 - Curvas de deslocamento transversal [MEF sem Mxy $(\mathrm{cm})$ ]

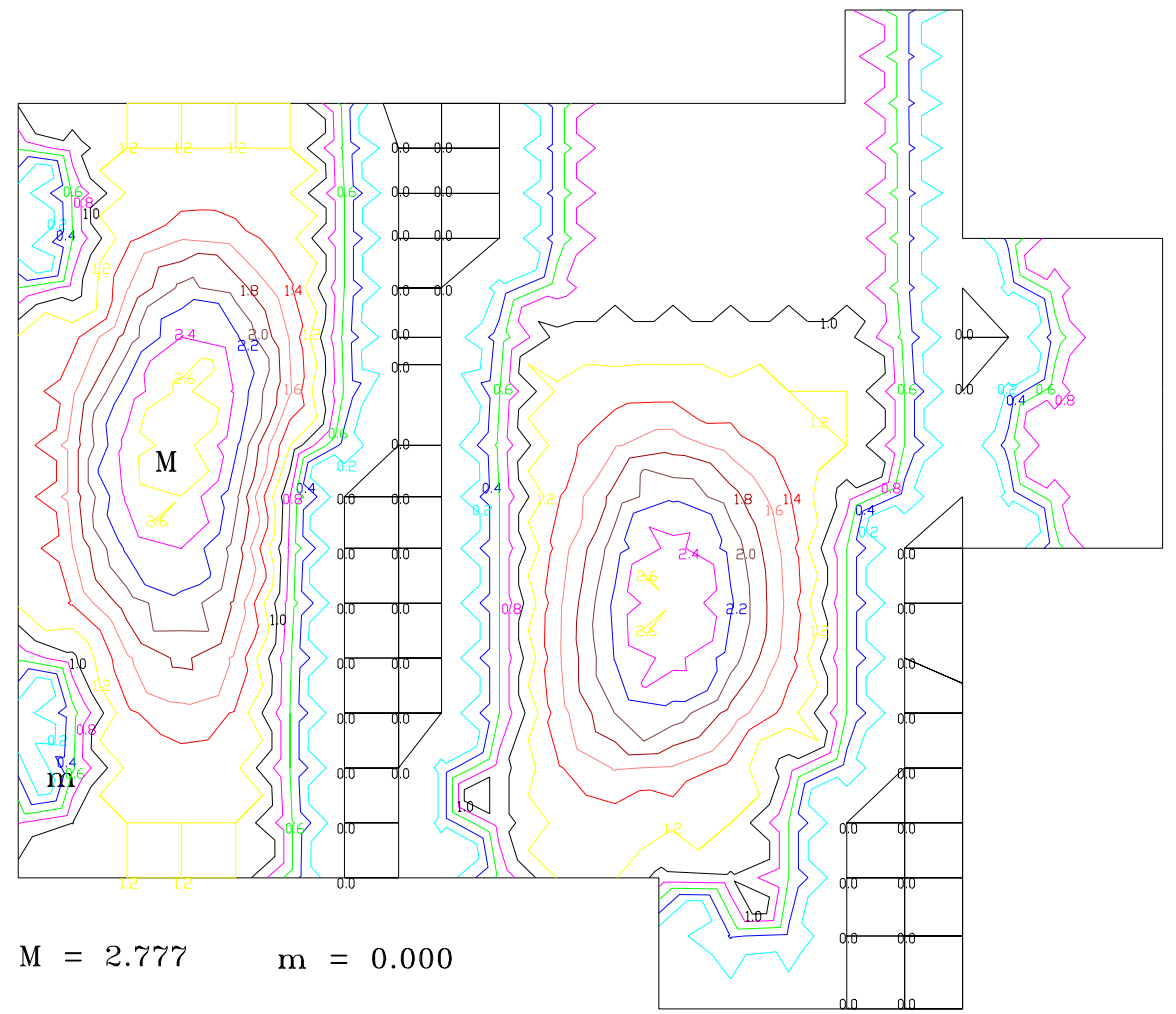

FIGURA 7.12 - Curvas de Asx positivas [MEF sem Mxy $\left(\mathrm{cm}^{2} / \mathrm{m}\right)$ ] 


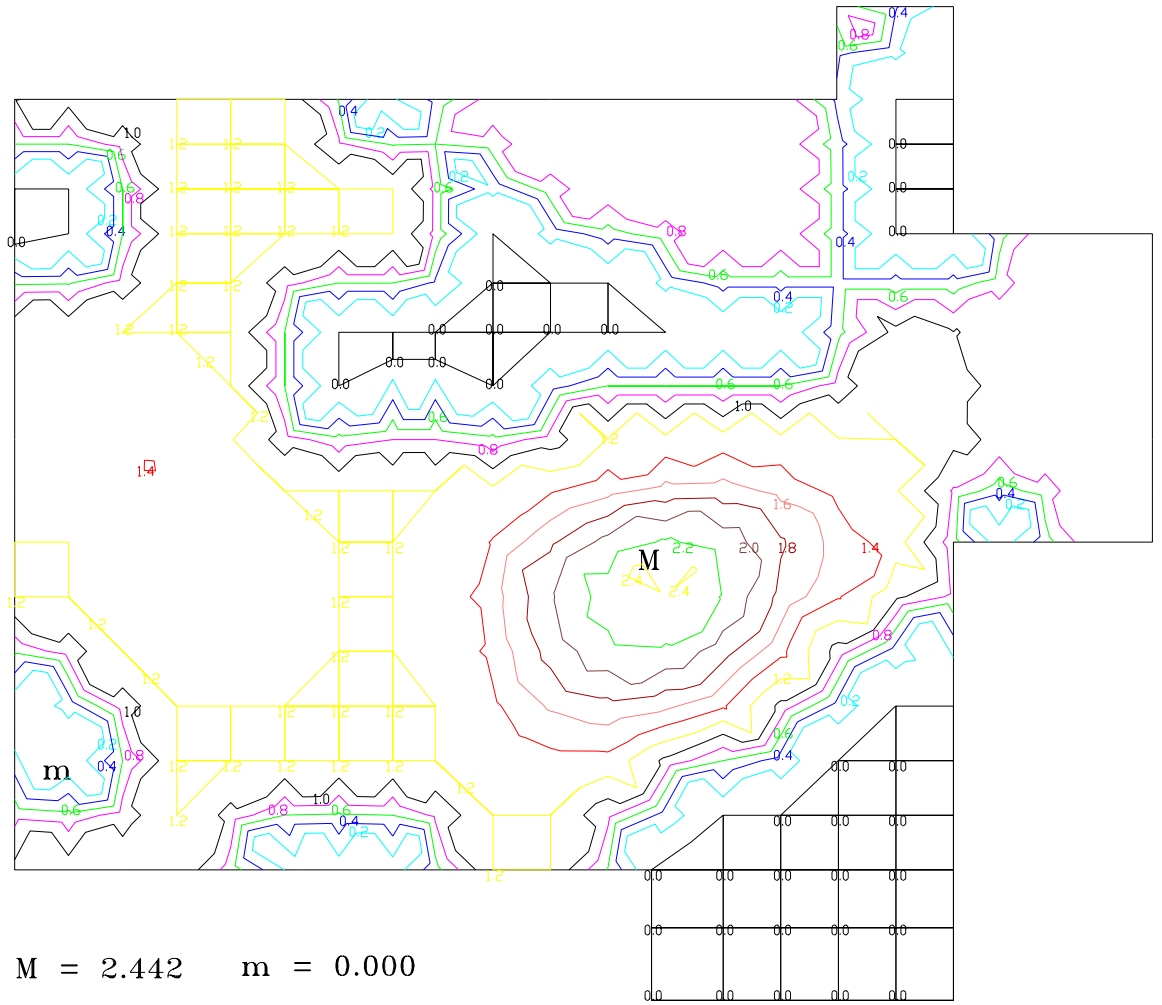

FIGURA 7.13 - Curvas de Asy positivas [MEF sem Mxy $\left(\mathrm{cm}^{2} / \mathrm{m}\right)$ ]

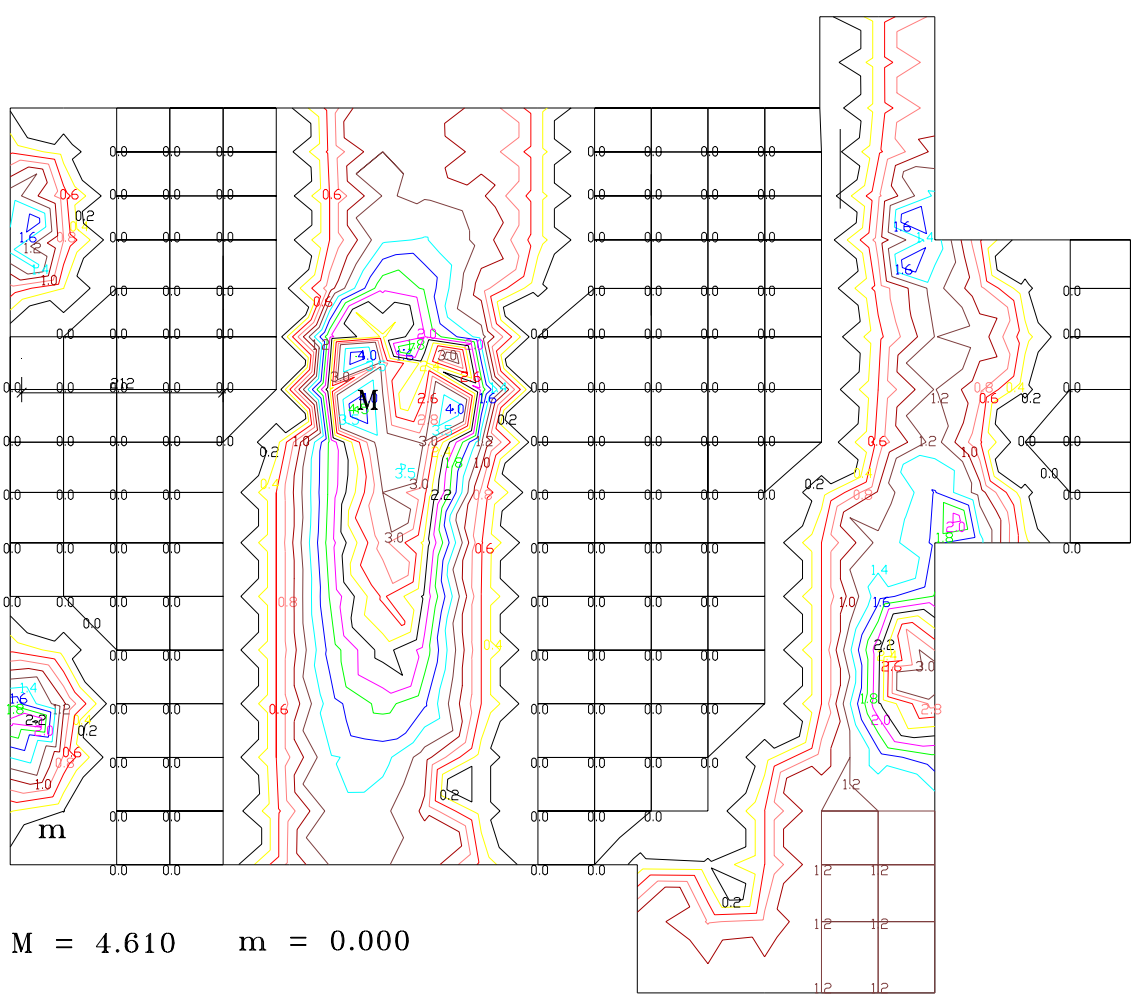

FIGURA 7.14 - Curvas de Asx negativas [MEF sem Mxy $\left(\mathrm{cm}^{2} / \mathrm{m}\right)$ ] 


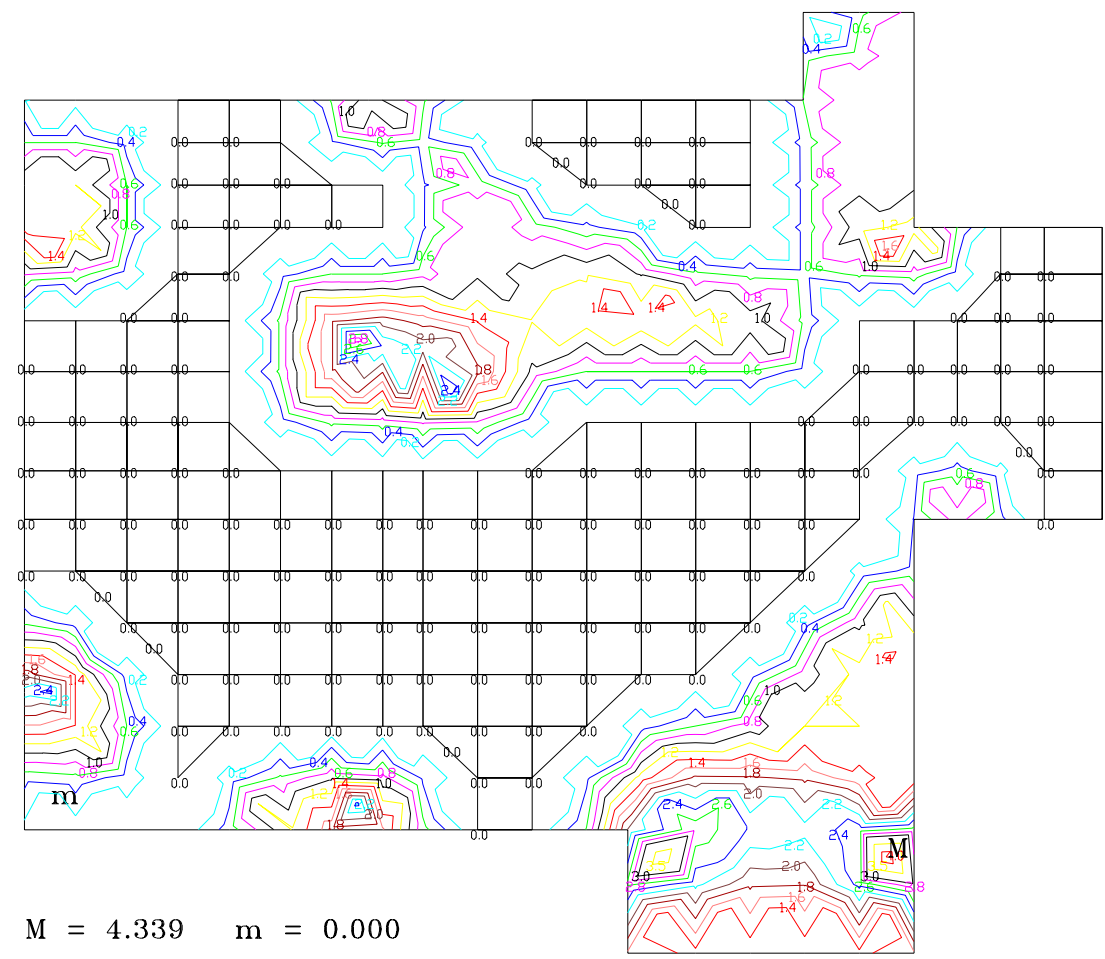

FIGURA 7.15 - Curvas de Asy negativas [MEF sem Mxy $\left(\mathrm{cm}^{2} / \mathrm{m}\right)$ ] 
7.4 Anexo D - Curvas do Pavimento Tipo (com Mxy)

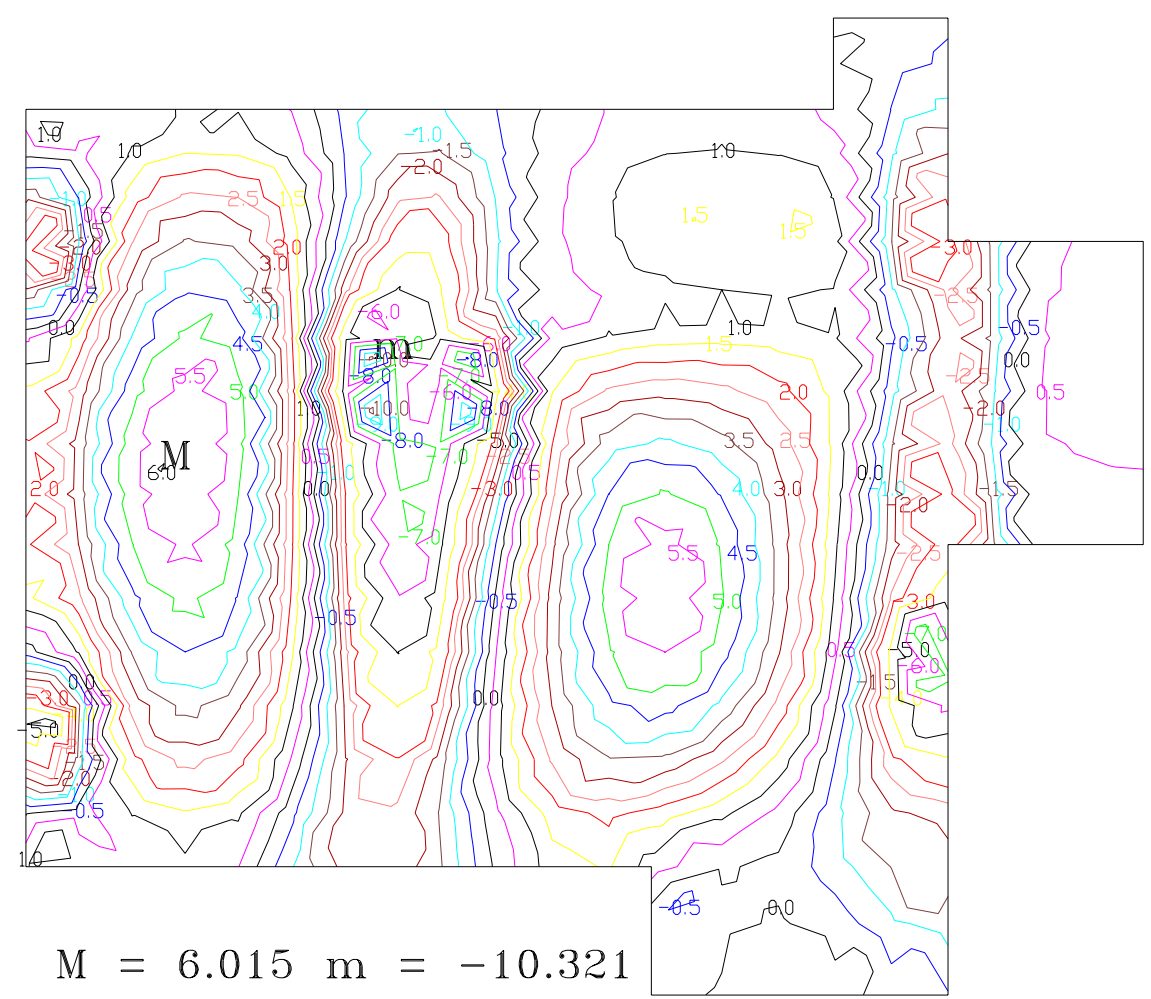

FIGURA 7.16 - Curvas de Mx [MEF com Mxy (KN.m/m)]

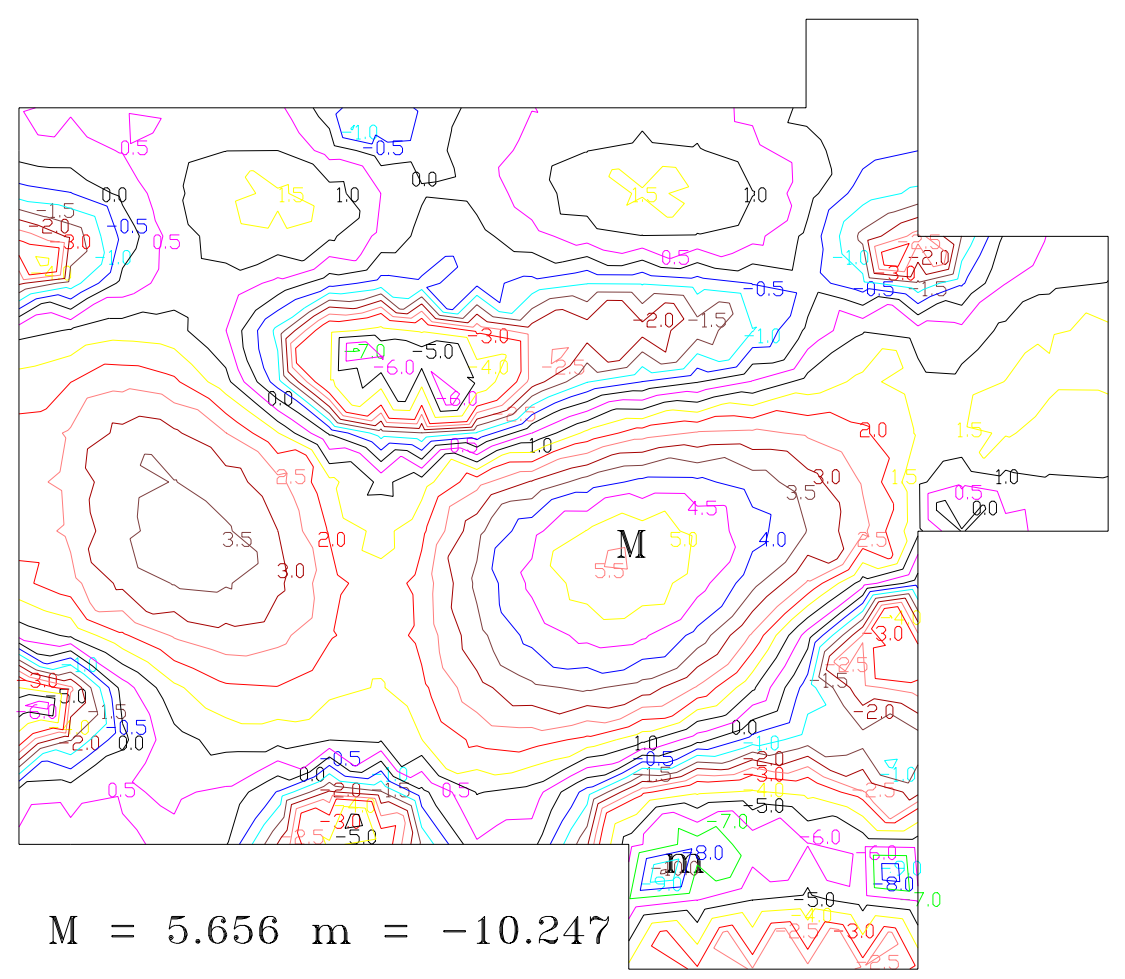

FIGURA 7.17 - Curva de My [MEF com Mxy (KN.m/m)] 


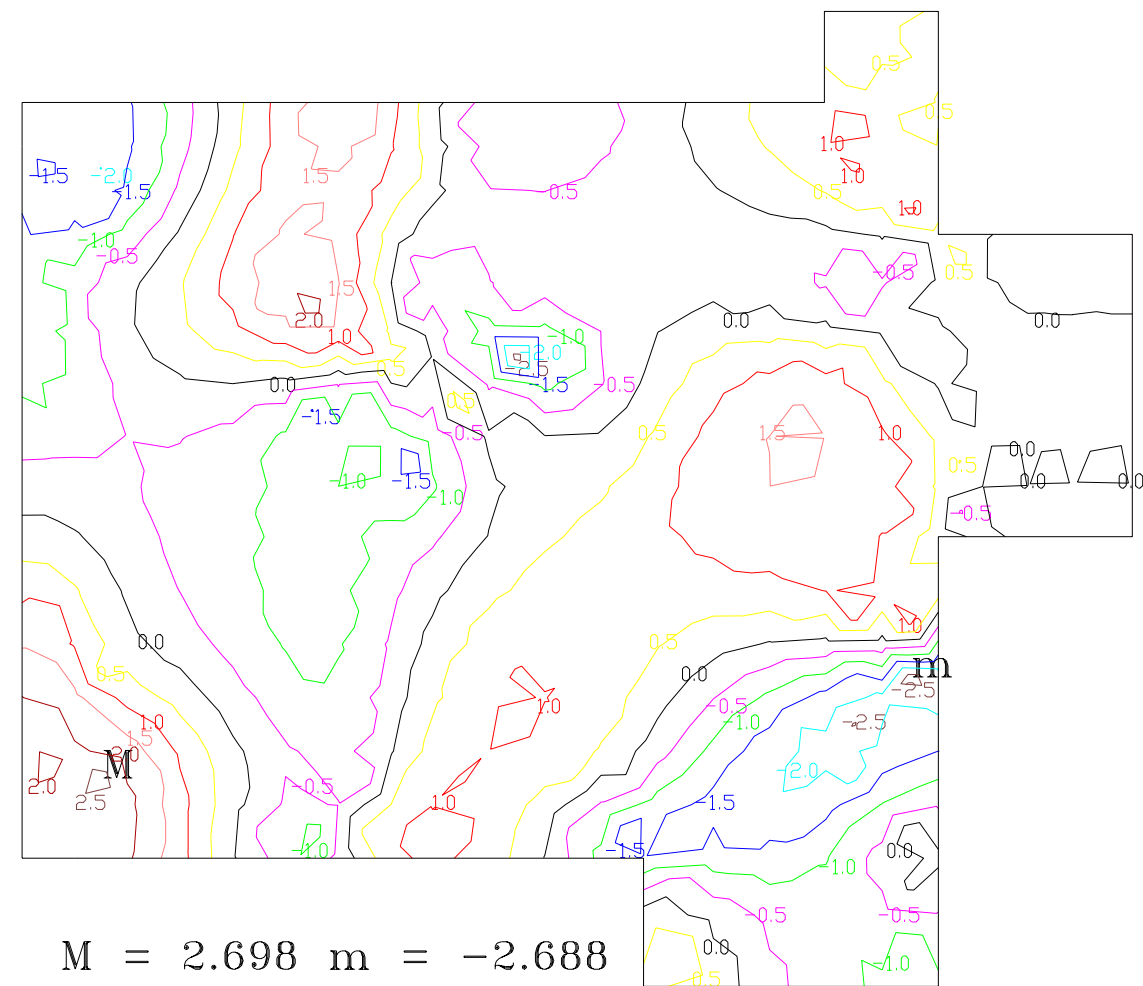

FIGURA 7.18 - Curva de Mxy [MEF com Mxy $(\mathrm{KN} \cdot \mathrm{m} / \mathrm{m})]$

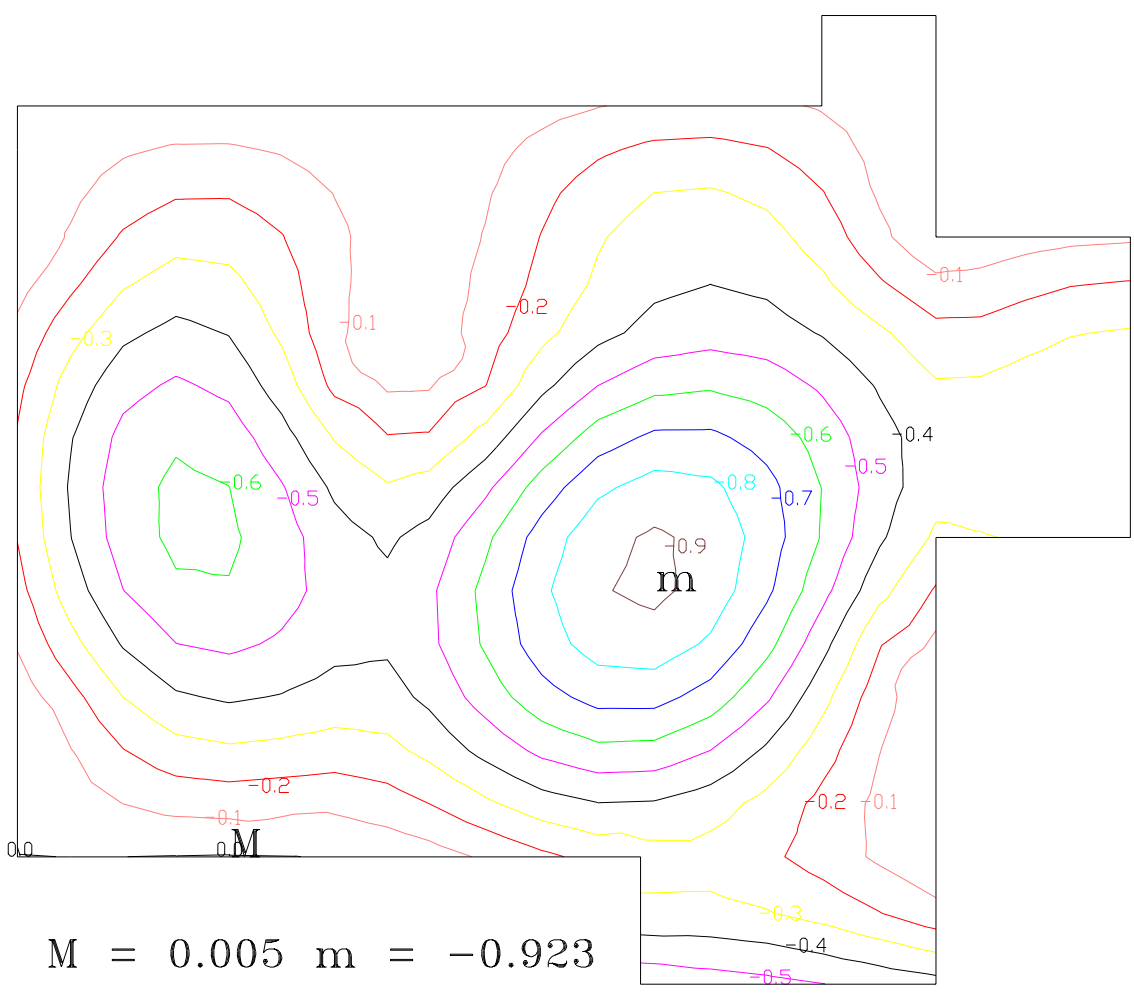

FIGURA 7.19 - Curvas de deslocamento transversal [MEF com Mxy (cm)] 


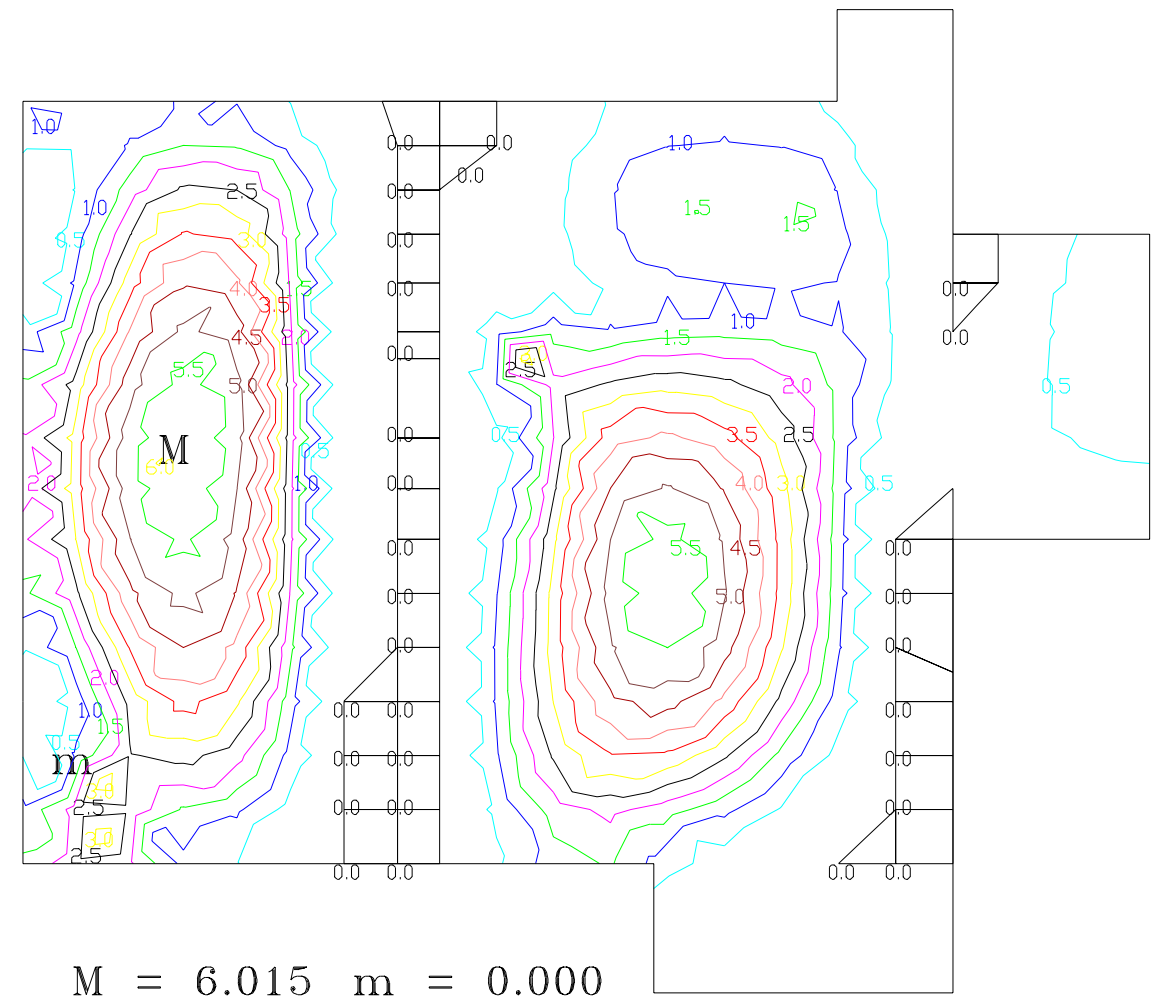

FIGURA 7.20 - Curva de $\mathrm{M}^{*} x$ positvos [MEF com Mxy $\left.(\mathrm{KN} \cdot \mathrm{m} / \mathrm{m})\right]$

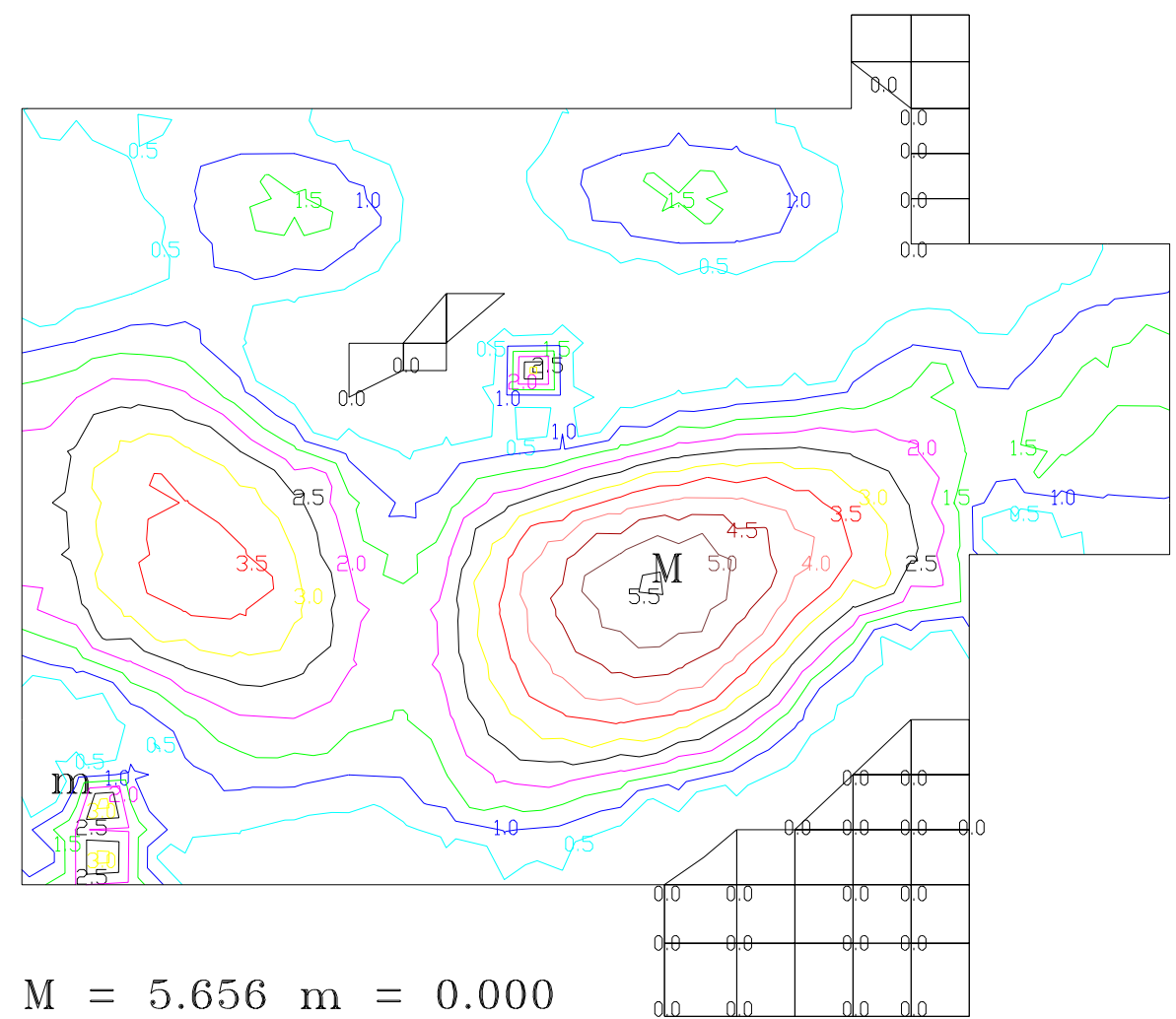

FIGURA 7.21 - Curva de $\mathrm{M}^{*} \mathrm{y}$ positvos [MEF com Mxy $(\mathrm{KN} \cdot \mathrm{m} / \mathrm{m})$ ] 


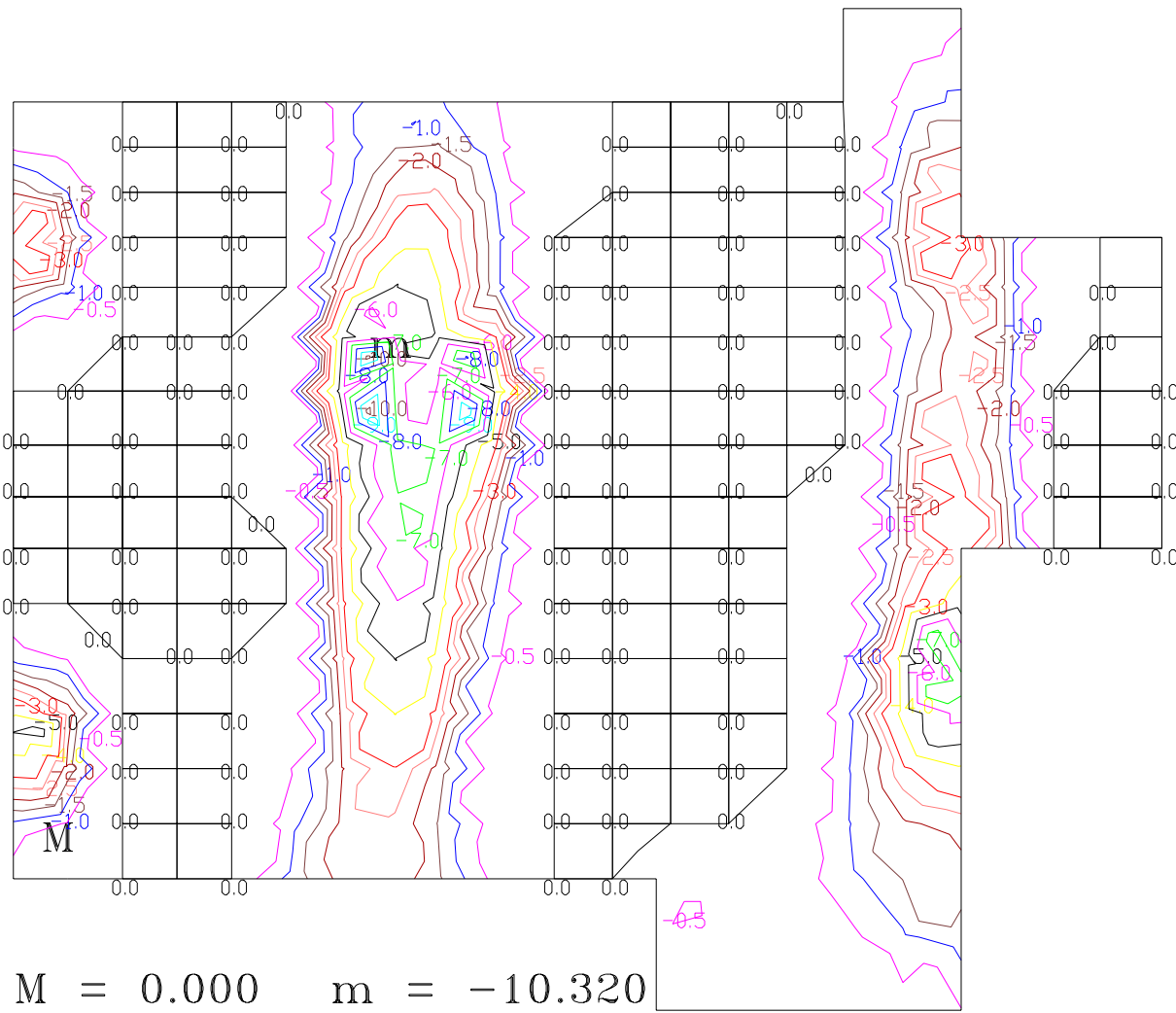

FIGURA 7.22 - Curva de $\mathrm{M}^{*} \mathrm{x}$ negatvos [MEF com Mxy $(\mathrm{KN} \cdot \mathrm{m} / \mathrm{m})$ ]

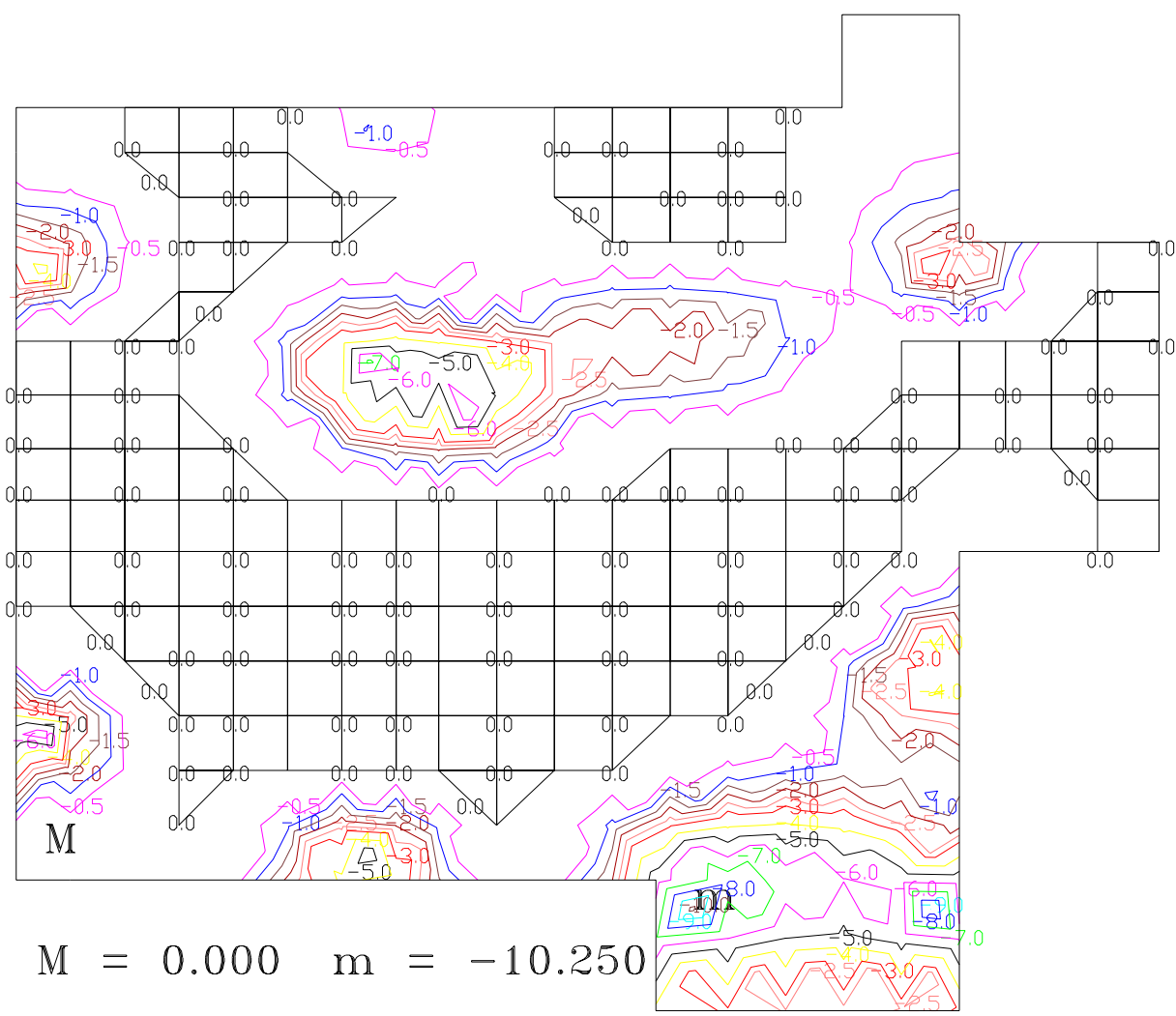

FIGURA 7.23 - Curva de $\mathrm{M}^{*} \mathrm{y}$ negativos [MEF com Mxy $(\mathrm{KN} \cdot \mathrm{m} / \mathrm{m})$ ] 


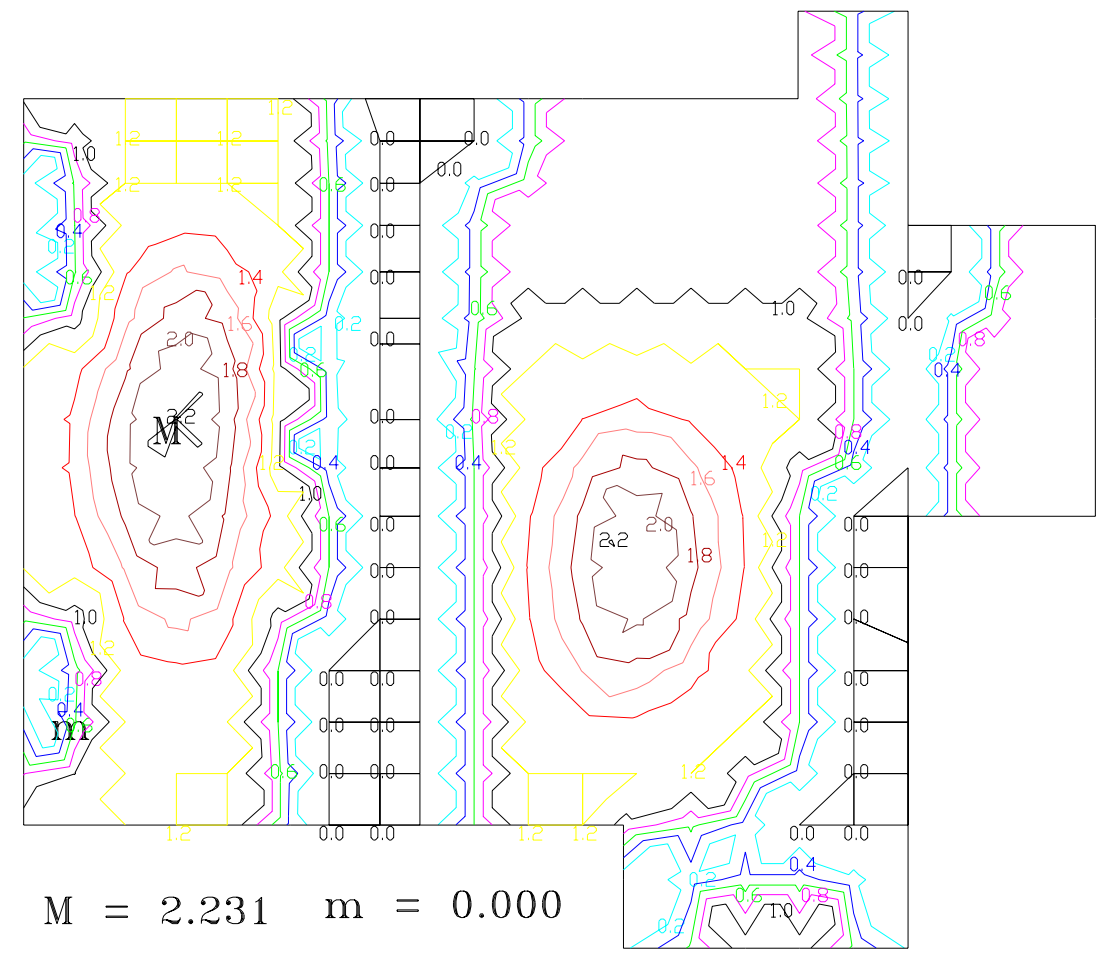

FIGURA 7.24 - Curvas de Asx positivas [MEF com Mxy $\left(\mathrm{cm}^{2} / \mathrm{m}\right)$ ]

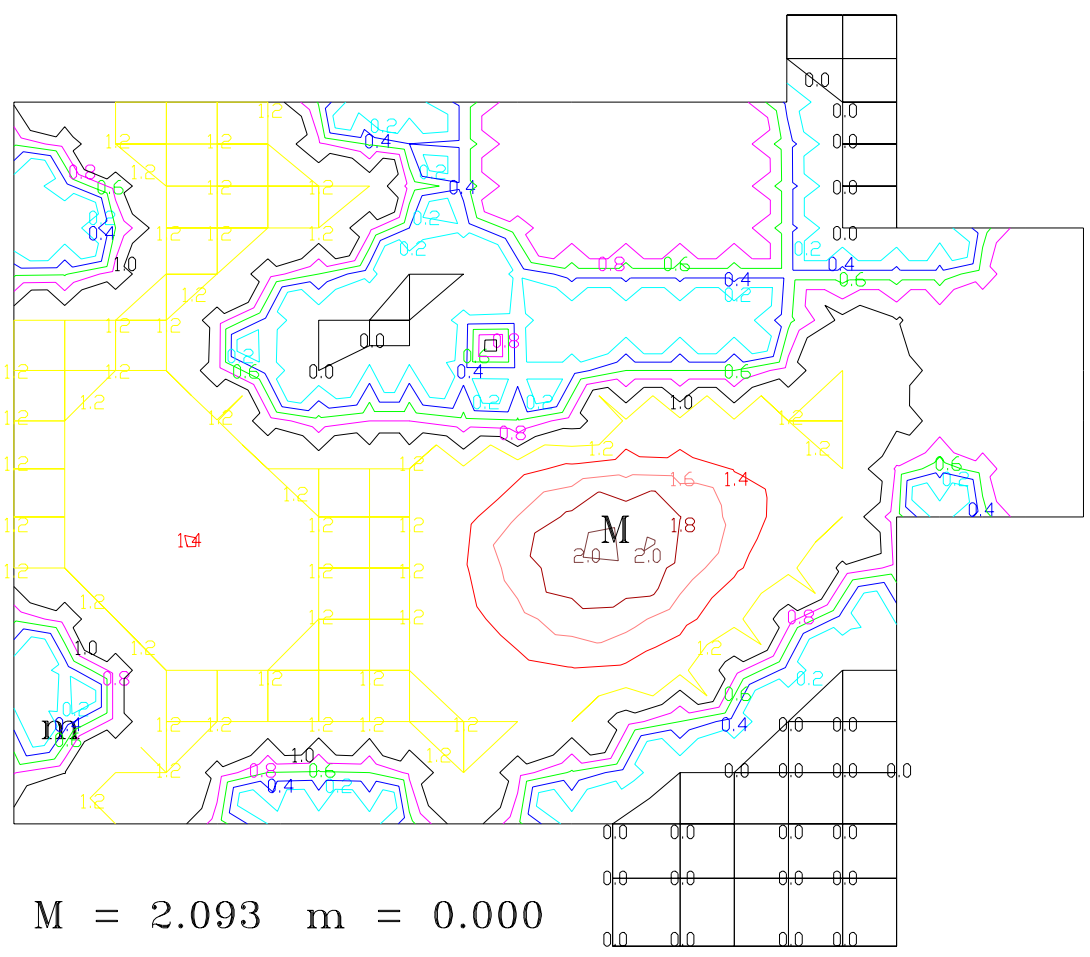

FIGURA 7.25 - Curvas de Asy positivas [MEF com Mxy $\left(\mathrm{cm}^{2} / \mathrm{m}\right)$ ] 


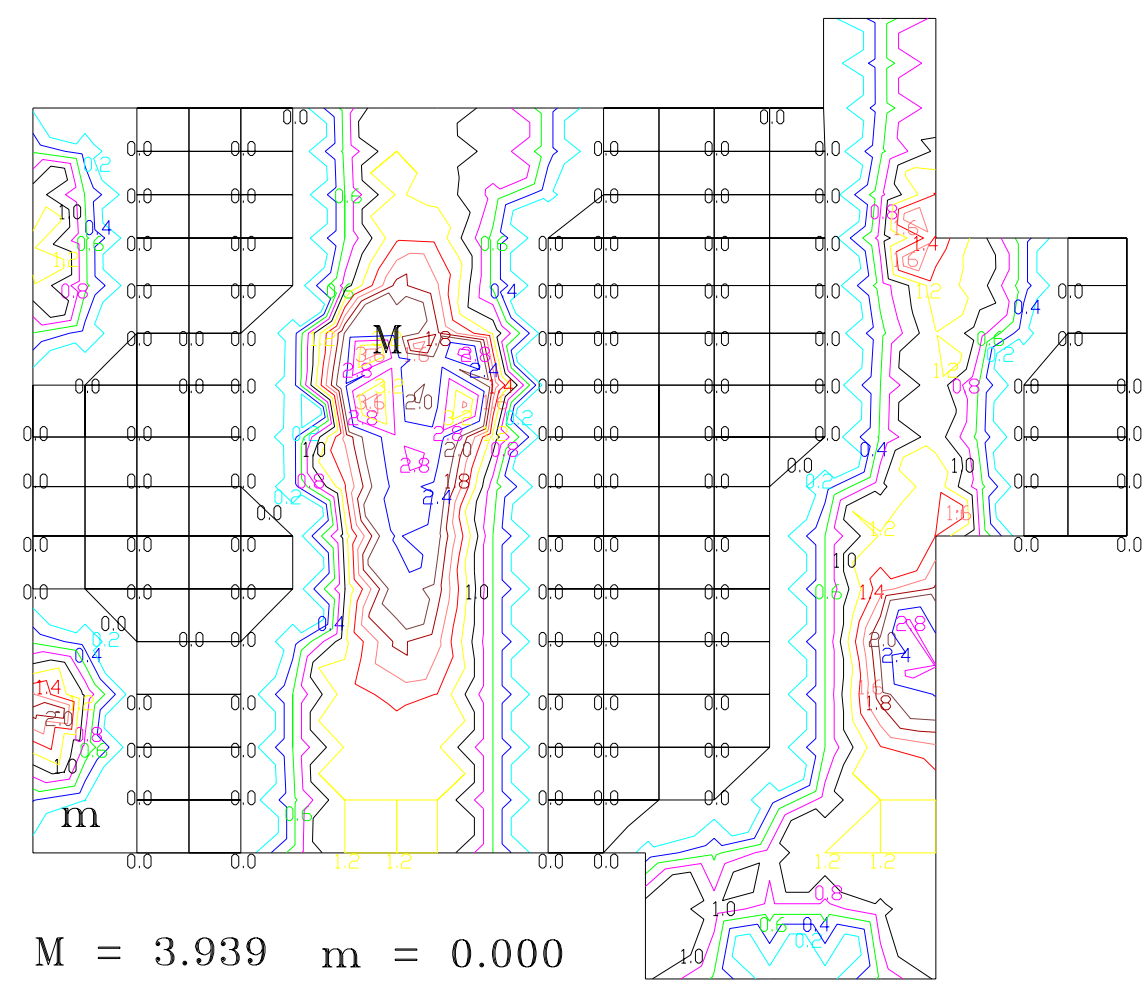

FIGURA 7.26 - Curvas de Asx negativas [MEF com Mxy $\left(\mathrm{cm}^{2} / \mathrm{m}\right)$ ]

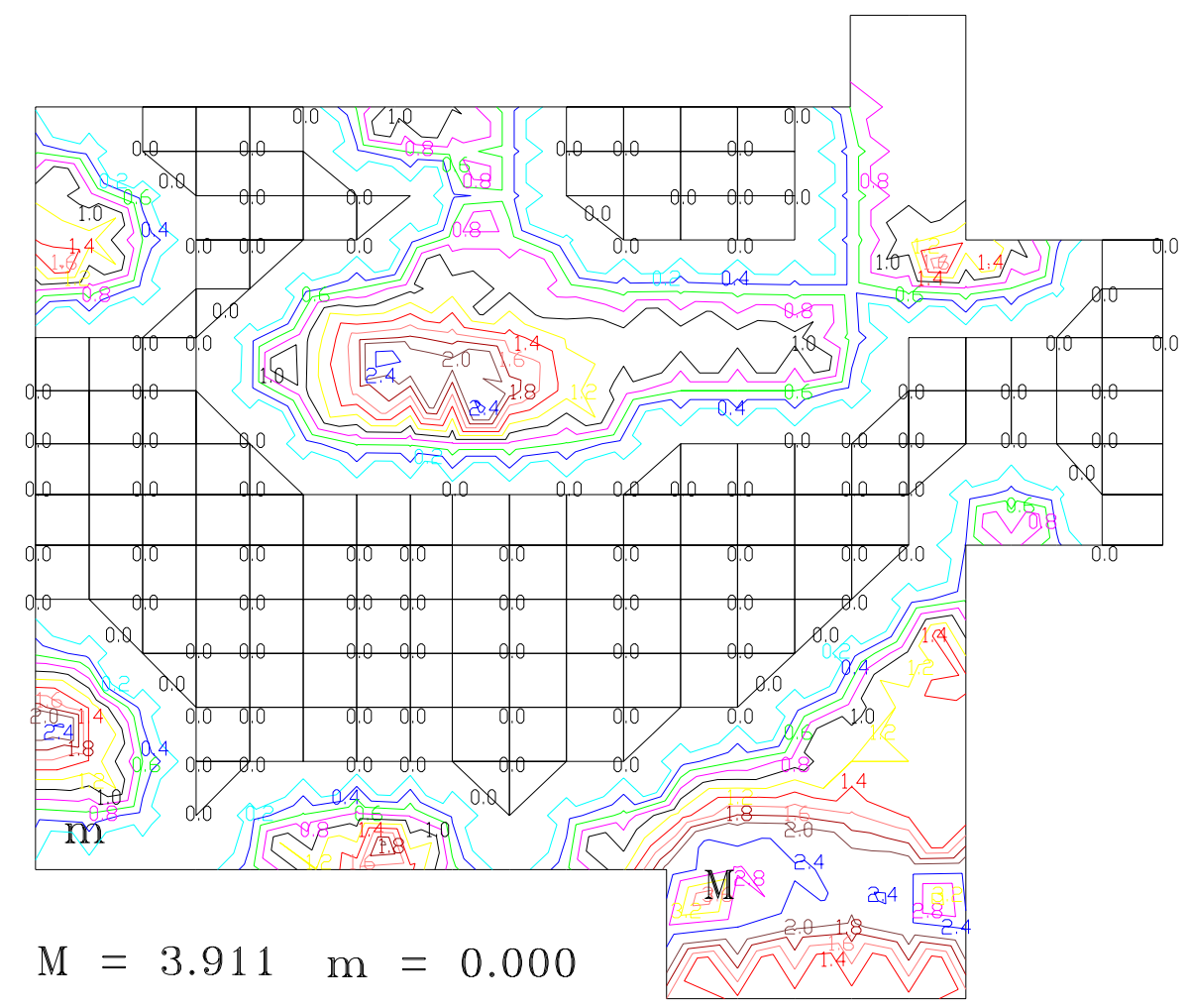

FIGURA 7.27 - Curvas de Asy negativas [MEF com Mxy $\left(\mathrm{cm}^{2} / \mathrm{m}\right)$ ] 


\section{REFERÊNCIAS BIBLIOGRÁFICAS}

ACl Committee 438 (1969). Tentative recommendations for the design of reinforced concrete members to resist. ACl Journal, v.66, January.

ALGOR SUPERDRAW SYSTEM (1987). Reference manual. Algor Interactive System, Inc.

AMERICAN CONCRETE INSTITUTE (1983). ACI 318M-83 - Building code requirements for reinforced concrete: metric version. Detroit.

AMERICAN CONCRETE INSTITUTE (1992). ACI 318-89 (revised 1992) Building code requirements for reinforced concrete and commentary . Detroit.

ASCE-ACI Committee 426 (1973). The shear strength of reinforced concrete members. Journal of Structural Division, ASCE, v.99, n.ST6, June.

ASCE-ACI Committee 426 (1974). The shear strength of reinforced concrete members: slabs. Journal of Structural Division, ASCE, v.100, n.ST8, August.

ASSOCIAÇÃO BRASILEIRA DE NORMAS TÉCNICAS (1982). NB 1 Projeto e execução de obras de concreto armado.

ASSOCIAÇÃO BRASILEIRA DE NORMAS TÉCNICAS (1989). NBR 7197 Projeto de edifícios de concreto protendido.

ASSOCIAÇÃO BRASILEIRA DE NORMAS TÉCNICAS (1993). NB 1 Projeto e execução de obras de concreto armado - texto base para revisão.

AUTODESK (1989). AUTOCAD Release 10 - Reference Manual. Autodesk, Inc. 
BAPTISTA, S.M. (1984). Análise de pavimentos de ediícios com a utilização do método dos elementos finitos. São Carlos. Dissertação (Mestrado) EESC, USP.

COMITÉ EURO-INTERNATIONAL DU BÉTON (1990). CEB-FIP Model Code 1990. Lausanne, CEB.

CORRÊA, M.R.S. (1991). Aperfeiçoamento de modelos usualmente empregados no projeto de sistemas estruturais de edifícios. São Carlos. Tese (Doutorado) - EESC, USP .

EUROCODE 2 (1992). Design of concrete structures. Part 1 - General rules and rules for buldings.

FANTI, G.; MANCINI, G. (1995). Ultimate limit state design of structural concrete shell elements. CEB Bulletim D'information, n.223.

FIGUEREDO FILHO, J.R. (1981). Sistemas estruturais de lajes sem vigas: subsídios para o projeto. São Carlos. Tese (Doutorado) - EESC, USP

FUSCO, P.B. (1982). Estruturas de concreto: solicitações tangenciais problemas básicos de cisalhamento no concreto estrutural - problemas gerais de dimensionamento. São Paulo, Escola Politécnica - USP.

G. S. T. ARMER, (1968). Discussão de WOOD, R.H. (1968). Concrete Magazine, London, August.

GIONGO, J.S. (1994ª). Concreto armado: vigas submetidas a esforços de torção. São Carlos, EESC-USP.

GIONGO, J.S. (1994b). Concreto armado: projeto estrutural de edifícios. São Carlos, EESC-USP.

GIONGO, J.S; TOTTI JUNIOR, F. (1994). Concreto armado: resistência de elementos fletidos submetidos à força cortante. São Carlos, EESC-USP.

HSU, T.T.C. (1968). Torsion of structural concrete - interaction surface for combined torsion, shear, and bending in beams without stirrups. $\mathrm{ACl}$ Structural Journal, v.66, January.

HSU, T.T.C.; HWANG C. (1977). Torsional limit design of spandrel beams. ACl Journal , v.74, February.

JAIN, S.C.; KENNEDY, J.B. (1974). Yield criterion for reinforced concrete slabs. Journal of the Structural Division, ASCE, vol. 100, March. 
JIMENEZ MONTOYA, P. (1969). Hormigon armado - tomo I. 3. Edicion, Barcelona, Editorial Gustavo Gili.

KANOH, Y.; YOSHIZAKI, S. (1979). Strength of slab-column connections transferring shear and moment. ACl Journal, v.76, March.

KIRK, D.W.; LASH, S.D. (1971). T-beams subject to combined bending and torsion. ACl Journal, v.68, February.

LAMPERT, P.; COLLINS, M. P. (1972). Torsion, bending and confusion - an attempt to establish the facts. $A C l$ Journal, v. 69, August.

LENSCHOW, R.; SOZEN, M. A. (1967). A yield criterion for reinforced concrete slabs. $\mathrm{ACl}$ Journal , v.64, May.

LEONHARDT, F.; MÖNNING, E. (1977). Construções de concreto - volume 1: princípios básicos do dimensionamento de estruturas de concreto armado. Rio de Janeiro, Editora Interciência.

LEONHARDT, F.; MÖNNING, E. (1978 $)$. Construções de concreto - volume 2: casos especiais de dimensionamento de estruturas de concreto. Rio de Janeiro, Editora Interciência.

LEONHARDT, F.; MÖNNING, E. (1978b). Construções de concreto volume 3: princípios básicos sobre a armação de estruturas de concreto armado. Rio de Janeiro, Editora Interciência.

LIAO, H.M.; FERGUSON, P. M. (1969). Combined torsion in reinforced concrete L-beams with stirrups. ACl Journal, v.67, December.

LISERRE, L.; (1993). Traçador de curvas de isovalor - saída no padrão DXF do Autocad. In: Simpósio de Iniciação Científica, 1., São Paulo, 1993, São Paulo, USP

MAC GREGOR, J.G. (1992). Reinforced concrete: mechanics and design. 2. ed, Englewood Cliffs (USA), Prentice-Hall.

MARTI, P.; KONG, K. (1987). Response of reinforced concrete slab elements to torsion. Journal of the Structural Division, ASCE, v.113, n.5, May.

NAWY, E.G. (1990). Reinforced concrete - a fundamental approach. 2. ed, Englewood Cliffs (USA), Prentice-Hall. 
OSBURN, D.L.; MAYOGLOV, B.; MATTOCK, A.H. (1969). Strength of reinforced concrete beams with web reinforcement in combined torsion, shear and bending. ACl Journal, v.66, January.

PARK, R.; GAMBLE, W.L. (1980). Reinforced concrete slabs. New York, John Wiley \& Sons.

PARK, R.; PAULAY, T. (1975). Reinforced concrete structures. New York, John Wiley \& Sons.

PINHEIRO, L.M. (1988). Análise elástica e plásticas de lajes retangulares de edifícios. São Carlos. Tese (Doutorado). EESC - USP.

RAMALHO,M.A. Sistema para análise de estruturas considerando interação com o meio elástico. São Carlos, Tese (Doutorado), EESCUSP.

SCHIEL, F. (1984). Introdução à resistência de materiais. São Paulo, Editora Harper e Row do Brasil.

TIMOSHENKO, S.P.; GOODIER, J.N. (1980). Teoria da elasticidade. 3. ed, Rio de Janeiro, Editora Guanabara Dois.

TIMOSHENKO, S.P; KRIEGER, S.W. (1959). Theory of plates and shells. Auckland, MacGraw Hill.

VICTOR, D.J.; FERGUSON, P. M. (1968). Reinforced concrete T-beams without stirrups under combined moment and torsion. ACl Journal, v.65, January.

WOOD, R.H. (1968). The reinforcement of slabs in accordance with a predetermined field of moments. Concrete Magazine, London,February. 